\title{
Generational Impacts on Organizational Commitment: An examination of the Baby Boom Generation and Generation $X$ at work
}

\author{
Kelley Love \\ B.Com (Honours), Carleton University
}

\begin{abstract}
Submitted to
The Faculty of Graduate Studies and Research

In partial fulfillment of the requirements for the degree of

Master of Business Administration
\end{abstract}

Sprott School of Business

Carleton University

Ottawa, Ontario

(C) copyright Kelley Love, 2005 


$\begin{array}{ll}\begin{array}{l}\text { Library and } \\ \text { Archives Canada }\end{array} & \begin{array}{l}\text { Bibliothèque et } \\ \text { Archives Canada }\end{array} \\ \begin{array}{l}\text { Published Heritage } \\ \text { Branch }\end{array} & \begin{array}{l}\text { Direction du } \\ \text { Patrimoine de l'édition }\end{array} \\ \begin{array}{l}\text { 395 Wellington Street } \\ \text { Ottawa ON K1A ON4 }\end{array} & \begin{array}{l}\text { 395, rue Wellington } \\ \text { Ottawa ON K1A ON4 } \\ \text { Canada }\end{array} \\ \end{array}$

Your file Votre référence ISBN: 0-494-10113-X

Our file Notre référence

ISBN: 0-494-10113-X

NOTICE:

The author has granted a nonexclusive license allowing Library and Archives Canada to reproduce, publish, archive, preserve, conserve, communicate to the public by telecommunication or on the Internet, loan, distribute and sell theses worldwide, for commercial or noncommercial purposes, in microform, paper, electronic and/or any other formats.

The author retains copyright ownership and moral rights in this thesis. Neither the thesis nor substantial extracts from it may be printed or otherwise reproduced without the author's permission.
AVIS:

L'auteur a accordé une licence non exclusive permettant à la Bibliothèque et Archives Canada de reproduire, publier, archiver, sauvegarder, conserver, transmettre au public par télécommunication ou par l'Internet, prêter, distribuer et vendre des thèses partout dans le monde, à des fins commerciales ou autres, sur support microforme, papier, électronique et/ou autres formats.

L'auteur conserve la propriété du droit d'auteur et des droits moraux qui protège cette thèse. $\mathrm{Ni}$ la thèse ni des extraits substantiels de celle-ci ne doivent être imprimés ou autrement reproduits sans son autorisation.
In compliance with the Canadian

Privacy Act some supporting forms may have been removed from this thesis.

While these forms may be included in the document page count, their removal does not represent any loss of content from the thesis.
Conformément à la loi canadienne sur la protection de la vie privée, quelques formulaires secondaires ont été enlevés de cette thèse.

Bien que ces formulaires aient inclus dans la pagination, il n'y aura aucun contenu manquant.

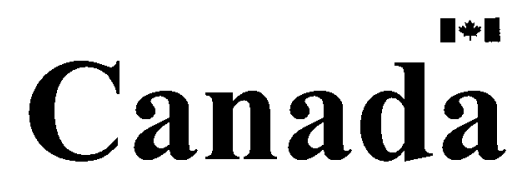




\section{Abstract}

The concept of differences between the generations is often explored in the popular press and in practitioners' journals. This is particularly true when discussing organizational commitment. This study examines whether there is an actual difference between Generation X and the Baby Boom Generation on levels of organizational commitment. An effort was made to control for potential confounds in the relationship such as gender, tenure, life cycle stage, industry sector, job type and organization of employment.

The results indicated that the perceived differences in organizational commitment between the generation have no empirical basis. It was concluded that generation cannot be used to accurately determine the level of an individual's organizational commitment. 


\section{Acknowledgements}

I would like to thank, first and foremost, my supervisor, Dr. Linda Duxbury for her help, guidance and patience through this process. Also, I would like to say thank you to my committee, Dr. Shaobo Ji, Dr. Judith Madill, Dr. Barbara Orser and Dr. Shibu Pal for supporting me. Finally, I would like to express my gratitude to Dr. Roland Thomas, Dr. Chris Higgins, Dr. George Haines Jr. and Professor Ann Woodside for their advice throughout the process.

I would particularly like to thank my family, without whom I could never have completed this process, in particular my parents, David and Elaine Love.

I would also like to thank my husband, Lee Goulet for his support in everything I do, for his love and for doing much more than his share of the daily chores while I worked.

To all the others who have helped me along the way, I am sincerely grateful that I have had so much assistance in my journey. 


\section{Table of Contents}

Abstract __ $i i$

Acknowledgements _____ iii

Table of Contents_____ iv

List of Tables _ $v i$

List of Figures _ vii

List of Figures __ vii

List of Appendices ___ viii

$1 \quad$ Introduction___ 1

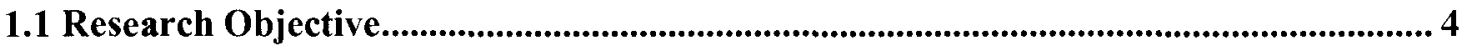

1.2 Significance of This Study ........................................................................................................... 5

$2 \quad$ Literature Review

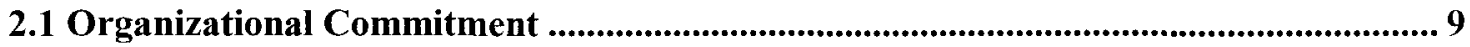

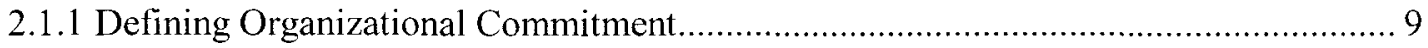

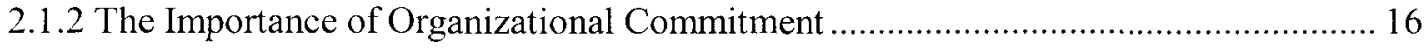

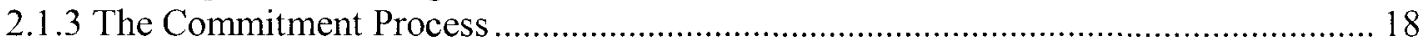

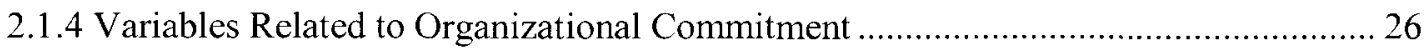

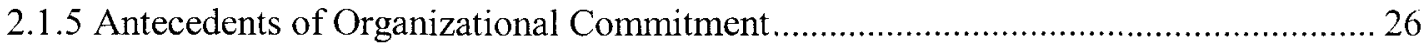

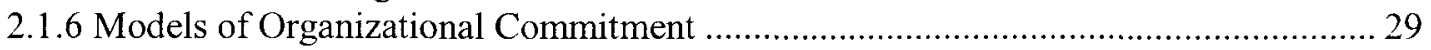

2.1.7 Measurements of Organizational Commitment ..................................................... 49

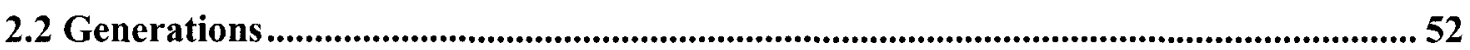

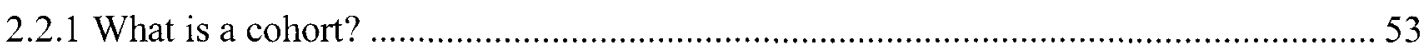

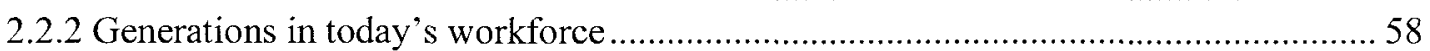

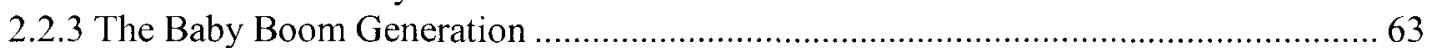

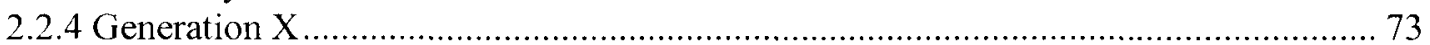

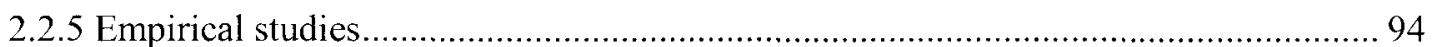

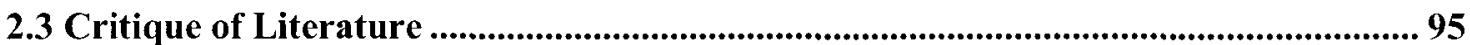

2.3.1 Critique of Organizational Commitment Literature .............................................. 95

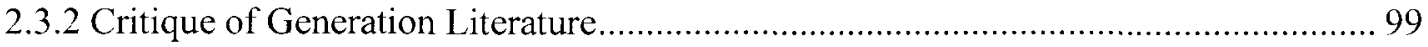

$3 \quad$ Theoretical Framework _ 104

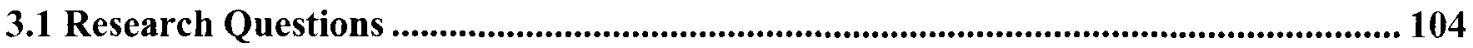

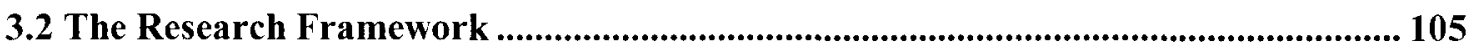

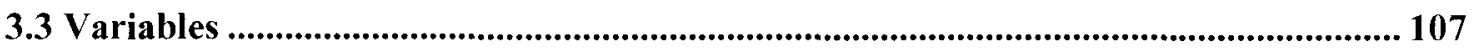

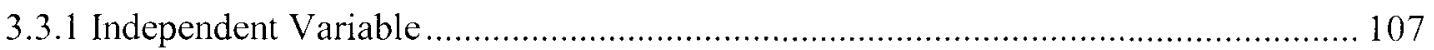

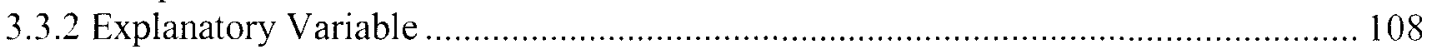

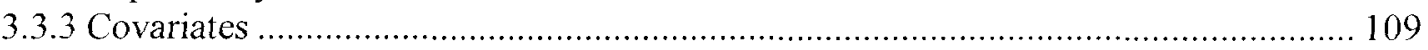

4 Methodology 127

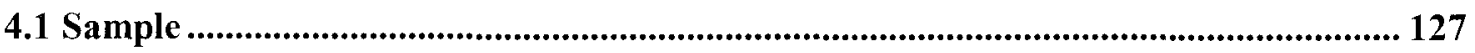

iv 


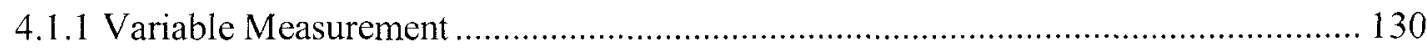

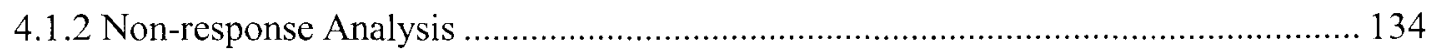

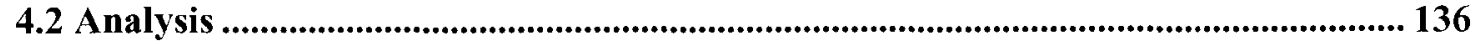

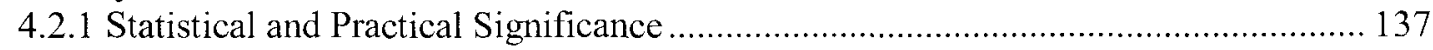

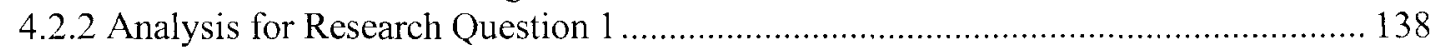

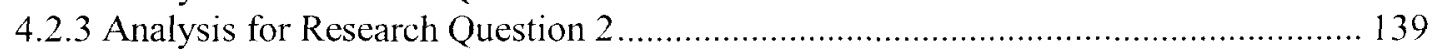

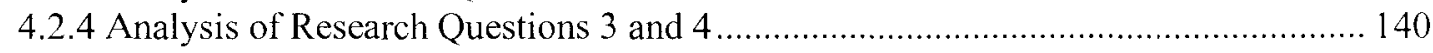

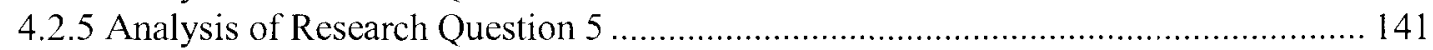

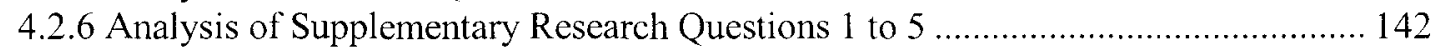

4.2.7 Analysis of Supplemental Research Question 6 ................................................ 142

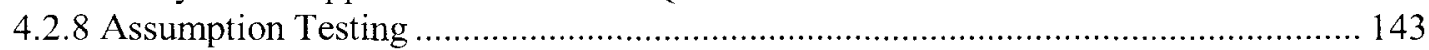

5 Results

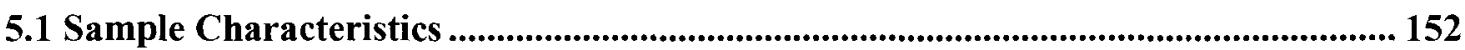

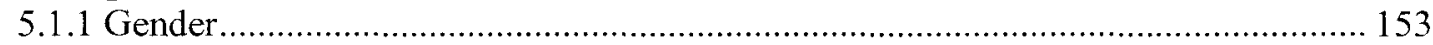

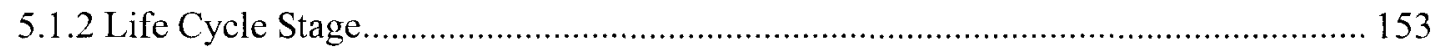

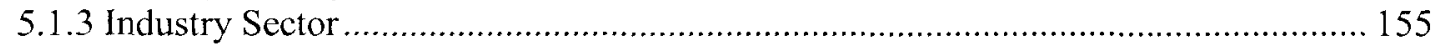

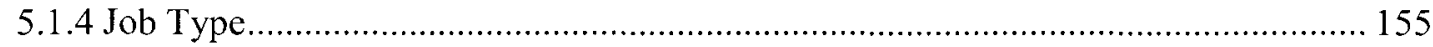

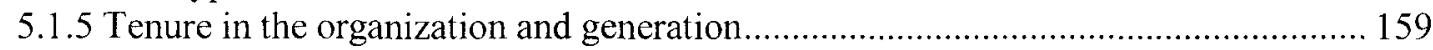

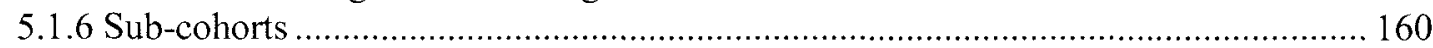

5.2 Sample Characteristics with respect to Organizational Commitment ......................... 161

5.3 Commitment Differences Between Generational Cohorts ........................................ 167

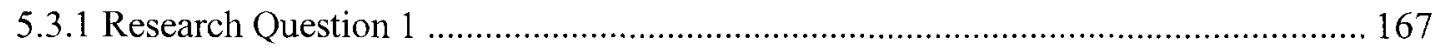

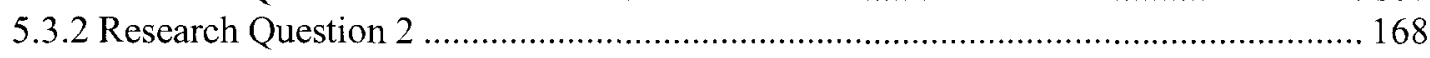

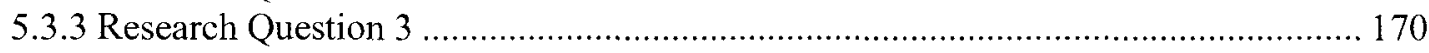

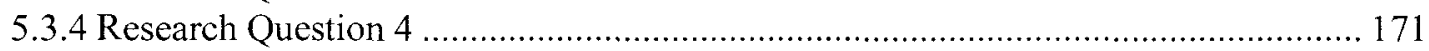

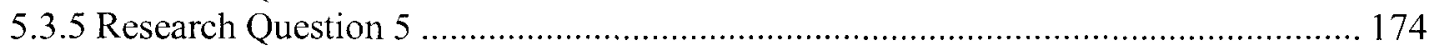

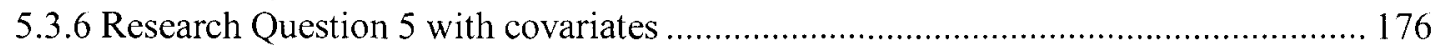

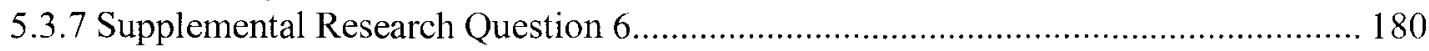

6 Discussion of Results _ 183

6.1 Discussion of Primary Research Questions.......................................................................... 183

6.2 Discussion of Supplemental Research Questions ........................................................ 187

7 Conclusions__ 194

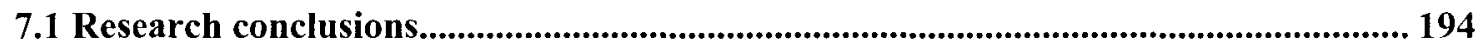

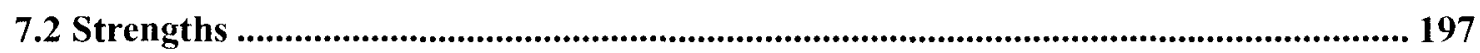

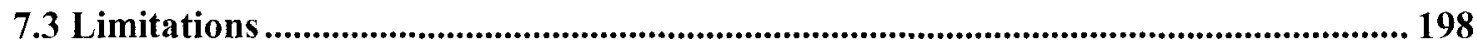

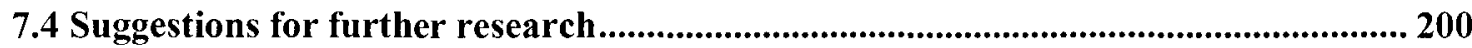

8 Bibliography__ 202 


\section{List of Tables}

Table 2.1 - Three bases of organizational commitment...............................................................30

Table 2.2 - Boundaries of the Baby Boom Generation .......................................................61

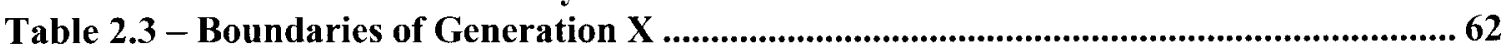

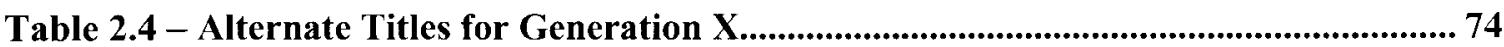

Table 2.5 - Terms Frequently Used to Describe Members of Generation X ......................... 82

Table 2.6 - Positive \& More Recent Perceptions of Generation X ........................................ 83

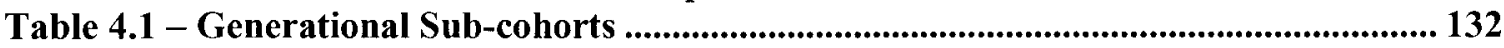

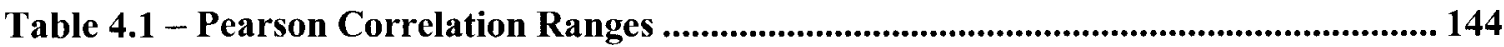

Table 4.2 - Pearson correlations between variables..................................................................... 145

Table 4.3 - Tolerance of explanatory variables ................................................................................. 146

Table 4.4 - Significance of interaction terms .................................................................................. 149

Table 5.1 - Sample by Generation and Gender (n) ...................................................................... 157

Table 5.2 - Sample by Generation and Gender (\%) .................................................................. 158

Table 5.3 - Mean tenure in the organization by generation and gender ................................ 159

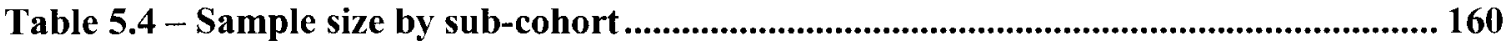

Table 5.5 - Mean organizational commitment by sub-cohort............................................ 161

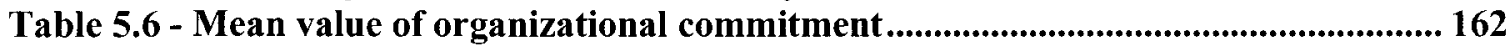

Table 5.7 - T-test for differences between genders.................................................................. 163

Table 5.8 - Differences in organizational commitment between groups within gender ..... 165

Table 5.9 - Interactions on organizational commitment between gender and covariates.. 166

Table 5.10 - Scheffé results for significant organizational commitment differences within

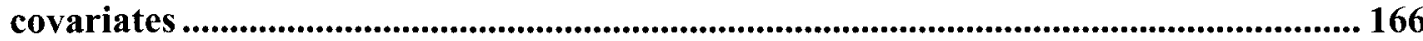

Table 5.11 - ANOVA Between Generation and Organizational Commitment ................... 168

Table 5.12 - ANCOVA Between Generation and Organizational Commitment.................. 169

Table 5.13 - Regression: Generation and covariates.................................................................... 170

Table 5.14- Regression with Beta values............................................................................................ 170

Table 5.15 - Regression: Hierarchical regression............................................................... 172

Table 5.16 - Regression 2: Standardized Coefficients for all three models .......................... 173

Table 5.17 - ANOVA: Generation X Sub-cohorts and Organizational Commitment ........ 174

Table 5.18 - ANOVA: Baby Boomer Sub-cohorts and Organizational Commitment........ 175

Table 5.19 - ANOVA: All Sub-cohorts and Organizational Commitment ........................... 176

Table 5.20 - ANCOVA: Generation X Sub-cohorts and Organizational Commitment with

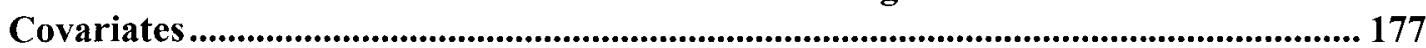

Table 5.21 - ANCOVA: Baby Boom Sub-cohorts and Organizational Commitment with

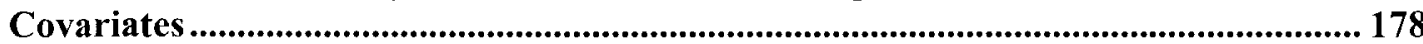

Table 5.22 - ANCOVA: All Sub-cohorts and Organizational Commitment with Covariates

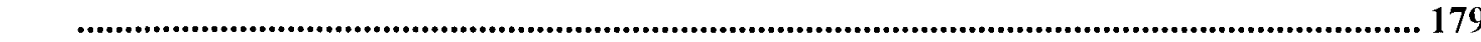

Table 5.23 - Significance Levels of Organizational Membership Results........................... 182 


\section{List of Figures}

Figure 2.1 - Stages in the development of organization commitment .................................... 19

Figure 2.2 - Brickman's Five-Stage Model of Commitment ..................................................... 25

Figure 2.3 - Major influences of the continuing development of organizational commitment

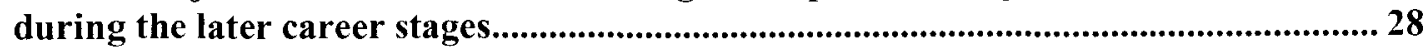

Figure 2.4 - Attitudinal Perspective of Commitment .................................................................. 44

Figure 2.5 - Behavioral Perspective of Commitment ................................................................. 45

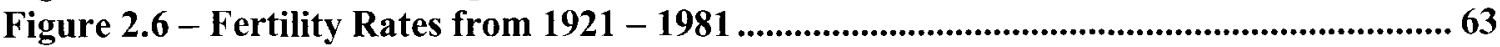

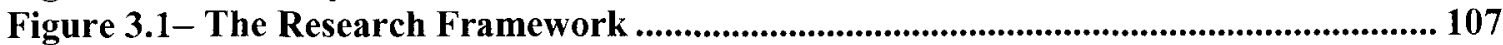

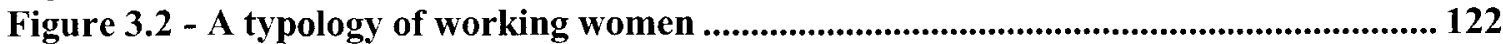

Figure 5.1 - Organizational Commitment Means for Industry Sectors by Gender ............. 167 


\section{List of Appendices}

Appendix A - A Flow Diagram of Processes and Events Leading to Commitment ............ 219

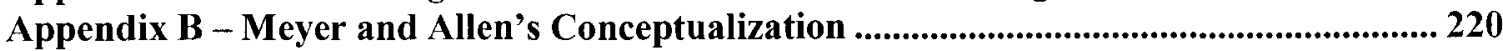

Appendix C - Organizational Commitment Questionnaire (OCQ) ....................................... 221

Appendix D - Meyer and Allen's Three Measures........................................................................ 222

Appendix E - Age Chart with Sub-cohorts ..................................................................................... 224

Appendix F - Balancing Work, Family and Lifestyle National Study (adapted to include only relevant sections)............................................................................................................... 225

Appendix G - Tabachnick and Fidell's Decision Tree.............................................................. 227

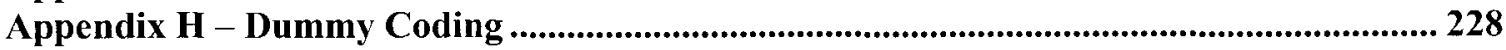

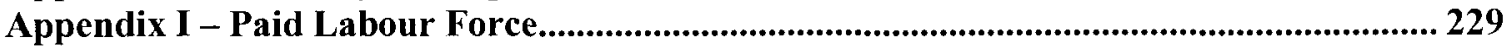

Appendix $J$ - ANCOVAs for Supplemental Research Question 6 ......................................... 230 


\section{Introduction}

While in her forties, Cornelia A. P. Comer wrote, "Deficiencies in you (the rising generation) irritate your seniors...your seniors also find themselves irritated and depressed because modern girls are louder-voiced (pp. 145 - 146)". She continued by saying, "The rising generation cannot spell...Veteran teachers are saying that never in their experience were young people so thirstily avid of pleasure as now...but this is different from anything we have ever seen in the young before. They are so keen about it - so selfish, and so hard! (pp. 145 - 147)”. Finally, she describes the rising generation as being "amiable, attractive, lovable even, but singularly lacking in force, personality, and the power to endure (p.148) ...the word 'unselfishness,' for instance, has vanished from their vocabularies (p.149)".

Randolph Bourne, a twenty-five year old man responded by explaining, "The most obvious retort to this is, of course, that the world in which we find ourselves is in no way of our own making...it is at least a plausible assumption that the world itself...may be partly to blame. (p. 591)". He continued by explaining that,

"The modern child from the age of ten is almost his own 'boss' (p. 592)...I doubt if any generation was ever thrown quite so completely on its own resources as ours is (p. 593)... The two generations misunderstand each other as they never did before (p. 592)... We have retained from childhood the propensity to see through things, and to tell the truth with startling frankness (p. 596)... We are more than half confident that the elder generation does not itself really believe all the conventional ideals which it seeks to force upon us (p. 597) ... You have been trying so long to reform the world by making men 'good,' and with such little success, that we may be pardoned if we turn our attention to the machinery of society, and give up for a time the attempt to make the operators of that machinery strictly moral. We are disgusted with sentimentality. (p. 598)".

He also stated that, 
"The rising generation has a very real feeling of coming straight up against a wall of diminishing opportunity. I do not see how it can be denied that practical opportunity is less for this generation than it has been for those preceding it (p. 594)...I have seen too many young men, drift idly about from one 'job' to another, without apparent ambition, until something happened to be presented to them which had a spark of individuality about it, whereupon they faced about and threw themselves into the task with an energy that brought success and honor (p. 595)".

Although these sentiments appear to apply directly to today's conflicting generations, these letters were written in 1911 (Comer, 1911; Bourne, 1911). There are similarities between the two disputing generations of that time and those that are present today (Howe \& Strauss, 1992). The similarities are so numerous, in fact, that many question whether the current difficulties between generations are due to the two current generations in the workplace or whether the difference is primarily the general struggle between youth and members of the preceding generation that has always occurred. To support this point, Weston (2000) claims that youth has always been criticized by its elders. Others, however, demonstrate that the work environment has changed so drastically in the recent past that the relationship between today's youth and work is not understood by their elders (Conlin et al., 1999; Foot, 1996). This thesis seeks to shed some light on this issue by examining the relationship between generations and a key work attitude: organizational commitment.

A generation is considered to be, "people (of) about the same age who in a given period have similar experiences that may affect them the same way (Rosow, 1978, pp. 66-67)". More details on what constitutes a generation will be addressed later in this thesis. The two dominant generations currently in the workforce are the Baby Boom Generation and Generation X. The Baby Boom Generation is defined for the purpose of 
this research as those born in Canada between 1947 and 1964 inclusive. Generation X is the generation which follows the Baby Boomers and whose members were born in Canada between 1965 and 1980 inclusive. There is some discussion regarding whether the Baby Boomers are really as different from their parents' generation as people initially felt (Scott, 2000), particularly once the Baby Boomers entered the workforce. There is little debate, however, over whether or not there is a difference between the Baby Boomers and the members of Generation $\mathrm{X}$ in the workplace. Whether this is because the generations are vastly different or because the work environment is vastly different or a combination of the two continues to be argued.

Organizational commitment is defined as "the relative strength of an individual's identification with and involvement in a particular organization" (Mowday et al., 1982, p. 27). Organizational commitment was often considered to be the foundation upon which the workplace was built, but this commitment is now felt to have all but disappeared with the entry of Generation X into the workforce (Losyk, 1997). Many also feel that the organization has become less committed to the employee since it offers little job security (Tulgan, 2000). Given the impact of organizational commitment on critical factors such as turnover, absenteeism and job satisfaction it is important for employers to understand the link between generation and organizational commitment.

This thesis is divided into seven sections. The first section outlines the research objectives and the relevance of a study on generational differences at work. A thorough 
review of literature relevant to this research is given in the second section. The literature review is divided into three parts: organizational commitment, generations and a critique of the literature. A theoretical framework will then be proposed in the third section including research questions and the research model. The fourth section will discuss the research methodology that was used to test the framework. The fifth section will examine the results from the data analysis followed by a discussion of the results in the sixth section. Finally, a conclusion including the strengths and limitations of this research as well as areas for future research will be addressed in the seventh section.

\subsection{Research Objective}

The objective of this thesis is to develop an understanding of the two primary generations in the workforce today: Baby Boomers (born beginning of 1947 to end of 1964) and Generation X (born beginning of 1965 to end of 1980). Specifically, this study examines the extent to which the popular press is justified in its belief that there is a difference in the level of organizational commitment experienced by these two groups. An effort will be made to:

- Determine whether organizational commitment is associated with generational membership. Specifically, to observe how the levels of organizational commitment reported by employed Baby Boomers compare to those reported by employed members of Generation $\mathrm{X}$

- Determine the impact of key potential confounds (gender, life cycle stage, tenure in the organization, industry sector of employment and job type) on 
the relationship between organizational commitment and generational membership

- Gauge the effectiveness of generational cohort as a predictor of organizational commitment

- Determine whether sub-cohorts can be identified within the Baby Boomer and Generation X groupings with respect to organizational commitment

\subsection{Significance of This Study}

Organizational commitment, the most extensively studied form of commitment, is of interest to both organizations and researchers. In fact, it has been one of the most commonly studied organizational attitudes since the 1960s (Meyer \& Allen, 1993). Management often feels that organizational commitment has decreased in recent years due to downsizing and other organizational changes (Meyer \& Allen, 1997). This is cause for concern as organizational commitment has been found to be strongly correlated to turnover (Mowday et al., 1982) which is, in turn, associated with higher costs due to the expenses associated with recruitment, education and training (Meyer \& Allen, 1997). Organizational commitment has also been linked to tenure, absenteeism and tardiness (Mowday et al., 1982; May et al., 2002; Meyer \& Allen, 1997). There is an additional belief, founded or not, that employees who are committed to the organization are more likely to work hard for the organization (Meyer \& Allen, 1997). This research will help organizations better understand the relationship between generations and commitment. 
This increased understanding should facilitate the design of appropriate strategies to increase commitment in the different groups.

While most researchers as well as the general public agree that there is a difference between the Baby Boom Generation and Generation X, very little empirical research has been conducted in this area (Smola \& Sutton, 2002; Tulgan, 1997). There are many views in the popular press and practitioners' journals regarding the level of commitment demonstrated by the different generations as well as discussions on the "generation gap" but few are empirically based. Although these different views have merit, it is impossible to give credence to one article or book over another when all are based strictly on opinion. Since there is a great deal of discussion in this area, it is evident that the general population has an interest in the topic. This research may provide a foundation for these discussions.

Although some research has been done with respect to age and organizational commitment (Cherrington et al., 1979; Cherrington, 1977; Dickson \& Buchholz, 1977; Taylor \& Thompson, 1976; Burke, R.J., 1994a; Cohen, 1993; Finegold et al., 2002), the use of the generation construct should result in a more robust understanding of the area, as it does not divide individuals arbitrarily into age ranges but looks at other distinguishing characteristics. In addition, since the majority of articles and people consider "Generation X" to be less committed to their organization and "Baby Boomers" to be more committed, the generational grouping fits with society's interest in this topic. 
While it would be interesting to examine whether $20-25$ year olds change their attitudes towards their organization over time (i.e. become more or less committed), such research requires a longitudinal approach and a longer span of time. Consequently, this research takes a cross-sectional approach to examine if, at this point in time, there are measurable differences in organizational commitment associated with generational membership. A connection between generations and organizational commitment will provide further empirical support for the idea that generational differences do or do not exist in attitudes toward work. This information will provide the organization with important information on how best to manage its workforce. In addition, it will demonstrate whether researchers studying organizational commitment should control for generation in order to produce a more robust study. 


\section{Literature Review}

This thesis will examine generations in the workforce by studying their reported levels of organizational commitment. It will attempt to determine any differences in organizational commitment between the Baby Boomers and members of Generation X. The literature in the area of organizational commitment is mature, as it has been examined in a variety of areas of study such as sociology, business and psychology, for more than half a century. The literature in the area of generations, however, is much less developed and is primarily found in the popular press and trade magazines. Little empirical research has been done on the Baby Boomers or Generation X with respect to their work attitudes. In fact, most of the research in this area has been performed by marketing groups who wish to target advertising to one group or the other.

This literature review will begin with an examination of the construct of organizational commitment. Included in this section are a summary of how the construct was developed and a review of key definitions and models. Section two of the literature review will discuss generations. This section will begin with a discussion on the use of a cohort as a variable followed by thorough discussions on the Baby Boom Generation and Generation $\mathrm{X}$. The focus here will be on identifying those factors that help define these age cohorts as generations. This section of the literature review will be based on both empirical studies and on popular opinion. Finally, a critique of both the organizational commitment literature and the generation literature will be presented. 


\subsection{Organizational Commitment}

There is a large and well developed literature on organizational commitment. To bring some structure to our discussion on this construct, this part of the literature review is divided into seven sections. The review begins by defining the construct. The definition that will be used for the purpose of this research will be presented as well as alternate definitions. The importance of organizational commitment as a concept will be examined in the second section in order to provide more depth on the relevance of this research. The third section will present different models that have been developed to describe the commitment process. Next, different variables related to organizational commitment will be examined. The fifth section will discuss antecedents of organizational commitment. Next, models of organizational commitment will be examined including Becker's side bets, Kanter's thesis, Etzioni's typology and Meyer and Allen's three-component model. Finally, section seven will examine different methods that have been proposed to measure organizational commitment. It is important to note that as there is an abundance of articles and research in this area, this literature review does not attempt to be exhaustive, but rather to discuss the most important articles in this area for the purpose of this study.

\subsubsection{Defining Organizational Commitment}

Becker stated in 1960 that the primary difficulty involved in the study of organizational commitment is the inconsistency between definitions of the term, particularly across disciplines. At that time, he observed that sociologists used the 
concept to analyze both individual and organizational behavior in order to characterize kinds of people or groups. Salancik (1977) agreed with this viewpoint, differentiating between the use of commitment by organizational behavior researchers and social psychologists. Becker (1960) further stressed that when the term "commitment" was introduced in a study, it was not explained but was considered as a given and that the definition was commonly understood (Becker, 1960). In order to fulfill the need for a common definition, Becker (1960) proposed a definition to be used as a point on which to base future research. Furthermore, he expected that the research would be used to improve upon this base definition. In his base definition of commitment, Becker explains that commitment is used to explain consistent behavior and actions that exist over a period of time and are directed toward a common goal (Becker, 1960).

Despite Becker's attempt at a more generally accepted definition, the term "organizational commitment" continued to be defined differently by nearly every researcher studying the construct. This may be in part because, as noted by Brickman (1987), commitment is an elastic term that can be used to describe both positive and negative emotions through the same underlying phenomenon. Similar to Becker's definition, Gerard (1965) uses commitment to explain "constraints, however minimal, which operate against undoing behavior (p.264)" and Hulin (1991) states that commitment explains "consistent sequences of behavior or courses of action" (Hulin, 1991). However, Hulin expands on this to emphasize that if there is not an alternative action that may be rejected, the sentiment is not actually commitment. Hulin (1991) 
defines organizational commitment more explicitly as an attitude, like attraction, directed toward the overall organization rather than specific work roles (Hulin, 1991).

An alternate definition, proposed by Farrell and Rusbult (1981), explained organizational commitment as the likelihood of an individual remaining with a job and feeling an attachment towards it, whether it is intrinsically satisfying or not. As mentioned above, Salancik (1977) found differences in the definitions of commitment used by organizational behavior researchers and those used by social psychologists. This resulted in him proposing two definitions of commitment: that to be used in the field of organizational behavior and that to be employed by social psychologists. He defined these two forms of commitment as follows. In organizational behavior, commitment is the identification by employees with goals and values that lead to a desire to maintain membership in the organization. In other words, the point of view under study is the attitude towards the organization itself. The social psychological view of commitment, on the other hand, focuses on how an individual's past behavior all but forces him or her to remain within the organization due to rewards and punishments that will be encountered otherwise. Salancik (1977) further observes that most definitions of organizational commitment are based on either attitude or behavior and, thus, fall into one of the above two categories of definitions.

Johnson (1973) uses a similar typology for commitment as he distinguishes between personal commitment, where there is a strong personal emotion involved in the 
commitment (value commitment) and behavioral commitment where prior actions determine future behaviors (forced commitment). Masters and Johnson (1974) also use a similar distinction as they identify commitments of obligation and commitments of responsiveness. The former explains commitment based on previous actions where some benefit is derived due to the previous actions and the latter is described as a feeling of pleasure from the commitment. Stebbins (1970) offers a dyadic approach with two dimensions of commitment: value commitment and forced commitment. Value commitment is explained as, "a frame of mind that arises from the presence, in exceptional number, of subjectively defined rewards associated with a particular position or social identity in which the person finds himself...(p. 527)". Forced commitment, however, is explained as "the awareness of the impossibility of choosing a different social identity...because of the imminence of penalties involved in making the switch ( $\mathrm{p}$. 527)" (Stebbins, 1970). These typologies help to resolve the difficulties that existed in defining organizational commitment, as it appears that different concepts of commitment were being examined without distinguishing between the two (Mowday et al., 1982).

Although the term "forced commitment" is used by Stebbins (1970), it should be noted that the commitment is not "forced" per se but rather that the costs of leaving are viewed as too high for the individual to consider. Many researchers consider commitment in the instance where there are actually no alternatives, as opposed to no logical or feasible alternatives, not to be commitment at all (Hulin, 1991). O'Reilly and Chatham (1986) identified a similar distinction as they suggest that (in their terms) 
identification and internalization are not necessarily forms of commitment but may instead be an explanation of how commitment develops. This approach leaves only continuance commitment as a true form of commitment. However, as mentioned above, there are those who believe that continuance commitment is not actually commitment because of the necessity, rather than the desire, employees feel to remain with the organization (O'Reilly and Caldwell, 1981).

Finally, in 1982, Mowday et al. examined previous definitions of organizational commitment and found that they all included the concept of the individual's attachment to the organization. Therefore, they concluded, that organizational commitment is, "the relative strength of an individual's identification with and involvement in a particular organization" (Mowday et al., 1982). Their definition also included three factors essential to organizational commitment: acceptance of organizational goals and values, willingness to exert effort on behalf of the organization and a strong desire to retain membership within the organization (Mowday et al., 1982). Of these three factors, it is possible that only the first two are particularly relevant in the current environment of high turnover (Swailes, 2002).

Although Mowday et al.'s (1982) definition continues to be critiqued and has several drawbacks, which will be noted shortly, since 1982 it has been considered by most to be the definitive definition of organizational commitment and has been used in most later research (May et al., 2002; Meyer \& Allen, 1997). It is particularly useful 
since, in the study of the workplace, commitment has been found to be distinct from a variety of other similar and widely studied constructs: job satisfaction, job involvement, career salience, occupational commitment, turnover intention and work group attachment (Meyer \& Allen, 1997).

Despite the widespread use of Mowday et al.'s definition, many researchers have found flaws in this conceptualization. Meyer and Allen (1991), for example, feel that this definition is too rigid and propose instead that there are three themes to definitions of commitment. These themes will be discussed later in this review in conjunction with their three-component model. It is interesting to note, however, that Meyer and Allen do not propose their own definition and that, in fact, they use Mowday et al.'s definition in their subsequent book (Meyer \& Allen, 1997). Hulin (1991) also observed that Mowday et al.'s definition goes beyond intentions to remain in the organization and includes behavioral elements. This observation brings into consideration the fact that relationships between job performance and attitudes have been difficult to establish, making Hulin question the aspect of the definition that involves acceptance of the organization's goals and values. Despite the concerns associated with Mowday et al.'s definition, this is the definition that is currently the most frequently used and upon which most current research on organizational commitment is based. Therefore, this is the definition that will be used for the purpose of this thesis. 
Organizational commitment has been an extensively researched area since the 1960s and has been the most extensively studied form of commitment since that time (Meyer \& Allen, 1993). It is important to distinguish organizational commitment from commitment to other referents within the work environment. Swailes, 2002, identified five referents of commitment. These referents are to the work, to a specific job, to a union or staff, to an occupation or to an organization (Swailes, 2002). Gouldner (1960) also identified commitment to an organization and commitment to specific values of an organization as different constructs. To this end, she identified four different patterns of commitment: to the supervisor or work group (local), to top management and the organization (global), to both local and global or to neither (Gouldner, 1960). For the purpose of this thesis, global commitment, more commonly called organizational commitment will be examined. Organizational commitment will be examined for the remainder of section 2.1. The focus, more specifically, will be on organizational commitment after the employee's initial entry into the organization, as opposed to prior to entry into the organization. This decision was made because it has been determined that the initial organizational commitment has a different structure and reasoning and is less stable than commitment in later stages of the employment relationship (Mowday et al., 1982; Werber \& Gould, 1984). To accommodate this distinction, this study is restricted to those individuals who have worked for more than one year in the organization. 


\subsubsection{The Importance of Organizational Commitment}

As previously mentioned, organizational commitment is one of the most commonly studied concepts in business research. It continues to be extensively studied because it is perceived as being important to the organization itself in a variety of ways. The ways in which organizational commitment is important will be discussed in this section. Following this, there will be a discussion regarding whether or not high organizational commitment is a positive thing. This is a topic that has come under some debate despite the fact that organizational commitment appears to be inherently positive.

Organizations perceive that organizational commitment is important due to a variety of positive variables that have been found to correlate with organizational commitment. As mentioned in the previous chapter, organizational commitment has been found to be related to turnover, tenure, absenteeism and tardiness (Mowday et al., 1982; May et al., 2002; Meyer \& Allen, 1997). It has also been found to be potentially related to performance or job satisfaction although results of studies have reached different conclusions in these areas (Swailes, 2002; Mowday et al., 1982; May \& Korczynski, 2002). Due to the variables that are related to organizational commitment, there is an obvious reason for organizations to strive to increase employee commitment. In the current workplace, higher knowledge and skills are required (Meyer \& Allen, 1997). There is a high cost incurred by the organization to develop and maintain knowledge skills. This investment is lost if the organization has high turnover or absenteeism due to lower levels of employee commitment. 
In society, there is a concern that individuals are uncommitted, over committed, or that individuals are unable to commit the way they were able to in the past (Brickman, 1987). This leads to some discussion as to whether or not high commitment is beneficial. In 1930, Freud began discussing whether or not society demanded too much commitment and suggested that conformity would result from such a focus (Brickman, 1987). Brickman (1987) reports conflicting points of view between those who feel that commitment is necessary for an individual to feel fulfilled and those who feel that commitment destroys the individuality that makes them human. Kanter (1968) believes that many social problems arise as the level of commitment in society decreases. Salancik (1977) on the other hand observes that whether or not the commitment can be considered positive is determined by the situation under which the commitment is experienced and the extent of the commitment. Although commitment appears to be inherently positive, there are potential drawbacks associated with this construct besides social complications. For example, if employees commit to the organization "blindly", the organization may lose its ability to innovate and become too entrenched in the previous methods of proceeding and quickly become outdated (Meyer \& Allen, 1997).

From a purely organizational perspective, management generally feels that commitment is waning due to the increasing amount of downsizing in recent years (Meyer \& Allen, 1997). In addition, it is becoming more of a concern to organizations that if an employee's commitment to the organization is dependent on the organization's 
loyalty to the employees, there may be little benefit to increasing commitment for the organizations in the current environment (Meyer \& Allen, 1997). However, as Meyer and Allen (1997) state, higher knowledge and skills are required in the current marketplace and the high costs of developing and maintaining knowledge skills continue to encourage organizations to strive for increased employee commitment. As will be discussed, absenteeism and turnover have been found to have a high negative correlation to organizational commitment (Mowday et al., 1982; May et al., 2002; Meyer \& Allen, 1997). Both of these variables have a high direct financial cost as well as costs to productivity and skill development.

\subsubsection{The Commitment Process}

Commitment is conceptualized as a process that begins prior to one's entry into an organization and that changes over time. A number of researchers have proposed models that describe this commitment process. Several of these models are reviewed in the following section including a three-staged model proposed by Mowday et al. (1982) and a five-staged model proposed by Brickman (1987).

\subsubsection{Mowday et al.'s Model}

There are several commitment processes that have been proposed in order to classify the different stages one goes through when moving from the point of time preceding the relationship to a stage of strong commitment. Mowday et al. (1982) 
proposed three stages to the commitment process with respect to the organization: preentry; early employment; and middle and late career stages (see Figure 2.1).

\section{Figure 2.1 - Stages in the development of organization commitment} (Mowday et al., 1982)

\begin{tabular}{l|c|c} 
& & \\
Pre-entry stage & Early employment stage & $\begin{array}{l}\text { Middle and late } \\
\text { career stages }\end{array}$ \\
& & \\
\hline Anticipation & Initiation & Entrenchment
\end{tabular}

Despite the confusion that may arise from beginning the process before the existence of the relationship, Mowday et al. (1982) felt that the pre-entry phase has an impact on later commitment that should not be ignored. According to their model, the pre-entry stage is based on the idea that making the choice to be employed in a certain organization causes the individual to become committed to that decision and to the expected behavior resulting from that decision (Mowday et al., 1982). ${ }^{1}$ Following the pre-entry stage, Mowday et al. (1982) hypothesize that individuals' attitudes will adjust to remain consistent with their choice and to prevent cognitive dissonance.

The pre-entry stage is considered to be a period of anticipation with varying degrees of commitment depending on the individual. Regardless of the level of commitment, however, this commitment is considered unstable and may change from day

\footnotetext{
${ }^{1}$ Wiener (1982) had a similar view regarding the value of the pre-entry stage as can be seen by the diagram in Appendix A.
} 
to day with the initial experiences in the organization (Mowday et al., 1982). Major determinants of commitment during this stage are considered to be: personal characteristics, expectations about the job and job choice factors (Mowday et al., 1982).

The second stage, according to Mowday et al.'s (1982) model is the early employment stage. This period consists of the first several months to the first year with the organization and is considered the initiation period. Many consider this to be the first stage in commitment since it is the point at which the employment within the organization actually begins. It is also considered to be a critical period for commitment in that it develops lasting attitudes as opposed to the pre-employment stage where attitudes are less stable (Mowday et al., 1982). Initial expectations regarding the organization and the job are confirmed or disproved during this period. Mowday et al. (1982) supported this phase by noting that most employees who terminated employment with the organization did so within the first year. Influences on commitment during this phase are considered to be: personal, organizational, or nonorganizational (Mowday et al., 1982). Personal influences involve the characteristics of the individual, including the propensity of the individual for commitment. Personal influences may be similar to those experienced during the pre-employment phase (Mowday et al., 1982). Organizational influences consist of job and work environment characteristics. Although research has not been conclusive on the reasons that certain environments may or may not be conducive to commitment, the work environment obviously impacts the employee's commitment to the organization. Nonorganizational influences include the characteristics 
of the organization in which the individual is employed. The characteristics of those organizations that do not employ the individual but of which the individual is aware would also be considered nonorganizational influences. This is most salient when the availability of employment with other firms is high (Mowday et al., 1982). Commitment developed during this phase begins to stabilize and this is often considered the most critical stage although commitment levels continue to change through later phases (Mowday et al., 1982).

The final stages of this model are the middle and late career stages. This period is considered the entrenchment period and is marked by more tenure, which often leads to more challenging and enjoyable work (Mowday et al., 1982). Investments (financial and other) are also expected to increase as an individual's tenure within an organization increases which may help increase commitment (Ritzer \& Trice, 1969; Alluto et al., 1973; Becker, 1960). This may be done by increasing social ties, decreasing external potential employment and increasing security within the organization (Mowday et al., 1982). It has been found that the longer an individual remains with an organization, the more likely he or she is to feel a high level of commitment to the organization (Mowday et al., 1982). 


\subsubsection{Brickman's Model}

Brickman (1987) proposed a 5-step model for the process of commitment which is more general and less focused on organizational commitment (see Figure 2.2 on page 25). Brickman believes that negative and positive forces interact to form commitment and only through the reconciliation of these forces can a true, deep commitment be formed. Furthermore, he perceived that there are continuous changes to the commitment relationship based on these negative and positive forces that will both threaten and strengthen the commitment itself (Brickman, 1987). He attributes some of these changes in commitment to the aging process and the reconciliation of different priorities and emotions as proposed by Riegel (1975). However, Brickman (1987) also feels that since priorities and emotions are continuously changing and evolving, there is no end point in the commitment process. Rather, his model perceived that people oscillate between varying levels of commitment. Accordingly, his five-step process was formulated to demonstrate the patterns of commitment rather than a series of sequential steps an individual will pass through in order to achieve high commitment (Brickman, 1987).

Brickman (1987) sees the first stage of commitment as exploratory in nature. This stage may be considered a "precommitment" stage due to the fact that the individual is determining whether the potential relationship with the employer should be developed (Brickman, 1987). Similar to Mowday et al. (1982), Brickman (1987) feels that the stage before an actual commitment is made is in fact one of the stages of commitment. This is due to the fact that emotions prior to the relationship may subtly shape the form of the 
later commitment if the relationship is actualized (Brickman, 1987). During the precommitment phase positive elements are encountered arousing positive emotional responses by the individual. If these positive elements are not encountered the commitment will not form as there is no incentive on the part of the employee to form the commitment.

Brickman (1987) also sees the second phase of commitment as being exploratory in nature although it has a different focus. During this phase, negative elements related to the potential commitment have begun to emerge and become factors in the commitment process. Due to the exploratory nature of this phase, these negative elements are generally due to external factors such as other job offers, family obligations or other elements that are not part of the commitment itself. These negative elements may, however, cause a threat to the commitment itself because the person making the commitment believes that what he or she needs or desires may not be achieved through this commitment. Once stage two has been overcome through a balance of negative and positive aspects, the individual enters stage three of his or her commitment (Brickman, 1987).

Stage three, as identified by Brickman (1987) tends to be a passionate form of commitment that focuses primarily on more intrinsic positive elements. The negative elements from phase two have been overcome and the commitment is proceeding so the individual looks inwards. Intrinsic positive elements may include a more challenging 
job, a friendlier work environment or additional responsibility. The extremely positive nature of this commitment may also be due, in part, to cognitive dissonance because the individual has decided to continue with the commitment process despite the negative aspects encountered (Brickman, 1987).

Brickman's definition of the fourth stage of commitment describes a fading of the passion and energy from stage three. The commitment is now marked by familiarity and expectedness and the individual may become bored or ambivalent to the object to which he or she is committed. In contrast to the negative elements encountered in phase two, during phase four the negative elements come from within the individual and not from external sources or from the object of commitment (Brickman, 1987). For example, the expectations of the individual may not have been met. He/she may not feel as confident of his or her abilities in performing his or her new functions or he/she may feel a lack of cohesiveness with his/her new coworkers.

Finally, stage five of Brickman's commitment process involves a bond of commitment. This bond is similar in nature to that in phase three except that it includes a deeper relationship than the initial bond. This stage also differs from stage three in that it involves a heightened awareness of both the negative and positive aspects of this bond. During this phase different positive and negative elements move in and out of the consciousness of the individual and his or her level of commitment continues to fluctuate subtly as his/her commitment continues. Individuals in this stage may move from phases 
of extreme passion to seemingly ambivalence and they alternatively contemplate and ignore the opposing forces (Brickman, 1987). It should be noted that, although Brickman (1987) hypothesizes that the stages of commitment must occur in this order, the length of time that each individual will stay in each phase depends entirely on the individual and the commitment. There is no general rule for the length of time it takes an individual to pass from one stage to the next.

Figure 2.2 - Brickman's Five-Stage Model of Commitment

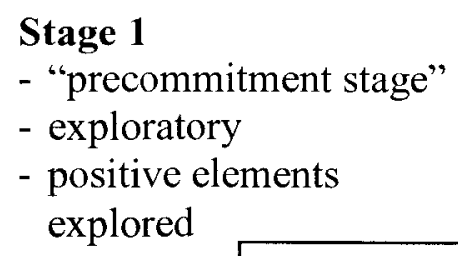

\section{Stage 2}

- exploratory

- negative elements explored

- external factors examined

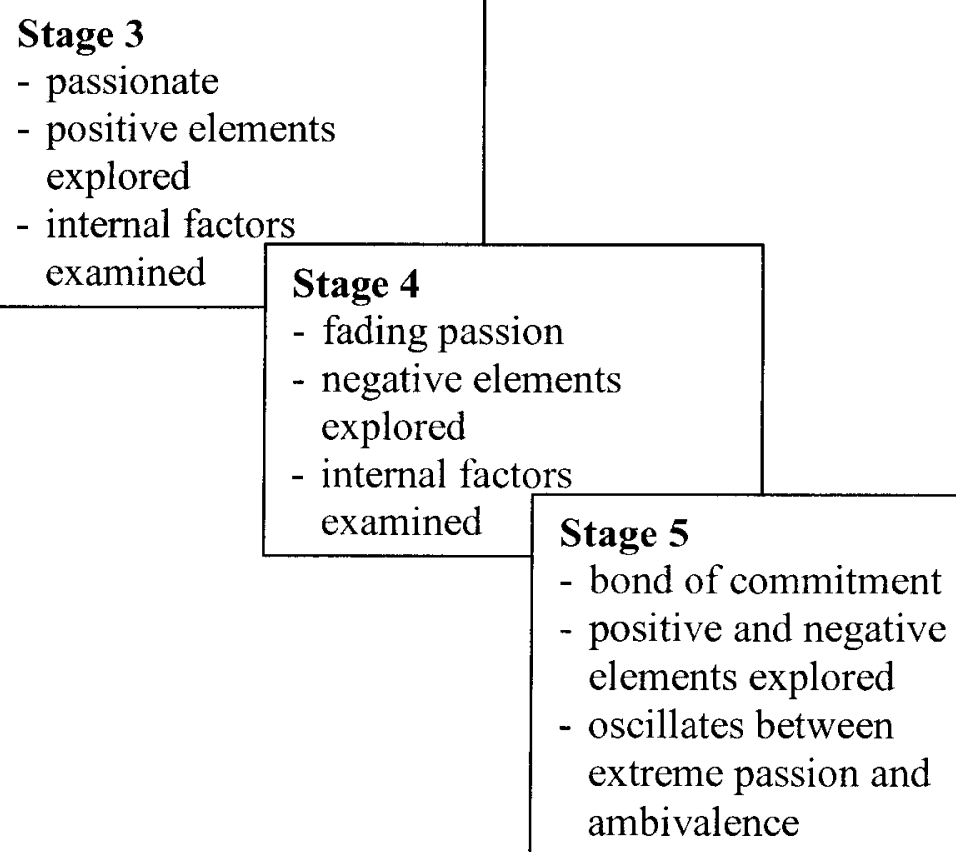




\subsubsection{Variables Related to Organizational Commitment}

There are many variables that are linked to organizational commitment and considered to be consequences of commitment although causality has never been definitively proven. Mowday et al. (1982) have identified at least 25 variables from other literature that are considered to be consequences of organizational commitment. These include: tenure, absenteeism (modestly related), tardiness (strongly, inversely related) and turnover (highly correlated) (Mowday et al., 1982; May et al., 2002; Meyer \& Allen, 1997). For turnover, the relationship with organizational commitment is particularly strong after the first year of employment (Werbel \& Gould, 1984). Performance has been found to have a weak relationship to commitment by some and to have no significant relationship by others (Swailes, 2002; Mowday et al., 1982). Researchers have also reached varying conclusions when relating organizational commitment to work effort or to job satisfaction (May \& Korczynski, 2002). The lack of a relationship between organizational commitment and both work effort and performance becomes less concrete when researchers begin to look at different forms of commitment. When employees with strong affective commitment are studied, a relationship is found to exist where one did not with the general concept of organizational commitment (Meyer \& Allen, 1997).

\subsubsection{Antecedents of Organizational Commitment}

A wide variety of factors have been hypothesized to be related to organizational commitment. These are important, as antecedents must be determined in order to 
properly measure the construct. Meyer and Allen (1991) acknowledged the difficulties in forming conclusions and synthesizing research that has been conducted in the area of organizational commitment. They attempted to rectify this situation in 1997 by synthesizing the results of previous studies. This was accomplished by categorizing the antecedents of organizational commitment as: characteristics of the organization, characteristics of the individual and previous work experiences. This new synthesis, however, was very similar to that which was provided by Steers in 1977 . He categorized the influences on organizational commitment as: personal characteristics, job- or rolerelated characteristics, work experiences and possibly structural characteristics (which are demonstrated by Mowday et al., (1982) as being similar to the organizational characteristics described by Meyer and Allen (1991)). Since Mowday et al. used the same classification as Steers and provided a more inclusive categorization as well as the definition for organizational commitment that will be used in this study, their categorization will be used here. Therefore, the following section will identify the relationship of organizational commitment to each group of antecedents: personal characteristics, job-related characteristics, work experiences and structural characteristics.

Personal characteristics, in general, have been found to have substantial relations to organizational commitment. These include: age, tenure in the organization, gender, and education. Age and tenure in the organization are positively related to commitment (Mowday et al., 1982; Swailes, 2002). It has also been found that tenure is one of the strongest predictors of commitment because it influences the level of job assignments, 
autonomy and extrinsic rewards (Mowday et al., 1982). This relationship can be seen, as demonstrated by Mowday et al. (1982) in Figure 2.3, below. Gender was found to be related to organizational commitment by Mowday et al. (1982) with women being more committed but was found to have no influence on commitment by Swailes (2002). Education has inconsistently been found to be negatively related to organizational commitment (Mowday et al., 1982).

Figure 2.3 - Major influences of the continuing development of organizational commitment during the later career stages

(Mowday et al. (1982), p. 65)

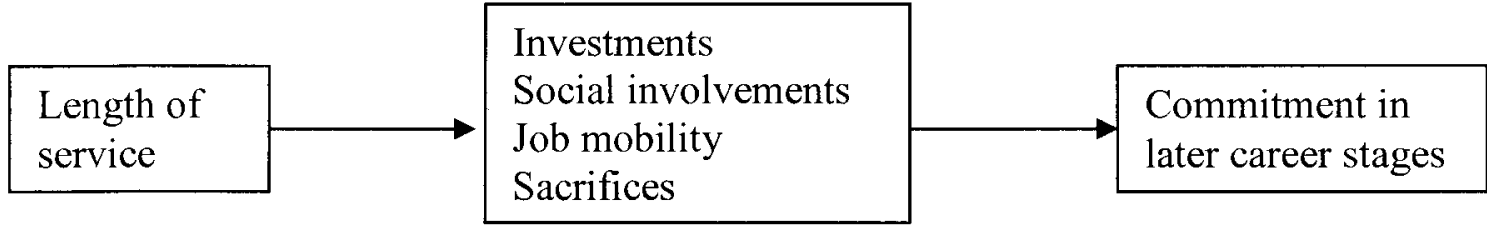

Job-related characteristics that affect organizational commitment are fewer but just as important. Although personal experiences can explain a person's propensity to commit, the job in which he/she is employed clearly has an impact on his/her level of commitment. Job scope and role clarification have been found to be positively related to organizational commitment while role overload has a strong negative relationship and role ambiguity has been found to have mixed results (Mowday et al., 1982).

With respect to work experiences, organizational dependability is considered to be most associated to organizational commitment with a high positive relationship. Supportive leadership, the intrinsic value of work (Swailes, 2002) and social involvement 
were also found to have a positive relationship with organizational commitment (Mowday et al., 1982).

Finally, in terms of structural characteristics, few were found to be related to organizational commitment although functional dependence, formalization, worker ownership and participation in decision-making were all found by some to be positively related (Mowday et al., 1982). Interestingly, it has been found that there may be a need for stable personal economic factors and social factors for high commitment to exist regardless of other factors (Swailes, 2002).

\subsubsection{Models of Organizational Commitment}

There are many models that have been developed, over time, to help explain organizational commitment. Current research tends to lean toward three bases of organizational commitment: attitudinal, continuance and normative (see Table 2.1 on page 30 for the origins of these three bases). In order to fully explore the area of organizational commitment, Becker's side bet theory of commitment will be examined first, followed by Kanter's typology, Etzioni’s typology and, finally, Meyer and Allen's three (or four) component model. These four models of commitment were chosen as they are representative of the common bases of commitment listed above and critical to the foundation of this research. Becker's model is representative of continuance commitment, Kanter's thesis describes all three bases of commitment to some extent and Etzioni's typology is identified as attitudinal or affective commitment. Meyer and 
Allen's model is the combination of the previously discussed theories into an overall theory of commitment. The three bases of commitment noted above are all components of this commitment as conceived by Meyer and Allen.

Table 2.1 - Three bases of organizational commitment (adapted from Swailes, 2002)

\begin{tabular}{l|l}
\hline Bases of organizational commitment & Originators/Developers \\
\hline Attitudinal or affective commitment (based upon & Etzioni (1961): Moral commitment \\
acceptance of and belief in the goals of an & Kanter (1968): Cohesion commitment \\
organization or group) & Mowday et al. (1982) \\
& O'Reilly and Chatman (1986): Internalization \\
\hline Continuance commitment (Based upon & Becker (1960): Side bet theory \\
socioeconomic factors) & Kanter (1968): Continuance commitment \\
& Meyer and Allen (1984) \\
& Mowday et al. (1982) \\
\hline Normative commitment (Based upon feelings of & Allen and Meyer (1990) \\
loyalty and obligation) & Kanter (1968): Control commitment \\
& O’Reilly and Chatman (1986): Identification \\
\hline
\end{tabular}

\subsubsection{Becker's Side Bets}

In 1960, Becker wrote his "Notes on the Concept of Commitment". As mentioned above, this began with a discussion on the ineffectiveness of the term commitment as it had been used up to that point. Becker stressed that little had been done in the way of formal analysis on the concept of commitment and proposed what he called, "a rudimentary theory of the social processes and conditions involved in the operation of this mechanism" (Becker, 1960, p. 32). Becker's side bet theory is based on his belief that individuals do not necessarily make commitments deliberately. 
Although he believed the definition to be tautological, Becker identified the general understanding of commitment as a state in which the individual will follow a consistent course (Becker, 1960). He believed that commitment results from incremental investments in an action (for this discussion, employment with a particular organization). These actions may initially be extraneous to the employment itself. The investments, or "side bets" may include, for example, elements such as non-transferable pensions, location of the employment and the individual's reputation. Each of these investments is small and is not necessarily enough on its own to form a commitment. Taken together, however, the sum of the investments becomes significant and it affects the individual's decision to leave the organization. The individual then loses any real power over the decision to remain employed (Becker, 1960; Alutto et al., 1973). Becker called these investments "side bets" and believed that as they accumulate, it becomes more difficult for the individual to leave the organization (Becker, 1960). In order to reap the benefits of the investment, the individual must remain with the organization thus causing him or her to increase his or her commitment to the consistent course of action of remaining an employee of the organization (Kanter, 1968). Therefore, the commitment results from the infeasibility of any other course of action due to the increasing number of investments (Becker, 1960). The reason for the "side bets" analogy is that the individual bets that continuing along this course of action, due to the constraints against an alternate action, will end in rewarding or at least satisfactory results (Kanter, 1968). This forms the basis of a consistent course of action which may be considered "commitment" (Becker, 1960). 
Becker (1960) felt that this theory could be a starting point for research and, once accepted or rejected through empirical testing, could be the basis for further research (Becker, 1960). Either to his credit or due to later researchers' inabilities, Becker's side bet theory continues to be examined and argued by a variety of researchers (Alluto et al., 1973; Meyer \& Allen, 1984; Shoemaker, Snizek \& Bryant, 1977; Ritzer \& Trice, 1969). Ironically, the theory Becker provided (apparently out of frustration) as a starting point for the study of organizational commitment, has remained a point of discussion in the field since its development and has remained a dominant theory on commitment.

Becker identified certain factors that must exist for these side bets to result in commitment. First, the individual must have potential alternatives for his or her actions. These alternatives will generally result in consequences in other aspects of the individual's life that may be directly or indirectly related to the commitment itself. Second, prior actions must have placed the individual in this position. Finally, the person must be aware of the side bets and the potential impact of his or her decision on these side bets (Becker, 1960). Although side bets are necessary in the commitment process, Becker stressed that side bets are not always made directly by the individual. Side bets may also be made through bureaucratic constraints such as a nontransferable pension or the loss of benefits for some period of time. They may also be made through societal expectations, such as a negative perception toward individuals who have changed jobs frequently (Becker, 1960) and these individuals are thus perceived as unable to commit. 
Career structures may also create side bets (Alutto et al., 1973). For example, the promotion ladder may require the individual joining another organization at a lower level than his/her current status. Side bets could also include choosing the career path that made you a part of the organization. This is due to the fact that an individual must select one direction in which to direct his/her resources with a reduced number of potential future paths (Kanter, 1968). Although the individual is aware of these constraints, he or she may not be aware of the fact that they are, indeed, constraints until the time at which they influence the decision of whether to end the relationship or not. Therefore, the commitment itself may be unintentional and its existence may only be discovered upon the realization of these constraints. Becker referred to this as "commitment by default" (Becker, 1960). Although this is the case for some commitment, it must be noted that not all commitments are unintentional. Some, possibly even most, commitments arise from conscious decisions on the part of the individual (Becker, 1960).

Becker's side bets are now often considered to represent continuance commitment (Swailes 2002; Meyer \& Allen, 1991) as it is defined above. There is also some discussion regarding whether his theory is actually just a definition for behavioral commitment (Salancik, 1977). Although Mowday, Porter and Steers (1982) believed that Becker's work was descriptive of behavioral commitment, Meyer and Allen (1991) stressed specifically that it is not behavioral commitment. However, when he wrote his article in 1960, Becker considered his side bets to be a partial theory on commitment itself as opposed to a form of commitment (Becker, 1960). 
Becker's theory has alternately been both proved and disproved depending on the study that attempted to empirically test his theory. First, it is important to emphasize that in his "notes", Becker stressed that his theory would be very difficult to test empirically since determining a way in which to sort out all elements that impact a commitment in social life requires a great deal of ingenuity (Becker, 1960). In 1969, Ritzer and Trice attempted to test Becker's side bet theory on a sample of personnel managers. They found that the side bet theory should be rejected based on their results (Ritzer \& Trice, 1969). Using the commitment score as the dependent variable and a significance level of 0.05 , they hypothesized a significant relationship between age and organizational commitment, a significant inverse relationship between education and organizational commitment, a significant relationship between salary and organizational commitment and a significant relationship between both marital status and organizational commitment and whether the individual has children and organizational commitment (Ritzer \& Trice, 1969). They found that only the relationship between salary and organizational commitment was significant using the side bet theory.

Ritzer and Trice (1969) found the lack of a significant relationship between age and organizational commitment to be the strongest proof for the rejection of the side bet theory because it seemed intuitive to them that the older you are, the more side bets you would have accumulated due to the increased number of side bets your age has allowed 
you to accumulate. They stated, in fact, "age in itself is a side bet" (Ritzer \& Trice, 1969).

It should be noted that this study was performed in 1969 when, according to the generational literature, it would be expected that salary would play an even greater role in organizational commitment than it would now with the most recent generations involved in the workforce (i.e. with a single breadwinner versus the dual career family). It should also be pointed out that the expected relationship between age and organizational commitment is likely to be even further diminished in the present environment by the shorter terms of employment, the nature of employment, the high levels of turnover and the ever-increasing acceptance of high employee turnover. Finally, it should be noted that the methods used in this study and those that adjusted Ritzer and Trice's measures in future studies have recently been scrutinized and their validity has been questioned. It has been proposed by Meyer and Allen $(1984,1991)$ that the measures used by Ritzer and Trice are actually more likely to reflect affective commitment, which will be discussed later, than Becker's perceptions of side bets.

Ritzer and Trice offered an alternate theory that the side bet theory is suitable only when there is no meaningful element of the occupation itself to which the individual may commit. They believed that the individual must commit to either the occupation or the organization in order to make his or her work life meaningful (Ritzer \& Trice, 1969). In their view of commitment, if the occupation is satisfying and intrinsically fulfilling, the 
individual will become committed to his/her occupation and only in the absence of this commitment will he/she become committed to the organization itself (Ritzer \& Trice, 1969). Ritzer and Trice (1969) further stated that, in their theory, side bets are not the basis upon which commitment is formed but that they do increase commitment once it has been established.

Following Ritzer and Trice's study, Alluto et al. (1973) made some changes to the methods used and repeated the study on a sample of teachers and hospital nurses and found that the side bet hypothesis was supported (Alluto et al., 1973). They believed that part of the reason that Ritzer and Trice did not find significant results was that their commitment index was not sufficiently sensitive to achieve the desired results (Alluto et al., 1973). Although test-retest reliability was found to be satisfactory in Ritzer and Trice's study, Alluto et al. suggested that item reliability may not have been satisfactory (Alluto et al., 1973). By changing several variables Ritzer and Trice used to determine commitment, Alluto et al. (1973) achieved very different results (Shoemaker et al., 1977; Alluto et al., 1973). They found significant, positive relationships between organizational commitment and each of age, education, years of experience and marital status as well as a curvilinear relationship between age, years of experience and occupational commitment (Shoemaker et al., 1977).

Regardless of later empirical testing on his theory, Becker proposed a variety of negative aspects to his theory that should be addressed. First, he noted that some of the 
investments that form bases of commitment are only considered of value to certain cultural groups in society (Becker, 1960). Second, Becker emphasized that there is no consistent definition (or there was no consistent definition at the time his theory was proposed) of commitment. This resulted in a scope for his theory that was limited to his definition of commitment (Becker, 1960). Becker also emphasized that his theory does nothing to address the variety of commitments an individual experiences in his or her life and how he or she prioritizes these commitments. Another concern Becker proposed for this theory is that it does not help explain consistently deviant behavior, which is a concern for its validity (Becker, 1960). Finally, as noted above, Becker stressed that his theory is difficult to test empirically (Becker, 1960).

Becker (1960) also addressed several advantages to be found in his side bet theory. First, his theory examines elements of commitment independently of the consistent behavior that is considered to define "commitment" and avoids the tautological difficulty in using commitment to define commitment. This is due to the fact that the side bets that are theorized to result in commitment are independent of the consistent activity that is considered to be "commitment" (Becker, 1960). In addition, it provides an exploration of the fact that people often become committed to actions for reasons that are independent of the actions themselves.

Although Becker never tested his theory and, in fact, considered his theory only a basis for future research in the area, his conceptualization has come under much debate. 
Although there is no definitive answer as to whether or not his theory is statistically significant or even how to accurately test it, he can be considered successful in achieving his goal of encouraging the empirical examination of "organizational commitment" on a more academic level.

\subsubsection{Etzioni’s Typology}

Etzioni (1975) used a different approach from other researchers who investigated commitment. In his examination, Etzioni identified three forms of involvement that an employee may experience with their organization in order for the organization to have power over the employee (Swailes, 2002; Mowday et al., 1982). In fact, the different forms of involvement proposed not only address the relationship between an employee and an organization but can be applied to any relationship where power is involved (Etzioni, 1975). The three forms of involvement are: moral involvement, calculative involvement and alienative involvement. These three forms are part of a continuum with moral involvement (commitment) and alienative involvement at the two extremes (Etzioni, 1975). Details on each of these three forms are provided below.

Etzioni sees moral involvement as a highly positive orientation. For the purpose of his examination of organizational commitment, this orientation is towards the organization. Etzioni (1975) identified this extreme as the position on the continuum where commitment exists. According to this model, there are two different forms that moral involvement may take: pure moral involvement and social moral involvement 
(Etzioni, 1975). Moral involvement is the result of an internalization of organizational norms (Swailes, 2002; Etzioni, 1975), values, goals and an identification with management (Mowday et al., 1982; Etzioni, 1975). It tends to develop between an individual and a person who is in a position of power relative to that individual (Etzioni, 1975). Social moral commitment, on the other hand, relies less on authority figures and more on the individual's peers. It occurs when the basis of an individual's commitment is formed by the social pressures exerted by one's peers (Etzioni, 1975). It is important that within one committed relationship it is possible for an individual to experience both forms of moral commitment although Etzioni (1975) stresses that, in general, one form is dominant.

Calculative involvement is based on either a mild positive or negative orientation (Etzioni, 1975). Commitment felt due to this form of involvement is based on an exchange relationship where the employee feels that there is an equal exchange between the organization and him/herself (Mowday et al., 1982). Etzioni (1975), in his model, held that true commitment can only be experienced through moral involvement and that calculative involvement and alienative involvement are not bases for commitment.

On the involvement continuum, alienative involvement represents the negative extreme where the individual is forced to be committed to the relationship or at least severely constrained with respect to his/her ability to remove him or herself from the commitment (Mowday et al., 1982). This form of involvement is intense, similar to 
moral involvement but the individual does not choose to be a part of the relationship and, thus, commitment does not exist (Etzioni, 1975). Examples of alienative commitment include an inmate's commitment to the prison or a drafted soldier's commitment to the military. Alienative involvement is not considered to be a basis for commitment by most researchers because the individual is essentially constrained from ending his or her relationship with the organization (Hulin, 1991).

\subsubsection{Kanter's Typology}

The most commonly used typology for forms of commitment is the one proposed by Kanter in 1968 (Swailes, 2002; Mowday et al., 1982). Her research was performed on utopian societies but can be extended to relate to organizations or other forms of commitment. Kanter (1968) determined that there are three forms of commitment, each of which may be independent of the others and is analytically distinct. The three forms are: continuance commitment, cohesion commitment and control commitment (Kanter, 1968). Continuance commitment is based on a cognitive commitment to a social role, regardless of the feelings toward the role itself (Kanter, 1968). Individuals develop a cognitive commitment to the organization based on a determination of belonging to the organization as being profitable in terms of benefits and costs (Kanter, 1968). Others using Kanter's typology define continuance commitment as commitment based on the cost of leaving due to the number of investments the employee has in the organization which is based on Becker's side bet theory discussed above (Swailes, 2002; Mowday et al., 1982). Continuance commitment is formed through sacrifices and investments where 
the individual must give up something good in order to belong to the organization or take a stake in the future profitability of the organization (Kanter, 1968). It is worth noting that some researchers believe that this is actually the antithesis of commitment (O’Reilly \& Caldwell, 1981; Meyer \& Allen, 1991) since the psychological bond is based on needing to stay with the organization because of the great loss that would be absorbed if the individual left the organization (O'Reilly \& Chatman, 1986).

The second form of commitment identified by Kanter (1968) is cohesion commitment. Instead of being based on cognitive processes, as continuance commitment is, cohesion commitment has a basis in social relationships (Kanter, 1968) and emotions (Meyer \& Allen, 1991). Individuals with cohesion commitment are committed to the organization because they have an attachment to a social group within the organization (Swailes, 2002). Cohesion commitment may be encouraged by having individuals identify more closely with other members of the organization through rituals and ceremonies such as orientation or pledges and oaths to the organization (Mowday et al., 1982).

Finally, control commitment is considered to be the third form of commitment in Kanter's (1968) typology. Control commitment is based on morals and values of the individual as the individual internalizes the norms and values of the organization (Kanter, 1968). The individual then uses these norms and values to guide his or her own behavior (Swailes, 2002; Mowday et al., 1982). Actors are committed to obeying the authority of 
the group or organization and the commitment is based on forming positive correlations between the values and actions of the organizations and their own values and actions (Kanter, 1968).

Kanter's (1968) three forms of commitment are all related in that they all represent the relationship between employees and the organizations for which they work (Meyer \& Allen, 1991). They are also highly interrelated in the sense that organizations try to use all three to form stronger ties (Mowday et al., 1982). Although these three forms of commitment are separate and it is analytically possible to distinguish between them, they may be causally related (Kanter, 1968).

In business organizations, there is generally more of an emphasis on promoting continuance commitment than on cohesion commitment (Kanter, 1968). Kanter (1968) also suggests that organizations with continuance commitment are likely to maintain their members, organizations with cohesion commitments should be able to withstand threats to their existence and organizations with control commitment should have little deviance by individuals. It should be noted, however, that her study examined utopian societies of the past rather than business organizations, which may decrease the importance of cohesion commitment to the organization in terms of maintaining the organization. 


\subsubsection{Meyer and Allen's Three-Component Model}

There are differing views regarding the forms organizational commitment may take. However, many researchers now use Meyer and Allen's (1991) views regarding the forms of commitment. Meyer and Allen (1991) found that underlying the various forms that have been presented by different researchers, were essentially two main forms of commitment. These are attitudinal commitment and behavioral commitment (Meyer \& Allen, 1991). This conceptualization is similar to that proposed by Salancik (1977), who noted that in organizational behavior, attitudinal commitment was examined as the process by which employees internalize the goals and values of the organization and intend to continue their relationship with that organization (Mowday et al., 1982; Swailes, 2002). Behavioral commitment, however, was observed more by social psychologists who focused on the behaviors of individuals and how past behaviors caused them to remain in a relationship with an organization based on their individual loss of freedom (Mowday et al., 1982; Swailes, 2002).

Attitudinal commitment is based on cognitive processes whereby the individual considers his or her relationship with the organization. This may include a comparison between the goals and values of the organization and those of the individual (Mowday et al., 1982). Meyer and Allen (1991) found that research in this area has focused primarily on the antecedents to attitudinal commitment and the resulting behaviors. This can be seen in Figure 2.4 where the solid arrows represent primary causal relations and the broken arrows represent secondary relations. Psychological state represents Meyer and 
Allen's (1991) broader definition of organizational commitment. Researchers studying behavioral commitment, however, tend to focus on the conditions under which certain behaviors will occur and the changes in attitude that result (Meyer \& Allen, 1991). Behavioral commitment is based on how individuals become entrenched in an organization and how they react to this situation (Mowday et al., 1982). Figure 2.5 demonstrates the general form of the research in behavioral commitment where solid arrows represent primary causal relations and broken arrows represent secondary relations. Once again, psychological state represents organizational commitment according to Meyer \& Allen's (1991) broader definition.

\section{Figure 2.4 - Attitudinal Perspective of Commitment}

(adapted from Meyer \& Allen, 1991)

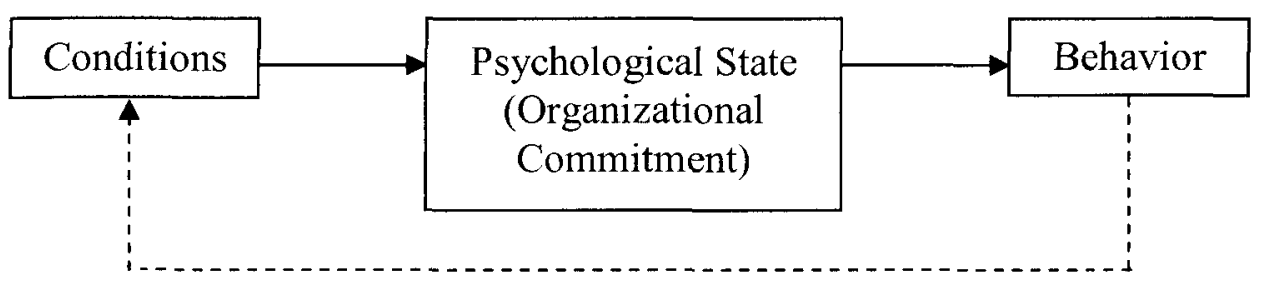


Figure 2.5 - Behavioral Perspective of Commitment

(Meyer \& Allen, 1991)

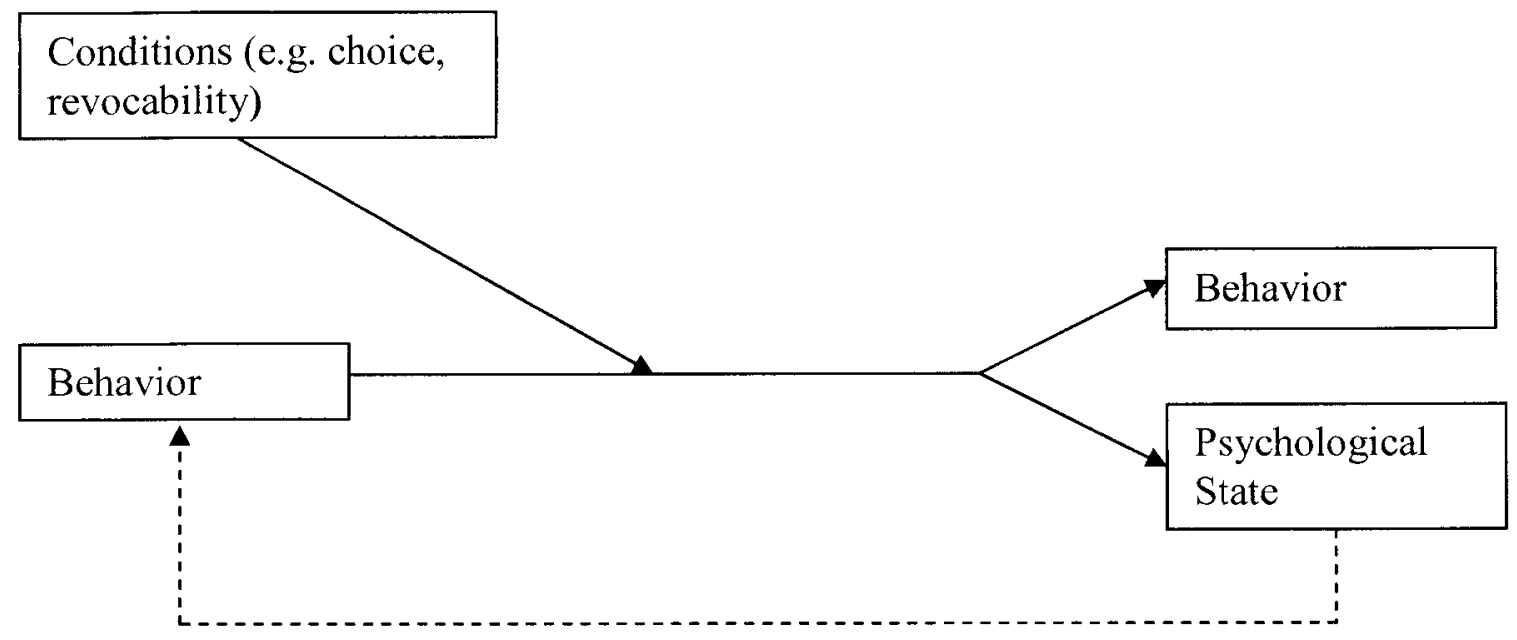

In order to help integrate the results of commitment research and previous commitment models, Meyer and Allen (1991) developed their three-component model. Although this model was not intended to include all previous research on commitment, they observed that underlying most of the different conceptualizations of commitment, there was a distinction between attitudinal and behavioral commitment, as discussed above (Meyer \& Allen, 1991; Dunham et al., 1994). They argue that commitment is not strictly an attitude but is a psychological state. This psychological state is based on the employee's relationship with the organization and the decision by the employee either to remain with the organization or to end the relationship (Meyer \& Allen, 1991). Although other researchers did observe that organizational commitment was potentially a multidimensional construct, they never identified the various dimensions (Meyer \& Allen, 1997). Recognizing the multi-dimensional nature of the commitment construct should encourage future researchers to determine the needs and values necessary for the 
development of commitment by addressing different facets of commitment (Meyer \& Allen, 1991).

As a psychological state, organizational commitment has at least three distinct components. These components are distinct as they involve different antecedents and different outcomes (Allen \& Meyer, 1990). The first component, based on Becker's side bets, is called "continuation commitment" by Meyer and Allen to reflect the idea that it is the continuation of the action of remaining with the organization. As described above, perceived costs prevent the employee from leaving the organization based on the feeling that he/she needs to stay with the organization or suffer losses (Meyer \& Allen, 1991). Although continuance commitment is easily built through the incurrence of costs by the employee (Meyer \& Allen, 1991), the outcomes found in research tend to be less positive than for other components of commitment (Mackenzie Davey, 1998).

The second component in Meyer and Allen's model is affective commitment. This is the most commonly discussed component in research and literature (Mackenzie Davey, 1998; Hackett et al., 1994) and is the one that the definition by Mowday et al. is considered to have addressed (McGee \& Ford, 1987). Affective commitment, which Kanter (1968) referred to as cohesion commitment, is based on an emotional attachment to the organization due to an identification with the organization. Employees feel the desire to remain with the organization because of the connection they feel with the values and goals of the organization (Meyer \& Allen, 1991). Research has shown that affective 
commitment is primarily related to the employee's work experiences although the reasoning behind this is not always clear and research has not been conclusive in this area (Meyer \& Allen, 1991; Allen \& Meyer, 1990). Personal experiences, job characteristics and structural characteristics are considered to influence affective commitment, along with work experiences (Mowday et al., 1991). Affective commitment has been related to a variety of positive outcomes with a varying degree of success (Mackenzie Davey, 1998). It has also been related to both performance and attendance although studies tend to be contradictory (Meyer \& Allen, 1997). Affective commitment and continuance commitment are the two components most studied in the literature and, due to the lack of distinction between them in the past, have often been confused or incorrectly grouped and analyzed together (McGee \& Ford, 1987).

The final component in Meyer and Allen's three-component model is normative commitment. Normative commitment exists when an individual feels an obligation to remain within the organization (Meyer \& Allen, 1991) and is the component that has been studied the least by researchers (Allen \& Meyer, 1990). Instead of feeling a desire or a need to continue the employment relationship, the employee feels that he or she should remain within the organization (Meyer \& Allen, 1991) due to a perception that it is morally right to do so (Marsh \& Mannari, 1977; Wiener, 1982). Normative commitment is based on the internalization of normative pressures. This may be due to socialization through role models or the use of rewards and punishments or, it may result from a strong sense of reciprocity felt by the individual to repay the organization for 
employing them and possibly for training him/her or offering him/her other opportunities (Meyer \& Allen, 1991). It has also been proposed by Allen and Meyer (1990) that an individual's experiences prior to and following the beginning of his or her relationship with the organization help shape this component of his or her commitment. These may be due to familial or societal pressures and organizational pressures, respectively (Wiener, 1982). One of the difficulties in examining normative commitment has been the lack of a measure of the concept. The only existing measure is Wiener and Vardi's three-item scale (1980), which has only been tested for internal consistency and has not been widely accepted due to a lack of testing (Allen \& Meyer, 1990)

It is worth noting that a possible fourth component has been identified within the three-component model. Factor analyses have demonstrated that the continuance commitment component can potentially be divided into two components: personal sacrifice from leaving the organization and the absence of job alternatives (Hackett et al., 1994). Allen and Meyer (1990) believe that these are simply factors of continuance commitment and that they are, more specifically, the absence of job alternatives and the magnitude or number of investments made by the employee.

Kanter identified similar items when discussing the different forms of commitment as discussed above (Kanter, 1968). However, where Kanter considered her three forms of commitment (continuance, cohesive and control) to be distinct types of commitment, Meyer and Allen consider them to be distinct but only components of 
commitment because they are not mutually exclusive (see Appendix B) (Meyer \& Allen, 1991). According to these researchers, each of the three components may be experienced simultaneously and to varying degrees by an individual employee (Meyer \& Allen, 1991) and the total of the three components form the individual's overall commitment (Allen \& Meyer, 1990). This combination of the three components, according to Meyer and Allen (1991), may result in behavioral influences.

Based on this model, Meyer and Allen propose scales for the measurement of each component of commitment that they have identified (Allen \& Meyer, 1990). These measures will be discussed in the following section.

\subsubsection{Measurements of Organizational Commitment}

There have been numerous methods that have been presented for the purpose of measuring commitment (Mowday et al., 1982). One of the challenges in adopting a suitable measure has been related to the difficulties in finding an acceptable definition that is used ubiquitously by researchers (Benkhoff, 1997; Allen \& Meyer, 1990). Early measurements (and even current measurements according to some (Benkhoff, 1997)) are flawed. Flaws noted in the literature include the fact that the measure did not distinguish between different underlying concepts (Benkhoff, 1997; Allen \& Meyer, 1990) and the psychometric properties were either unidentified or unacceptable (Mowday et al., 1982). There are currently a variety of measures of organizational commitment that are generally accepted by researchers and that have acceptable psychometric properties. Although 
each has associated difficulties, those that will be discussed are the Organizational Commitment Questionnaire (OCQ) and Meyer and Allen's measures of commitment as these are currently the most commonly used measures (Meyer \& Allen, 1991; Gallie et al., 1998).

\subsubsection{Organizational Commitment Questionnaire}

The Organizational Commitment Questionnaire (OCQ) was developed by Porter and Smith in 1970 in an unpublished paper and was subsequently published by Mowday, Steers and Porter (1979). Prior to this, there were no measures of commitment that were acceptable in that any that had been created had either no identified psychometric properties or inadequate psychometric properties (Mowday et al., 1982). The OCQ was designed to measure attitudinal rather than behavioral commitment (Mowday et al., 1982; McGee \& Ford, 1987) and is now considered to measure affective commitment according to the three-component model (Meyer \& Allen, 1997). The OCQ is the most commonly used measurement of organizational commitment (Meyer \& Allen, 1991; Gallie et al., 1998) and was found by Mathieu and Zajac (1990) to have been used in 103 of the 174 samples in their review of organizational commitment research. It has been found to have a very high level of consistency with Cronbach's alphas ranging from 0.82 to 0.93 (Subramaniam \& Mia, 2003). It is also the measure of commitment that is used in this study. 
Porter and Smith (1970) developed a 15-item questionnaire to measure the three components of the Mowday et al. (1982) definition of commitment: acceptance of organizational goals and values, willingness to exert effort on behalf of the organization and a strong desire to retain membership within the organization. The instrument used a 7-point Likert scale ranging from strongly disagree to strongly agree (see Appendix C). There was also a shorter 9-item instrument based on the OCQ that was tested and found to have similar results to the full questionnaire (Mowday et al., 1982).

\subsubsection{Meyer and Allen's Three Measures}

In order to measure organizational commitment according to their ThreeComponent model, Meyer and Allen (1991) have three components of organizational commitment: affective commitment, continuance commitment and normative commitment. Before finalizing their model, in 1990, they developed scales to measure each of the individual items of their model (Allen \& Meyer, 1990). They are named the Affective Commitment Scale (ACS), the Continuance Commitment Scale (CCS) and the Normative Commitment Scale (NCS). These scales can be seen in Appendix D. Each scale is a set of eight questions gauged on a 7-point Likert scale ranging from strongly disagree to strongly agree. Some of these items were based on questions used in previous research. It was found that the reliability (co-efficient alpha) of each scale was relatively high with values of $0.87,0.75$ and 0.79 for each of the ACS, the CCS and the NCS respectively. It was found that the OCQ correlated significantly with the ACS and moderately with the NCS. There is also a relatively high correlation between the ACS 
and the NCS. The OCQ did not, however, correlate significantly with the CCS. Meyer and Allen's (1991) study determined that their three factors are empirically testable. However, there was a great deal of overlap between the ACS and the NCS. Although Allen and Meyer (1991) succeeded in measuring each of their three components of organizational commitment, these scales cannot be used together in order to achieve an overall score of commitment. Therefore, although the OCQ may not test each of the identified components of organizational commitment, it provides a scale that correlates well with two of the three dimensions and provides an overall measure for organizational commitment.

\subsection{Generations}

The concept of the generation was first put forward by Mannheim in 1920 . Empirical investigation into this concept is almost nonexistent. Most of the discussion of the concept of generations can be found in the discipline of sociology. However, generational differences may play an important role in explaining work attitudes. If the perceived "generation gap" truly exists and the generations have very different attitudes toward the workplace, it is critical that these differences are examined. An understanding of the different attitudes may help the generations coexist in the workplace more easily. It may also allow managers and human resource practitioners to make changes in the workplace to better suit the generations that are currently in the workforce or that soon will be. 


\subsubsection{What is a cohort?}

Rosow (1978) says that a social cohort: "(1) consists of people who share a given life experience; (2) this experience is socially or historically structured, and (3) it occurs in a common generational framework; (4) its effects distinguish one generation from another; and (5) these effects are relatively stable over the life course" (p. 67). Despite the use of this definition for this study, there have been other conceptions of the cohort that should be discussed. Mannheim was the first researcher to explore the concept of social cohorts in depth in the early 1920s (Laufer \& Bengtson, 1974). This was, in part, an attempt to rectify the two dominant views of the concept of generations at the time (i.e. the positivist formulation with a set period of time in which a generation should occur and the romantic-historical formulation in which generations co-exist and are based on social distinctions). Mannheim (1952) described the generation as a form of identity of location and age group that is related to the historical-social process. He identified several characteristics of our society that are essential for generations to exist as a social concept. These are:

(a) "new participants in the cultural process are emerging, whilst

(b) former participants in that process are continually disappearing;

(c) members of any one generation can participate only in a temporally limited section of the historical process,

(d) it is therefore necessary continually to transmit the accumulated cultural heritage; and

(e) the transition from generation to generation is a continuous process (p.292)".

Mannheim (1952) stressed in particular that generations share similarities to class membership as there is a common physical and historical location associated with each. Since then, others have used this definition as a basis for the current understanding of a 
generation. It has been defined as a group of individuals within a population who experienced "the same event within the same time period" (Ryder, 1965, p. 845). Although this may be any event, most commonly this event is considered birth and aging through the same era (Ryder, 1965). More specific than a cohort, this situation may be called an age cohort although the term cohort is now generally applied to this particular instance. Others define cohorts not just by age but also by social circumstances. For example, Smola and Sutton (2002) define cohorts by birth years, location and significant life events. Jurkiewicz and Brown (1998) defined an age cohort as "a group of people who share a given historical or socially structured life experience, the effects of which are relatively stable... and serve to distinguish one generation from another." (p.19).

Rosow (1978) included both age group and social experiences in his definition. He defined a cohort as "people (of) about the same age who in a given period have similar experiences that may affect them the same way. (pp. 66 - 67)". However, Rosow (1978) added that in order to be considered members of the same social cohort, several conditions must be satisfied. These are: individuals must share a given life experience that is socially or historically structured, the effects of the experience must distinguish one generation from another, and the effects must be reasonably stable through the course of the generation's life (Rosow, 1978).

The idea of an age cohort has been used by historians and demographers extensively through the years (Ryder, 1965). As the term "age cohort" is often used 
interchangeably with generation, these terms will be used interchangeably in this research. Rosow's definition, as identified above, will be used for the purpose of this research as it stresses the social factors that are critical to a person's view of the world. Such a definition is also consistent with the fact that generations are not constant from one location to another as people in different locations face different circumstances as they age. Since the context of this study will be Canadian generations, it is important to differentiate between social factors influencing Canadians and those influencing other countries.

As distinctive social experiences are critical to the definition of a cohort, those experiences that may be relevant should be examined. These social factors also provide the framework for the life experiences of cohorts as they age. Factors influencing cohorts can be categorized into five categories: economic, demographic, political, ecological and environmental (Rosow, 1978). Economic factors may include periods of scarcity (Rosow, 1978) such as the Depression, or periods of relative wealth such as the 1920 s. Demographic factors include the cohort's size relative to the preceding and succeeding cohorts (Ryder, 1965). Ryder (1965) stated that society must adjust each time a cohort reaches a new life stage and, as such, large variations in the size of cohorts will have impacts on the cohorts and on society in general. The political climate has had a significant impact on recent generations as Canada and North America have undergone periods of war and peace that have been considered to define some generations. Another political factor that has had an impact particularly in the workforce has been the feminist 
movement. Ecological and environmental factors have, particularly in more recent years, altered the behaviors of both organizations and individuals, which in turn have had an impact on individuals growing up during times of environmental concern. Rosow (1978) identified a sixth potential factor influencing cohorts. He felt that periods of relative health and disease would also affect individuals in different cohorts.

\subsubsection{Defining Cohort Boundaries}

Generations do not have distinct boundaries and there is little consensus on the actual years that should be used to distinguish one cohort from another. This is partly due to the difficulties of combining the quantitative measures of age and time with the qualitative measures of values and historical events (Scott, 2000). It is also partly a result of generations attempting to group together a large number of individuals with their own values and opinions and attempting to generalize them across the group and differentiate them from other groups (Washburn, 2000). In order to attempt to define the generations, sequential birth years are used, although some argue that year of completion of education, year of marriage or other significant life events may be used (Ryder, 1965). However, Rosow (1978) stressed that qualitative rather than quantitative criteria should be used. In other words, groups should not be segmented into five- or ten-year intervals but should be segmented by the general trends that apply to the group as a whole. Scott $(2000)$ agreed with this view stating that too often age becomes too much of a focus on dividing cohorts and detracts from the sociological and historical events that define the cohort. Others disagree, and feel that a generation should share historical or social experiences 
but should, however, be divided into five to seven year intervals with each interval identified with a first wave, a core group and a last wave (Smola \& Sutton, 2002).

Rosow (1978) suggested that in order to determine the boundaries of generations, factors such as war and other political issues that may affect youth be considered although this becomes difficult when there is more than one salient event that occurred in near succession. Laufer and Bengston (1974), similarly, felt that generations should be defined within the structural, technological and historical framework of the period. However, they believed that new generations begin when the following occurs: new skills are required in the workplace, new patterns of social organization develop and alterations in values in lifestyles are required to adjust to the above changes (Laufer \& Bengston, 1974). Although there are many different boundaries assigned to the current generations, it is important to note that arbitrarily choosing boundaries in isolation of others' criteria will result in boundaries that are impractical for research purposes (Rosow, 1978).

\subsubsection{Difficulties in using the cohort in research}

Clearly, the lack of easily distinguishable cohorts makes the use of cohorts in research difficult but this may be overcome by using similar distinctions to those that have been made in the past (Rosow, 1978). The difficulty in distinguishing cohorts has been further magnified by the fact that the use of generations for explanatory purposes has proved difficult although this may be due to inadequate subgroups or an inadequate examination of other variables that may influence the generational effect (Laufer \& 
Bengston, 1974). Scott (2000) agreed, stating that the difficulties in defining the cohorts may be the cause of empirical studies having varying levels of success when using cohorts to predict attitudes or behaviour. She also pointed out that many characteristics that identify the cohort impact more than just the cohort. This results in a number of variables that may intervene between generation and outcome. For example, multiculturalism may affect the values of the generation due to both the additional exposure to other cultures and the values of the individuals from that culture who then become part of the cohort. In order to rectify this difficulty, Rosow (1978) observed that any time the between group differences exceed the within group differences, this may be considered a cohort effect (Rosow, 1978). For the purposes of this thesis, the above will be considered a distinguishing factor for generational differences.

\subsubsection{Generations in today's workforce}

Today's workforce has a diverse group of individuals coming from four different generations. Although the precise boundaries and names for the generations differ (see Tables 2.2 and 2.3 ), there is a general consensus that the two primary generations in today's workforce are the Baby Boomers and Generation X. Although there are varying names for Generation X, this is the title most commonly used. For the purpose of this study, Baby Boomers will be defined as individuals born in Canada between the years 1947 and 1964 (inclusive) and members of Generation X will be defined as individuals born in Canada between the years 1965 and 1980 (inclusive). This is both in keeping with the various boundaries that have been defined by other researchers (see Tables 2.2 
and 2.3) and by the years in which the birth rate was particularly high for the Baby Boom Generation and the years in which the birth rate slowed dramatically for Generation X (see Figure 2.6).

As many of the references listed below are American and the American boom occurred slightly before the Canadian boom (Foot, 1996), the Canadian boom will be more accurately depicted through these boundaries as they were defined by Canadian researchers. In order to determine the dates to be used as starting and ending points for each generation, both the literature and the birth rates had to be examined. 1947 is both the year identified by Foot (1996) as the beginning of the Baby Boom cohort and the year that the number of births returned to the pre-war and pre-depression level, as can be seen in Figure 2.6. The end of 1964 ends the Baby Boom Generation as births returned to their levels at the end of World War II (see Figure 2.6). This is consistent with Adams' boundaries of the Baby Boom ending and Generation X beginning in 1965 as, for the sake of this research, individuals had to belong to either one birth year or the other. 1980 concluded Generation X as Canadian authors (specifically Adams (1997) and Barnard et al. (1998)) end Generation $X$ in either the late 1970 s or the early 1980 s. Figure 2.6 also demonstrates births hitting a low at this point.

In order to examine the generations in today's workforce the literature review is divided into two sections. The Baby Boomers will be examined first. Included in this section is a discussion of the influences that helped shape their attitudes. Next, members 
of Generation X will be examined with a similar focus on the influences in their lives that may have shaped their attitudes.

It should be noted that the majority of the articles regarding generations are from the popular press and that little empirical research has been conducted in this area. As such, many of the espoused values and attitudes of the Generation are a result of observations of individuals as opposed to the result of empirical data. In addition, many of the observations made have had an American bias and extensive research has not been done in Canada. However, in terms of a social, political and economic environment, Canada in many ways reflects, or follows soon after, the United States and, therefore, many of the observations made by Americans or regarding Americans may also reflect the environment in Canada. 
Table 2.2 - Boundaries of the Baby Boom Generation

(* denotes Canadian research)

\begin{tabular}{|l|l|l|}
\hline \multicolumn{1}{|c|}{ Researcher(s) } & \multicolumn{1}{c|}{$\begin{array}{c}\text { Year of } \\
\text { Research }\end{array}$} & $\begin{array}{c}\text { Birth Year } \\
\text { Boundaries }\end{array}$ \\
\hline *Adams & 1997 & $1944-1965$ \\
\hline Doverspike et al. & 2000 & $1943-1964$ \\
\hline Cambiano et al. & 2001 & $1943-1960$ \\
\hline Fowler & 2003 & $1946-1960$ \\
\hline Schrammel & 1998 & $1946-1964$ \\
\hline Jurkiewicz \& Brown & 1998 & $1943-1960$ \\
\hline Losyk & 1997 & $1946-1964$ \\
\hline Washburn & 2000 & $1945-1964$ \\
\hline *Foot & 1996 & $1947-1966$ \\
\hline Pekala & 2001 & $1946-1964$ \\
\hline Conger & 2001 & $1943-1964$ \\
\hline Kiechel & 1989 & $1946-1964$ \\
\hline Bertholf \& Loveless & 2001 & $1945-1965$ \\
\hline Ruch & 2000 & $1936-1955$ \\
\hline Howe \& Strauss & 1993 & $1946-1964$ \\
\hline
\end{tabular}


Table 2.3 - Boundaries of Generation X

\begin{tabular}{|l|l|l|}
\hline \multicolumn{1}{|c|}{ Researcher(s) } & \multicolumn{1}{|c|}{$\begin{array}{c}\text { Year of } \\
\text { Research }\end{array}$} & Birth Year Boundaries \\
\hline Cambiano et al. & 2001 & $1961-1981$ \\
\hline *Adams & 1997 & mid-1960s - early 1980s \\
\hline Losyk & 1997 & $1965-1976$ \\
\hline *Barnard et al. & 1998 & Early 1960s - Late 1970s \\
\hline *Foot & 1996 & $1960-1966$ \\
\hline *Burke & 1994 & $1965-1974$ \\
\hline Bova \& Kroth & 2001 & $1965-1981$ \\
\hline Jurkiewicz \& Brown & 1998 & $1961-1981$ \\
\hline Conger & 2001 & $1965-1981$ \\
\hline Charrier et al. & 2000 & $1961-1981$ \\
\hline Stewart & 2002 & $1965-1977$ \\
\hline Jurkiewicz & 2000 & $1963-1981$ \\
\hline Pekala & 2001 & $1965-1978$ \\
\hline Paulin \& Riordon & 1998 & $1965-1977$ \\
\hline Bertholf \& Loveless & 2001 & $1965-1978$ \\
\hline Miller & 2000 & $1965-1981$ \\
\hline Hessen & 2001 & $1963-1978$ \\
\hline Doverspike et al. & 2001 & $1965-1980$ \\
\hline Poindexter \& Lasorsa & 1999 & $1965-1977$ \\
\hline Ruch & 2000 & $1966-1975$ \\
\hline Jennings & 2000 & $1965-1979$ \\
\hline Munk & 1998 & $1965-1977$ \\
\hline Fong & 2000 & $1963-1977$ \\
\hline Washburn & 2000 & $1965-1981$ \\
\hline Stauffer & 1997 & $1964-1982$ \\
\hline Schrammel & 1998 & $1965-1976$ \\
\hline Tulgan & 2000 & $1963-1977$ \\
\hline & & \\
\hline
\end{tabular}


Figure 2.6 - Fertility Rates from 1921 - 1981

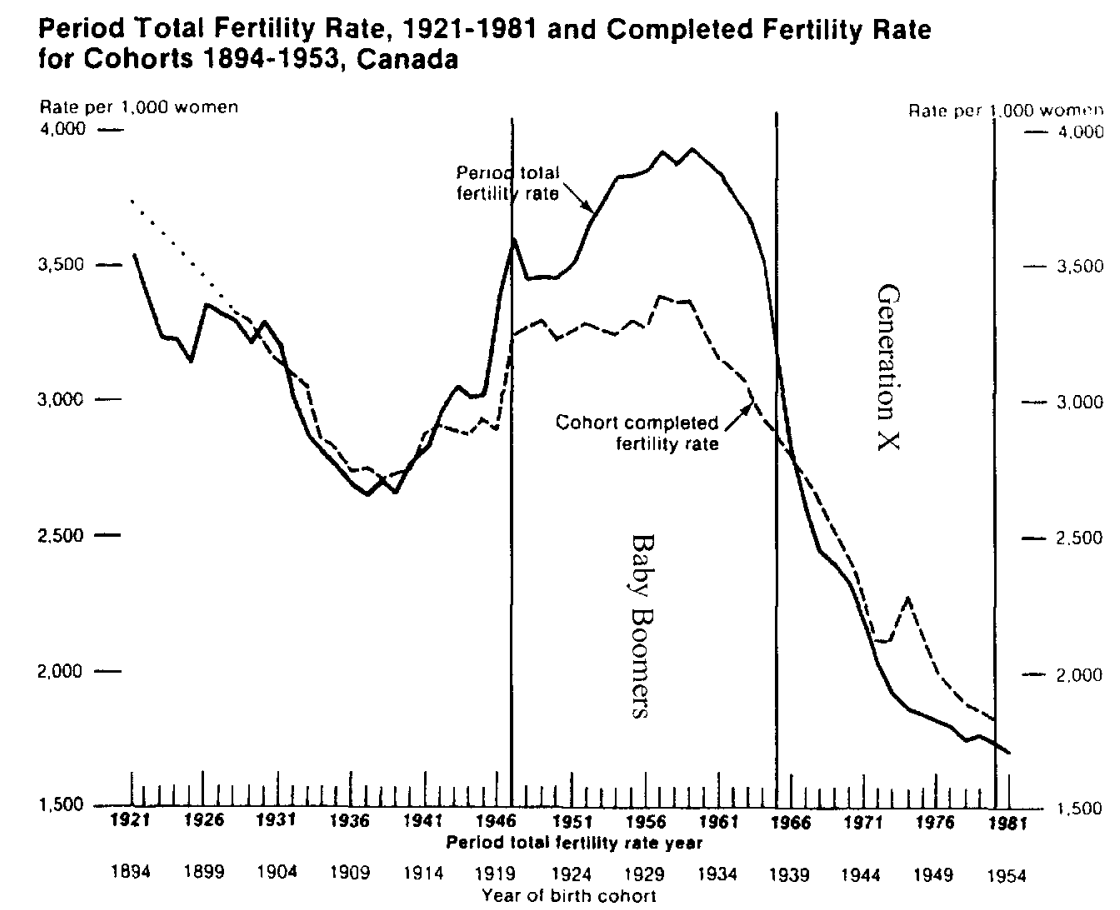

Source: Romaniuc, Fertility in Canada: From Baby-boom to Baby-bust: Current Demographic Analysis

\subsubsection{The Baby Boom Generation}

As previously mentioned, the Baby Boomers are considered to be those individuals born in Canada between 1947 and 1964. Cohorts are defined by the social context of the era in which a generation is raised and all influences in individuals' lives are considered to play a critical part in the values and attitudes that they hold in the future. As such, in order to examine the Baby Boomers' values and attitudes in the workforce, this study will first examine their influences growing up and stereotypes, generalizations and values of Baby Boomers. Next, their views on the workforce and their personal careers will be examined. 
The Baby Boomers are unique in that their generation was considered distinct from previous generations to the extent that this was the first time that the term "generation gap" was used (Washburn, 2000). The term was used to describe the "gap" between the Baby Boomers and their parents' generation. Although previous generations had been considered distinct based on life altering events, this was the first generation that was considered very distinct politically and socially. These differences are believed to have contributed to the first major rift between two generations. Washburn (2000) emphasizes that previous assumptions regarding values, pride and trust that had existed in the past were questioned and, for the most part, reformulated or lost once the Baby Boomers entered society.

\subsubsection{Baby Boomers Growing up}

Growing up, the Baby Boomers had a very different environment from any previous generation. They were born at the end of World War II during a time of high fertility rates (Schrammel, 1998) and are the largest cohort currently in Canada. Only four Western countries had baby booms following the Second World War: Canada, the United States, Australia and New Zealand. Of these, Canada had the largest "boom" with an average of four children born to each Canadian woman at the boom's peak (Foot, 1996). Baby Boomers were born in an ideal era politically, economically and socially (Schrammel, 1998), sometimes giving them the nickname "the lucky generation" (Foot, 1996). They missed both World Wars and were born into a country that was both 
peaceful and economically prosperous (Scott, 2000). A major influence on their development of ideas may have been that following the Second World War, the United States was seen as a dominant world force (Tulgan, 2000). Part of the baby boom was a result of the large population of immigrants of childbearing age who immigrated to North America during this period and the economic prosperity that allowed couples to have larger families with a small financial burden compared to their parents (Foot, 1996). This initiated a change in the political and social structure that would help shape the characteristics of the Baby Boomers.

The economic growth at the time of the Baby Boomers' births resulted in an increasing standard of living. Baby Boomers were raised during an economic expansion (Tulgan, 2000) that led to a period of full employment and mass consumerism (Scott, 2000). It was assumed that economic progress would continue (Fowler, 2003) causing each future generation to exceed the standard of living of their parents. Baby Boomers grew up with a feeling of entitlement based on all the advantages they were raised with and came to expect (Smola \& Sutton, 2002). The relative wealth with which Baby Boomers grew up allowed them to be driven less by material needs and more by spiritual needs and personal growth (Fowler, 2003; Adams, 1997). This led to social changes that began to emerge prior to the Baby Boomers' entry into the workforce but that would greatly impact the workforce in future years. The financial freedom experienced by this generation allowed their attentions to be drawn instead to sexual freedom, feminism and civil rights (Adams, 1997). In fact, according to Washburn (2000) it was these views that 
were made explicit through Vietnam War protests, often referred to as the "Woodstock mindset", that caused the gap between the Baby Boomers and the two preceding generations.

As Baby Boomers began to enter the workforce, the workplace was also beginning to change. Roles were becoming more demanding and increased education was required to meet the needs of the available jobs (Tulgan, 2000). Baby Boomers were the first generation to have such a large surge of secondary and post-secondary graduates (Conger, 2001). As such, their period of maturation was much longer than for previous generations (Tulgan, 2000). Baby Boomers remained in school longer and had what both previous and future generations may consider an idealized life with few social or economic difficulties other than their personal push for improved conditions. However, the situation differed based on the individual's time of birth within the Baby Boom Generation. Early Baby Boomers were able to take advantage of all the benefits of a booming economy and the relatively small cohort preceding it. Later Baby Boomers, however, had much more difficulty getting and keeping work as the economy stopped expanding. Early Baby Boomers had saturated the workplace, and prices had begun to rise in the marketplace (Foot, 1996).

Although the Baby Boomers experienced great advantages in their lives (Barnard et al., 1998), they also went through a period of political and social unrest. Some of these periods, arguably, may have been caused by their social views and excess leisure 
time over previous generations. During the formative years of the Baby Boomers, Watergate had a large impact on their views of authority. Combined with the turmoil of the Vietnam War and the Baby Boomers' general disapproval of this political decision, the political atmosphere led Baby Boomers to view authority as vulnerable (Conger, 2001). As a result, they began to distrust authority and to lose respect for authority. They also lost the loyalty that prior generations had to their institutions (Smola \& Sutton, 2002): social, political and organizational. The Baby Boom Generation ended for a variety of reasons including the fact that: (1) women began working at rates that had, up to that time, been unprecedented, (2) women began pursuing higher education, and (3) the introduction of the birth control pill greatly reduced birth rates (Foot, 1996).

\subsubsection{Stereotypes, Generalizations and Values of Baby Boomers}

There are relatively few documented stereotypes of Baby Boomers as less was written on the Baby Boomers' values and personalities than on: (1) how to cope with such large numbers of individuals passing through the system simultaneously, and (2) the supposed "generation gap" of the time. Describing the values of the Baby Boom is further complicated by the fact that there are two different views of the Baby Boomers: (1) the view that developed as they grew up (i.e. as being idealists with high principles, who were considered to be righteous and arrogant) (Barnard et al., 1998), and (2) the opposing view that developed once they entered the workforce (i.e. materialistic, driven, achievement-oriented and self-centred) (Burke, 1994). Pekala (2001) summarized these 
two views by noting that Baby Boomers evolved from hippies with the values associated with that lifestyle into yuppies who only cared about work.

\subsubsection{Subgroups}

Although it is reasonable to examine a generation as a unit, it should be noted that there are many within group differences that can also be identified. In order to examine subgroups for each of the Baby Boomers and Generation X, Adams (1997) used a sociocultural map with a horizontal axis of social/individual and a vertical axis of traditional/modern. In order to develop this map, approximately 2600 interviews were conducted asking approximately 250 questions to a representative sample of Canadians. Once placed on the map, clusters of values are found to coincide with the different subgroups of the generations. Adams (1997) divided the Baby Boomers into four groups: disengaged Darwinists, autonomous rebels, anxious communitarians and connected enthusiasts. Disengaged Darwinists are the largest subgroup of the Baby Boomers as they represent 41 per cent of this group. Younger Baby Boomers have more of a tendency to belong to this subgroup and there are more men and more blue-collar workers in this category than in others. They are described as "angry white guys" who are social Darwinists and readily accept authority. Technology, rapid change and the equal rights movements intimidate them and they tend to consider employment equity to be reverse discrimination. They do not feel particularly strong connections to their family, their community, their country or to religion. Adams (1997) describes the second largest subgroup of Baby Boomers as autonomous rebels. Comprising 25 per cent of the 
Baby Boomer population, they tend to be professionals with more education and higher incomes than others. They have a strong value system, considering the environment, equality, spirituality and education (both formal and informal) to be priorities. They seek autonomy and personal fulfillment and, as such, are uncertain about bureaucracies and authority. They also feel comfortable with the changing world as they are active rather than reactive and try to form the world around them instead of adjusting to it. A third group of Baby Boomers are considered anxious communitarians. They comprise 20 per cent of Baby Boomers and are almost the antithesis of disengaged Darwinists. The anxious communitarians reject social Darwinism, believe that society has a responsibility to the less fortunate and are anxious about life in general so they tend to empathize with those who are less fortunate. They believe in equality but want recognition and status and believe in authority. Overall, they do not adapt well to changes and are primarily driven by society's expectations rather than their own desires. The final fourteen per cent of Baby Boomers are classified by Adams (1997) as connected enthusiasts. They are very sociable and emotional and are enthusiastic about new technologies that allow improved communications. They are risk-takers who seek experiences and are motivated by status. They are concerned with the ethics of the organizations for which they work. Overall the risk takers have relatively youthful attitudes, similar to some Generation $\mathrm{X}$ groups. 


\subsubsection{Baby Boomers at Work}

Baby Boomers entered a workforce that had a very different appearance and influence than it does today, as the earliest Baby Boomers retire. The oldest Baby Boomers entered the workforce starting in the early 1960s as they finished their secondary school and post secondary education. When the earliest Baby Boomers began working, they entered the workforce in an era of job security and dues paying (Ruch, 2000). This was particularly true in Canada, a nation that led all developed countries in job creation in the 1960s and 1970s (Foot, 1996). This was the work environment of their fathers' generation (as few of their mothers worked (Howe \& Strauss, 1993)) in which hard work and loyalty to the organization were rewarded by consecutive promotions, salary increases and, upon retirement, a pension (Bertholf \& Loveless, 2001; Ruch, 2000). This led to Baby Boomers feeling relatively secure and comfortable with the bureaucratic workforce.

After the 1970s, job creation in Canada began to slow and technology began replacing many entry-level positions (Foot, 1996), resulting in the later Baby Boomers having a great deal more difficulty finding employment than the early Baby Boomers. In addition to the difficulties in finding employment, there were further difficulties for later Baby Boomers in that upper management became clogged and there was little room for the expected promotions (Foot, 1996). The clog in management began an era of restructuring including layoffs and reorganization, thus reducing the number of managers and employees within organizations (Hall \& Richter, 1990). Many Baby Boomers were 
downsized, particularly those in middle management. Those remaining in an organization were often caught with no room to advance and became frustrated (Foot, 1996). As this continued through the early 1990s, Baby Boomers remained a significant proportion of the workforce composing approximately fifty-five percent of the American workforce (Hall \& Richter, 1990; Kiechel, 1989). The difficulties of moving ahead in a large organization led some to either quit their jobs at larger organizations in order to work for small businesses or to form their own small business (Foot, 1996).

Baby Boomers in the workforce are unlike both those generations preceding them and those in later generations. In general, they are considered to be "workaholics" (Kiechel, 1989; Pekala, 2001) and are often defined by their jobs (Pekala, 2001). Few Baby Boomers would ever consider leaving a job without having another to take its place (Pekala, 2001). They are loyal employees although this loyalty is sometime directed towards a team or a project rather than the organization as a whole (Kiechel, 1989; Jennings, 2000). They find work to be stimulating and allow it to influence all aspects of their lives. Many, in fact, do not intend to retire completely but plan to work part-time, on contract or for themselves.

For many Baby Boomers, their jobs get more focus than their families and they are considered, in general, to be better friends than spouses or parents because of this focus (Kiechel, 1989). Baby Boomers, contrary to their earlier social interests, have very traditional values at work and consider material success important (Smola \& Sutton, 
2002). Boomers do have a slightly different way of interacting at work than many traditionalists. They consider communication critical and may become frustrated if team members do not communicate (Kiechel, 1989). They believe that consensus building is important (Smola \& Sutton, 2002) and have a need for autonomy (Hall \& Richter, 1990). They also tend to respect others' needs for autonomy while sharing responsibility (Kiechel, 1989).

Although Baby Boomers developed a distrust for authority and question authority (Hall \& Richter, 1990), many have progressed through their careers to become managers. Many consider a management position to be positive because of the security it ensures rather than the monetary benefits it offers (Kiechel, 1989). Baby Boomers in managerial positions are also the last generation to have wives at home to more or less take care of all domestic matters (Kiechel, 1989). This has given them the flexibility to work long, hard hours. They differ from previous generations in that they not only disrespect hierarchy but they do not enjoy giving orders (Conger, 2001; Kiechel, 1989). Conger (2001), however, noted that Boomers are just as controlling as previous generations. They are simply more subtle and manipulative in their methods.

Baby Boomers manage their subordinates differently from previous generations in many positive ways as well. They tend to use a more participatory form of management (Kiechel, 1989) and have great respect for the autonomy of others (Conger, 2001; Kiechel, 1989). They also encourage communication on their teams, a sharing of 
responsibility (Conger, 2001) and mentor their employees (Smola \& Sutton, 2002). In fact, it has been suggested that their loyalties tend to be to their co-workers and projects or teams rather than to the organization itself (Kiechel, 1989). This last finding may have relevance with respect to their levels of organizational commitment.

\subsubsection{Generation X}

As mentioned above, Generation $\mathrm{X}$ is considered to be those individuals, born in North America between 1965 and 1980. In other words, this is the generation of Canadians born after the Baby Boom generation. Similar to the Baby Boom generation, Generation $\mathrm{X}$ will be examined with respect to the environment members experienced growing up, stereotypes, generalizations and values followed by its members' views of the workforce and of their personal careers. Although there is some debate regarding whether or not Generation $\mathrm{X}$ is actually different from previous generations or whether the characteristics observed are merely the characteristics of youth (Barnard et al., 1998; Tulgan, 2000), most researchers consider Generation $X$ to be unique and distinct from previous generations (Burke, 1994a; Tulgan, 1997; Tulgan 2000).

Generation $\mathrm{X}$ is considered to have its own values and expectations (Charrier et al., 2000) based on a vastly different childhood and workforce experiences. Although Bova and Kroth (2001) emphasized that differences between the generations are not explicit, the social atmosphere in which Generation $\mathrm{X}$ was raised was monumentally different from that in which previous generations were raised. Therefore, although the 
differences may not be "immutable and irreparable", as assumed according to Zemke et al. (2000), they definitely exist and should be examined.

Regardless of other differences, Generation $X$ represents a divide between the Industrial Age and the Information Age (Barnard et al., 1998; Fowler, 2003; Tulgan, 2000 ) in addition to the technological divide between the preceding generation (the Baby Boomers) and the following generation (the Echo Generation). This position between those who remember a time before the personal computer would fit on a desk and those who cannot remember a time before the personal computer was on virtually every employee's desk has led it to be named the "Nexus" Generation (Barnard et al., 1998), or the "Bridge" generation (Fowler, 2003). The term "Generation X" is most commonly used although it has a negative connotation to some because Douglas Coupland (1992) initiated this term in his book Generation X: Tales for an Accelerated Culture to refer to individuals who are considered "slackers". There are a vast number of monikers used to describe this generation (see Table 2.4 below).

Table 2.4 - Alternate Titles for Generation X

\begin{tabular}{|l|l|}
\hline \multicolumn{2}{|c|}{ Additional Terms for Generation X } \\
\hline The Nexus Generation & Baby Bust Generation \\
\hline NeXt Generation & Nowhere Generation \\
\hline Thirteeners & Bridge Generation \\
\hline Scarce Generation & Boomerang Generation \\
\hline High-Tech Generation & Caretaker Generation \\
\hline $\begin{array}{l}\text { Yiffies (young, individualistic, freedom- } \\
\text { minded and few) }\end{array}$ & New Lost Generation \\
\hline MTV Generation & Computer Babies \\
\hline Posties (Post Yuppies) & Upbeat Generation \\
\hline
\end{tabular}


Despite the vast amount of negative discussion surrounding Generation $\mathrm{X}$ (Pekala, 2001; Tulgan, 1997), there has been little empirical research done to confirm or deny these stereotypes (Burke, 1994a). This lack of empirical research, similar to that found when examining the Baby Boomer Generation, results in a reliance on the popular press for information. While this source of data is not ideal, it demonstrates the interest of the general population regarding this topic.

\subsubsection{Generation X Growing Up}

Generation $\mathrm{X}$ began as the Baby Boom ended. The conditions that ended the Baby Boom meant that Generation X was a smaller cohort. As opposed to the American dominance that existed at the time of the Baby Boomers' births, Generation $\mathrm{X}$ was born during a relative decline in American global power (Tulgan, 2000). Generation X is also the most diverse generation identified to this time (Smola \& Sutton, 2002). Different cultures, ethnicities, family structures, and household incomes that existed in previous generations are creating this diversity (Howe \& Strauss, 1993). Due to the human rights movements of the Baby Boomers (Washburn, 2000) and the high levels of immigration to North America (Pekala, 2001), the Generation X cohort is more diverse. Family structure has also changed dramatically in North America with improved health care allowing individuals to live longer. Many members of Generation X grew up with their Baby Boomer parents caring for their own elderly parents, grandparents, or extended family (Charrier et al., 2000). The diversity they experienced through their youth allows 
members of Generation X to emphasize similarities rather than differences in all aspects of life (Smola \& Sutton, 2002).

The earliest memories of Generation X include the Vietnam War (Fong, 2001), Watergate, the Iranian hostage crisis (Fowler, 2003; Deutschman, 1990), the Challenger disaster (Fong, 2001) and gasoline rationing. Although the majority of members of Generation $\mathrm{X}$ are too young to remember the Vietnam War, the number of movies and television programs made about the conflict, combined with the use of television as a constant source of information, form Generation X's strongest collective memory (Deutschman, 1990). Later members of Generation X grew up in similar conditions with life-altering incidents including the Persian Gulf War, the AIDS outbreak, pollution, nuclear threats combined with escalating crime (Losyk, 1997). Although the Baby Boomers grew up with the Cold War and the Kennedy assassinations, by the time these later events occurred, the Baby Boomers were in their early adulthood. Generation X, however, had many of these defining events (such as the Persian Gulf War) occurring through their formative years combined with an increased exposure due to television and the continuous barrage of information, mostly negative, that it provided (Fong, 2001). Exposés and inside stories became frequent and gave members of Generation X few public figures to admire (Deutschman, 1990).

Despite the events mentioned above that formed the political environment of Generation X, members grew up during a period of relative peace in their home country, 
relative economic comfort and significant technological advances (Charrier et al., 2000). However, the "world" in their own homes was less stable than the world surrounding them (Jurkiewicz \& Brown, 1998). In most homes, either both parents worked (Conger, 2001; Losyk, 1997) or there was only one parent as the results of the divorce rate almost doubling between 1965 and 1977 (Fowler, 2003). Almost half of the members of Generation Xs' parents were divorced, leading to an unstable home environment (Losyk, 1997; Burke, 1994a; Fong, 2001; Buckley, 2001). Many members of Generation X were latchkey children (Pekala, 2001; Tulgan, 2000; Burke, 2001). This led to them relying more on their friends than on their parents (Fong, 2001; Smola \& Sutton, 2002) and developing individualistic attitudes (Buckley, 2001; Smola \& Sutton, 2002) as they had more time alone at home at a younger age than any previous generation (Losyk, 1997). The members of Generation $\mathrm{X}$ grew up watching television and playing video or computer games (Bova \& Kroth, 2001; Losyk, 1997). They became independent at a young age and many grew up quickly, taking care of themselves or, in some cases, helping to support a single-parent family (Losyk, 1997; Tulgan, 2000). In this case members of Generation X were quite different from the Baby Boomers who were able to extend their childhood (Foot, 1996). Members of Generation X learned how to use computers at a young age as the technological revolution began in their youth (Bova \& Kroth, 2001). In fact, they developed along with the computer systems, as opposed to the members of the Echo Boom group (the Baby Boomers' children who followed Generation X) who grew up always knowing computers, and the Boomers who were not 
exposed to information technology until they were adults (Barnard et al., 1998; Adams, 1997).

Many of the early experiences of members of Generation $\mathrm{X}$ also formed their early views of organizations and shaped their personal goals for the workplace. Firstly, both those who had divorced parents and those whose parents worked out of the home and saw work as a priority resented the lack of time their parents had for them (Losyk, 1997). Secondly, members of Generation X saw a great wave of downsizing during their childhood. They saw their parents, at age 50, laid off from organizations to which they had devoted their lives and from which they expected loyalty and a pension. This greatly influenced members of Generation Xs' views on loyalty to and from organizations (Smola \& Sutton, 2002; Fong, 2001; Bova \& Kroth, 2001; Ruch, 2000; Stewart, 2002; Charrier et al., 2002). They also grew up during a period of falling wages, reduced benefits and increasingly flattened organizations where products and services took priority over people (Ruch, 2000). In the 1990s, the university standards fell, allowing a higher percentage of this cohort to enter university (Foot, 1996). As a result, Generation $\mathrm{X}$ has obtained higher levels of education than any generation in history with $60 \%$ of members having completed at least one year of post-secondary education (Watson, 2002) and $54 \%$ completing more than one year of post-secondary education (Charrier et al., 2002). Not co-incidentally, members of Generation $X$ also have more student loans and credit card debt than previous generations (Watson, 2002). 
Despite their education, when the members of Generation $X$ were entering the workforce in the $1980 \mathrm{~s}$ and $1990 \mathrm{~s}$, it was difficult to find a job and they were forced to take entry-level positions (Pekala, 2001; Ruch, 2000). This was, in part, due to the same downsizing that their parents experienced (Foot, 1996) and also partly due to an early 1980s recession followed by the 1987 stock market crash and another recession in the early 1990s (Fowler, 2003). Whereas the Baby Boomers were born into an era of increasing prosperity where an individual's wealth was likely to exceed that of their parents, Generation $\mathrm{X}$ was born into the first generation in a century whose income was not expected to match that of their parents (Howe \& Strauss, 1993). This phenomenon has occurred because the continuously rising wages that the Baby Boomers experienced had receded by the time Generation $X$ entered the workforce (Watson, 2002). Therefore, the Generation X group are more likely to be unemployed or underemployed than any preceding generation (Burke, 1994a). They are also more likely to be living at home with their parents at an older age than any preceding generation (Gross \& Scott, 1990). In addition, on every economic criterion examined by Paulin and Riordon (1998), members of Generation X are worse off than the Baby Boomers with the sole exception of having more entertainment-based goods on which to expend disposable income.

With the lowest birth rates since World War II occurring in 1975, the early 1980s began to show a new shift in thinking back towards the family with divorce rates falling and parental attitudes moving away from the neglect Generation $\mathrm{X}$ experienced towards a new era of protection (Howe \& Strauss, 1993). Generation X, however, remained 
impacted by their location in time, between two large birth cohorts, each of which was better off materially (Washburn, 2000) and both of which received more protection from their parents (Howe \& Strauss, 1993).

\subsubsection{Stereotypes and generalizations}

Generation X has been possibly the most criticized and stereotyped of any generation. While the Baby Boomers were considered unique as a generation, they have few stereotypes other than being idealistic and lucky. The Baby Boomers were considered young and naïve and it was felt that they would grow out of these idealistic attitudes once they entered the workforce. The data would suggest that this did, in fact, occur. Generation X, however, was not only stereotyped from the early days of their generation by the Baby Boomers who did not understand them (Poindexter \&Larsorsa, 1999) but, overall, the stereotypes were very negative. The initial negative connotations of "Generation X" may have come from Douglas Coupland's (1992) book of the same name (Fowler, 2003) but the reputation of the generation has endured based on young celebrities and criminals (Howe \& Strauss, 1993) (i.e. Dennis Rodman, Kurt Cobain and the Menendez brothers (Fowler, 2003)) who have helped provide fuel for the most negative beliefs. In a study performed by Poindexter and Lasorsa (1999), it was found that forty percent of those who knew the term "Generation $X$ " considered it to be negative with one in ten considering "Generation X" to refer to slackers (Tulgan, 2000) implying laziness and aimlessness (Barnard et al., 1998; Doverspike et al., 2000; Stewart, 2002). Only six per cent of those questioned said that they considered the term 
inappropriate or misleading. These stereotypes endure because of the media (Tulgan, 2000) although marketers have also propagated the commonly held beliefs about members of Generation X (Fowler, 2003).

As noted above, the most frequent stereotypes or opinions regarding Generation $\mathrm{X}$ are negative. Members of this generation are frequently called cynical (Jurkiewicz \& Brown, 1998; Burke, 1994a; Pekala, 2001; Burke, 1994b) and naïve (Jurkiewicz \& Brown, 1998; Barnard et al., 1998; Jurkiewicz, 2000). For other terms commonly used to define the members of Generation X, see Table 2.5.

One of the most common views of Generation $\mathrm{X}$ with respect to the workforce is that they are untrusting of large organizations (Burke, 1994a; Barnard et al., 1998), fearful of commitment (Fowler, 2003) and that they do not care about the organization (Munk, 1998) but, instead, are more focused on personal pursuits (Buckley, 2001). Many also consider them to harbour anger toward Baby Boomers who were given every opportunity, including better career prospects in their youth (Burke, 1994a), and did not appreciate it (Pekala, 2001). While these views regarding the organization may be widespread among the members of Generation X, other terms used to describe them, particularly those in Table 2.5 follow the media-driven stereotype. Although these adjectives may accurately describe some members of Generation X (see Section 2.2.4.4) the majority of the members of Generation X do not fit this mould. 
Table 2.5 - Terms Frequently Used to Describe Members of Generation X

\begin{tabular}{|l|l|}
\hline Terms & Source \\
\hline $\begin{array}{l}\text { Cynical, sullen, contemptuous, naïve, arrogant, unfocused, } \\
\text { materialistic, individualistic }\end{array}$ & $\begin{array}{l}\text { Jurkiewicz \& Brown, } \\
1998 ; \text { Jurkiewicz, 2000 }\end{array}$ \\
\hline $\begin{array}{l}\text { Slack, aimless, marginalized, reckless, naïve, rebellious, } \\
\text { lonely, troubled }\end{array}$ & Barnard et al., 1998 \\
\hline $\begin{array}{l}\text { Unmotivated, apathetic, easily distracted, arrogant, self- } \\
\text { satisfied, cynics, slackers, having short attention spans, } \\
\text { demanding of managers, nihilistic }\end{array}$ & Tulgan, 1997 \\
\hline Lost, passive, powerless & Fowler, 2003 \\
\hline Cynical, alienated, angry & Burke, 1994b \\
\hline Cynical, defiant & Pekala, 2002 \\
\hline Cynical, alienated, untrusting & Burke, 1994a \\
\hline Slackers, cynics, whiners, drifters and malcontents & Stewart, 2002 \\
\hline Impatient, self-confident, opportunistic, selfish, spoiled & Munk, 1998 \\
\hline Cynical, apathetic, disrespectful, losers and slackers & $\begin{array}{l}\text { Poindexter \& Lasorsa, } \\
1999\end{array}$ \\
\hline
\end{tabular}

Recently, more positive views of Generation X have been presented. The belief that Generation $\mathrm{X}$ is different than previous generations remains but the negative stereotypes are dissipating (see Table 2.6). The negative stereotypes have been found to be particularly untrue in the work environment (Miller, 2000). While members of Generation X may be considered as arrogant, cynical and individualistic (Tulgan, 1997; Jurkiewicz \& Brown, 1998; Jurkiewicz, 2000), others view them as being independent, adaptive and self-sufficient (Buckley, 2001; Howe \& Strauss, 1993; Stewart, 2002). In the workforce they adapt easily to the rapid tempo of change as they have learned from their childhood to expect it (Bova \& Kroth, 2001; Buckley, 2001). They are flexible and comfortable with technology (Poindexter \& Lasorsa, 1999), diversity in the workforce (Burke, 1994a), and multitasking since they have been bombarded with a high volume of 
information throughout their lives and have learned to process it quickly (Buckley, 2001). There are three things that have been predominant in the lives of members of Generation X: information, immediacy and independence. They have grown accustomed to and thrive in an environment that supplies these elements both at home and in the workplace (Tulgan, 2000).

Table 2.6 - Positive \& More Recent Perceptions of Generation X

\begin{tabular}{|l|l|}
\hline Terms & Source \\
\hline $\begin{array}{l}\text { Flexible, adaptable, technoliterate, info-savvy, independent, } \\
\text { entrepreneurial }\end{array}$ & Tulgan, 2000 \\
\hline Environmentally conscious & Burke, 1994a \\
\hline $\begin{array}{l}\text { Optimistic, savvy, confident, ambitious, determined, } \\
\text { independent, and materialistic }\end{array}$ & $\begin{array}{l}\text { Poindexter \& Lasorsa, } \\
1990\end{array}$ \\
\hline $\begin{array}{l}\text { Ambitious, savvy, independent, pragmatic, self-sufficient, } \\
\text { and impatient }\end{array}$ & Stewart, 2002 \\
\hline $\begin{array}{l}\text { Individualists, fiercely independent, wanting to set their own } \\
\text { goals }\end{array}$ & Jurkiewicz, 2000 \\
\hline
\end{tabular}

Again, it should be noted that, as with the negative aspects, it is likely that these positive aspects of Generation X do not necessarily characterize all groups of Generation X.

\subsubsection{Values \& Priorities}

The values and priorities of the members of Generation $X$ were, in part, defined by growing up in families with either a single parent who worked or where both parents worked (Maccoby, 1988). Whereas the Baby Boomers are considered to have placed work as their top priority and used traditional benchmarks such as money, titles, security and ladder climbing as gauges to their success (Deutschman, 1990), members of 
Generation X define success differently (Burke, 1994a). A study performed by Burke (1994a), found that members of Generation X, in order of priority, ranked children first, followed by the home, their career and their marriage. They want traditional families, happy marriages and time for their children including weekends, evenings and holidays (Conger, 2001). Other researchers have also found that members of Generation $\mathrm{X}$ consider leisure, family, lifestyle and personal experiences to be as important as work (Deutschman, 1990).

Younger members of the workforce have always had different values than the older generations in the workforce but, in the past, the younger generations have quickly adjusted and adopted the status quo (Burke, 1994a). However, as the oldest members of Generation $X$ approach their $40 \mathrm{~s}$, it is clear that the same will not happen for this generation. Even prior to their entry into the workforce members of Generation X were concerned about balance in their lives, divorce, materialism and their personal relationships (Burke, 1994a). Quality of life has a priority over work with members of Generation $\mathrm{X}$ willing to exchange promotions and raises for more time for family or personal interests (Charrier et al., 2000; Washburn, 2000). This has resulted in a greater number of employees looking for short workweeks or moving to home-based businesses (Buckley, 2001).

Despite the quest for balance in their lives, members of Generation X still entered the workplace prepared to work. However, once the long hours and reduced leisure time 
became habitual and they saw their superiors displaying this same tendency, they began to look for ways of achieving a more balanced lifestyle, often by considering work to have a lower priority (Deutschman, 1990). In fact, in Burke's (1994b) study, he found that of soon-to-be university graduates, a large proportion expected life to be very difficult for approximately five years but then felt that their lives would be relatively easier after that. They explained this perception by pointing out that they did not expect to work as hard after their initial move into the workforce. Maccoby observed that the newest members of the workforce in 1988, who belonged to Generation X, are willing to work hard but instead of doing so for status (as was the norm prior to this generation) they do it for self-development. Balance is a common desire in their lives with most wanting more balance in their lives than they perceive their parents to have had (Charrier et al., 2000).

Members of Generation $\mathrm{X}$ also place a high value on maintaining a standard of living that allows their family to be able to live comfortably. As such, they also tend to be savers and are careful not to rely on the government for their financial security (Miller, 2000). In addition to their families, they tend to form strong bonds with close friends or virtual families rather than formalized associations (Washburn, 2000). Also, they demonstrate more ethical and environmental consciousness than their predecessors did at a younger age (Burke, 1994a). 


\subsubsection{Subgroups}

Although cohorts have similarities within the group, there are also necessarily differences as well. Generation $\mathrm{X}$ is no different as members within the generation do not all share the generalized values and tendencies (Hessen, 2001). The stereotype of members of Generation X as "slackers" is a result of one of these subgroups getting more attention than others (Paulin \& Riordon, 1998) and it is likely that the more recent, positive views may be a result of a focus on a different subgroup. In order to better understand any research that has been performed on the generation as a whole, it is important to explore potential subgroups - particularly when trying to separate myth from reality. Two typologies of subgroups are presented here, one by Adams (1997) and one presented by Paulin and Riordon (1998).

Adams (1997) hypothesized five different subgroups within Generation X. These are: aimless dependents, thrill-seeking materialists, new Aquarians, autonomous postmaterialists and social hedonists. While the aimless dependents are the largest Generation X subgroup, they still comprise only 27 per cent of this population. Despite this fact, the values of this group are the basis of most of the negative stereotypes of this generation. Members of Generation $\mathrm{X}$ in this grouping tend to be unemotional and form little attachment to anything in their lives. They are resentful and anti-social and have little confidence in the government or large organizations. Essentially, they possess many of the traits that the old stereotype of "Gen Xers" engendered. 
The next largest subgroup identified by Adams (1997), the thrill-seeking materialists, comprise 25 per cent of Generation X's population. They tend to be the younger members of the generation and are more traditional in many respects considering salary the most critical job consideration followed by job security. They are confident but tend to react to the environment around them rather than forming their own identities.

Twenty per cent of Generation X is classified by Adams (1997) as autonomous post-materialists who reject authority and are very confident. Again, younger members of Generation $\mathrm{X}$ are more likely to belong to this group. This group is non-traditional in that they are the most supportive of equal rights and the least likely to be religious. They also have little concern for what others think of them and are classified as "hard socialDarwinists".

The social hedonists who comprise 15 per cent of Generation X population may also be considered to have some of the stereotypical tendencies of the "Generation Xer" as they focus on immediate gratification and have a limited attention span. This group focuses on having a good time but in the work force this group is primarily concerned with pay and being recognized for their accomplishments. However, unlike the stereotypical "Generation Xer", this group has confidence in the government and large organizations. 
The final group of Adams' classification (1997) is the new Aquarians. They comprise 13 per cent of the Generation X population and have the firmest belief systems in terms of the environment and gender and racial equality. They question government and traditional religion but are spiritual and believe in the global village. They are risktakers and believe in experiencing everything first-hand. They demonstrate this belief by taking a strong interest in both current technologies and cultural products.

Paulin and Riordon (1998) used a different typology based on psychology and cultural anthropology and found four subgroups within Generation X. These are: cynical disdainers, traditional materialists, hippies revisited and fifties macho. Cynical disdainers are the stereotypical "Generation Xers" who are pessimistic and skeptical. They are most like the aimless dependents in Adams' typology. Traditional materialists are positive and optimistic and, according to Paulin and Riordon (1998), are most like the Baby Boomers. The group labeled "Hippies revisited" by Paulin and Riordon (1998) emulate the lifestyle and values of the sixties. They are similar to the new Aquarians as defined by Adams. Finally, the fifties machos are conservatives who are least open to diversity and are most similar to the autonomous post-materialists in Adams' typology.

\subsubsection{Generation $\mathrm{X}$ at Work}

The environment at the time when Generation $\mathrm{X}$ began to enter the workforce was vastly different from the one into which the Baby Boomers entered. Firstly, as previously mentioned, the workforce was more diverse with more minorities and women in the 
workforce (Tulgan, 2000). Secondly, the basis of the work environment was quite different as society moved away from the industrial age and towards the information age (Tulgan, 2000). The pace of business changed dramatically requiring companies to be more responsive to remain competitive (Conger, 2001). Thirdly, the economy was very different from the time when the first Baby Boomers began to work. While the Baby Boomers came of age during an economic expansion (Foot, 1996), aided by an increase in consumption due to their large numbers, the members of Generation X entered the workforce as the recession of the early 1980s began (Fowler, 2003). As previously mentioned, the 1987 stock market crash followed this and a second recession began in the early 1990s (Schrammel, 1998; Ruch, 2000; Fowler, 2003) causing young adults in the 1990 s to experience less success than those in the 1970 s and $1980 \mathrm{~s}$. The situation did not improve when the economy picked up as the unemployment of young adults grew, even as overall employment increased (Schrammel, 1998). With such a dynamic environment, the members of Generation $\mathrm{X}$ had different experiences and particular expectations and demands of the workplace.

When members of Generation X entered the workforce, it was without an expectation of the benefits that had been taken for granted in the past. They did not expect job security, pensions or a traditional career path (Jurkiewicz, 2000; Jurkiewicz \& Brown, 1998). The fact that much of the work that was available to this group was contract work (Scott, 2000) reinforced their negative expectations. They have experienced and have come to expect periods of unemployment or underemployment 
(Burke, 1994a) and, as such, often choose to change jobs frequently, remaining in one job for only eighteen months on average (Jurkiewicz, 2000; Pekala, 2001). In the past, employees who moved with such frequency would be negatively labeled as poor employment risks whereas now such behavior has become acceptable, as tenure no longer holds the admiration it once did (Jennings, 2000). Because of the negative views that members of Generation $\mathrm{X}$ have towards the traditional career ladder (Jennings, 2000), moving from job to job allows them to gain experience and advance in their careers (Bova \& Kroth, 2001). Through the various jobs they hold, they develop portable skills (Munk, 1998) and develop career security through the ability to move from organization to organization with additional skills and expertise (Tulgan, 1997; Ruch, 2000).

Generation X needs and demands a different work environment than the Baby Boomers (Bova \& Kroth, 2001; Jennings, 2000; Deutschman, 1990). As such, the old method of hiring "getting the best candidate for the least amount of money" no longer applies (Jennings, 2000). They will not remain in organizations with less than ideal working conditions (Jennings, 2000) and, as such, frustrate managers with their apparent lack of loyalty (Tulgan, 1997).

In addition to a concern about the loyalty of members of Generation X, managers also feel that they do not understand members of Generation $\mathrm{X}$ and this generation is seen as arrogant, critical and unwilling to pay their dues (Jurkiewicz, 2000). Tulgan (2000) 
argues that rather than being arrogant, they are independent and rather than being critical, they are searching for additional information as members of Generation $\mathrm{X}$ are used to the vast amounts of information they were exposed to in their childhood. They are also criticized for questioning managers, for being materialistic and for treating a job as a job instead of the defining characteristic of their life (Charrier et al., 2000). These behaviors have led many managers to believe that this generation has no work ethic (Jurkiewicz, 2000). Managers from generations prior to the Baby Boom Generation may not have these perceptions but instead perceive members of Generation $X$ in the same way as they viewed the Baby Boomers - as naïve individuals who will begin to play by the rules when they are older (Tulgan, 2000).

For their part, members of Generation $\mathrm{X}$ present difficulties to managers as they demand good management and will go elsewhere if they do not find it (Tulgan, 2000). They do not respect managers unquestioningly as they do not respect authority (Charrier et al., 2000). Some, in fact, even resent authority (Bertholf \& Loveless, 2001) and have little faith in institutions (Washburn, 2000; Stewart, 2002). Instead, titles and power must match the competence of the individual in order to gain the respect of these employees (Hessen, 2001; Losyk, 1997). When members of Generation X are micromanaged, they do not respond well but instead fake compliance and look for a job elsewhere (Maccoby, 1988). Similarly, they become frustrated with managers who are good at managing but have little technical knowledge (Ruch, 2000). Members of Generation X want managers who will be mentors (Jurkiewicz, 2000). They want managers who will answer their 
questions (Charrier et al., 2000; Losyk, 1997), appreciate them and give them timely and useful feedback (Charrier et al., 2000). Members of Generation X are willing to stay with an organization that instills confidence in its employees (Stewart, 2002) and allows them to train and develop their skills so that they are able to leave if they must.

Members of the Generation $\mathrm{X}$ are also able to be more demanding of managers than their predecessors because they have different needs and values at work and home than the Baby Boomers. As mentioned previously, they value traditional authority and the career path far less than Baby Boomers do. However, their expectations and needs in the workplace influence the ease with which they have adapted to today's workplace. The remainder of this section will be dedicated to discussing the values, needs and desires of members of Generation X at work. Surprisingly, it has been found that the assumptions about what members of Generation X want at work and the reality of what they want are dissimilar (Jurkiewicz, 2000).

Due to the fact that they expect to change jobs many times throughout their careers, members of Generation X prefer organizations that allow them to develop their skills and experience (Bova \& Kroth, 2001; Hessen, 2001). They also appreciate mentoring and coaching in the workplace, as it helps them to further develop themselves (Charrier et al., 2000; Weston, 2001; Bertholf \& Loveless, 2001). In addition, being listened to is valued, as it helps them feel productive (Hessen, 2001). They are not just in the workplace for money but for self-development and self-fulfillment (Burke, 1994a; 
Maccoby, 1988; Munk, 1998). Although when changing jobs they will often look for salary and other benefits, members of Generation $\mathrm{X}$ also want flexible schedules and facilities that allow for better work-life balance such as day-care centers (Jennings, 2000; Hessen, 2001; Bova \& Kroth, 2001).

Generation $\mathrm{X}$ wants clearly defined goals and guidelines and the autonomy to achieve these goals as they see fit (Buckley, 2001; Tulgan, 2000; Jurkiewicz \& Brown, 1998; Losyk, 1997). Members of Generation X want to be challenged (Hessen, 2001; Bova \& Kroth, 2001; Charrier et al., 2000; Tulgan, 1997; Burke, 1994a; Pekala, 2001), they want variety in the workplace (Barnard et al., 1998) and they want interesting and stimulating work (Conger, 2001; Charrier et al., 2000; Maccoby, 1988; Pekala, 2001). They also want meaningful and timely feedback regarding their work and their productivity (Charrier et al., 2000; Tulgan, 1997) and to be recognized for their achievements (Burke, 1994a; Pekala, 2001). Similarly, they want to participate in decision-making and be valued (Charrier et al., 2000).

Members of Generation $\mathrm{X}$ also have specific expectations and needs regarding the people within the organization and the culture. They appreciate work environments that are similar to communities, as they do not belong to traditional associations such as the church or other clubs (Conger, 2001). They value a sense of belonging, teamwork and security (Jurkiewicz \& Brown, 1998) and enjoy solving problems with team members (Maccoby, 1988). It appears to some that members of Generation $\mathrm{X}$ do not leave the 
organization but instead leave the people within the organization, most notably their managers (Pekala, 2001). In fact, in the absence of this ideal environment comprising all the different elements they look for at work, they will move on to another workplace that may be more enjoyable and satisfying (Weston, 2001). Contrary to popular opinion, Munk (1998) has found that if they enjoy their job and their work environment they will devote themselves to their work, even at the expense of other aspects of their lives. Members of Generation $\mathrm{X}$ are also more likely to work over forty hours a week than Baby Boomers did at this age (Marciniak, 2002).

\subsubsection{Empirical studies}

As mentioned above, the majority of studies on Generation $\mathrm{X}$ are from the popular press and are opinion-based as opposed to empirically tested. Both empirically tested results and popular opinion are relevant in this research, as popular opinion has driven it. However, empirical studies are clearly preferred in terms of theory development as they are based on data and research and not simply observation. It is therefore important to identify which of the articles cited in the preceding sections are research based since the conclusions drawn from empirical data are likely to be more robust and accurate.

Eight of the articles cited in the above literature review (including those by Burke (1994a), Burke (1994b), Altimus \& Tersine (1973), Bengtson \& Lovejoy (1973), Cambiano et al. (2001), Cherrington et al. (1979), Smola \& Sutton (2002) and Conger 
(2001)) are empirical academic studies. Given the prolific nature of empirically based organizational commitment literature, this is a relatively small number of empirical studies. This list can be augmented by including demographic studies done by Foot (1996), Adams (1997) and Barnard et al. (1998). While these studies were intended for popular consumption, they were all based on rigorous data collection and analysis. In addition to these, several other articles report results of empirical studies in this area (i.e. Jurkiewicz (2000), Jurkiewicz and Brown (1998), Poindexter \& Lasorsa (1999)). All of these articles were, however, written for practitioners' journals and not academic studies.

\subsection{Critique of Literature}

In order to provide a thorough examination of the topics of organizational commitment and generation, a critique of both areas of research is necessary. Firstly, a critique of the research on organizational commitment will be offered. A discussion critiquing the literature on generations will follow.

\subsubsection{Critique of Organizational Commitment Literature}

The study of organizational commitment is a mature field. As such, there are many opportunities to build on previous research. The area has been thoroughly researched on many dimensions including both the construct of organizational commitment and the more general psychological construct of commitment. Five primary issues will be discussed with respect to the organizational commitment literature. First, measurement and definition issues will be discussed. Next, the problem of potentially 
outdated research will be examined. The third point will be a discussion of the artificial division of lives into work-life and home-life in organizational commitment literature. The value of commitment and the fact that its value is taken for granted in much of the literature will then be examined.

As Swailes (2002) suggests, the theoretical framework of organizational commitment has enlarged and progressed, yet the clarity has not. Although problems with the definition and measurements of commitment were presented in Chapter 2, there remain several difficulties that should not go unmentioned. The accepted definition by Mowday et al. (1982) has several issues including both those listed in Chapter 2 and that the "desire to maintain membership" in the organization is used in the definitions but may also be considered as a consequence of organizational commitment. The term "organizational commitment" is also often used when the researcher is discussing "affective commitment" which may cause later researchers difficulties when examining the constructs.

The main difficulty with the measurement of organizational commitment in current research is that the three-component model developed by Meyer and Allen (1991) often competes with the more generalized concept of organizational commitment as used by Mowday et al. (1982). Concerns include the fact that despite the belief of Meyer and Allen (1991) that their three components (affective, continuance and normative commitment) are not different forms of commitment but are components of one 
underlying construct, researchers sometimes use only one of these components in their research while others use all three. Other researchers use the OCQ that was developed by Mowday et al. (1982), which is intended to measure the overall level of organizational commitment but actually measures affective commitment. Still others develop their own measurements for organizational commitment or use the measure developed by Cook and Wall in 1980. This makes comparisons between different studies difficult.

A second difficulty with the literature on organizational commitment is that it was founded decades ago yet current research does not take the current organizational climate into account. Without considering the context of the organization, the construct cannot be properly examined. Yet, the commitment research has maintained a steady path while the organizational context has not. For example, the idea of committed employees wanting to remain in the organization may not be as relevant today as it was in previous years as younger workers are more mobile and change jobs more often (Jurkiewicz, 2000). Also, because organizations have undergone restructuring over the past few decades and layoffs have occurred, it appears that long tenure is not valued as it was in the past (Swailes, 2002). The assumption continues to be that employees continue to work for one or few large organizations through their careers which is no longer the case. In addition, organizational commitment literature takes little notice of the globalization of the workplace. Although studies are done throughout the world, there is little consideration that the values and behaviours of one ethnic group may not apply to other ethnic groups in the same workplace in the same location (Swailes, 2002). 
A third major difficulty with organizational commitment research is that it often does not take the reality of individuals' lives into account. Although every worker's primary focus of commitment cannot always be the organization, it has not been adequately tested as a zero-sum game. Berg et al., (2003) discuss commitment with a view that every individual has a certain amount of commitment to give to all areas of his or her life and if the commitment is focused on one aspect, another must invariably suffer. However, there is a lack of evidence that individuals can be committed to one focus such as their families and not have it negatively impact their level of organizational commitment. This is of particular concern since this fact plays a role in many of the arguments as to why women may be less committed than men. Becker (1992) suggests that strong multiple commitments are possible. Swailes (2002) acknowledges that commitments are not static but, rather, they are dynamic. Therefore, at varying points in time an individual's focus may be on one area of commitment and not negatively impact other foci of commitment.

Also, the underlying value judgment in the literature that organizational commitment is inherently good remains questionable. Researchers as far back as Freud in 1930 have considered that too much commitment may have negative repercussions such as conformity (Brickman, 1987). There is also an assumption made that the organization is "right" and employees who are not committed to it are "wrong" (Swailes, 2002) regardless of the organization and its values. Any employee not upholding the 
organization's values is considered to have low organizational commitment despite the fact that an employee who wishes to improve the organization may have a greater affinity to the organization than one who is willing to accept the status quo. Finally, individuals who continuously change organizations to develop their skills and experience (as described in the above section on Generation $\mathrm{X}$ ) may be of more benefit to an organization than an employee who wishes to remain there and internalizes the values of the organization but who is not willing to continuously update his or her skills.

\subsubsection{Critique of Generation Literature}

The literature regarding generations is much less mature and developed than that of organizational commitment. Mannheim (1952) is considered the first to have synthesized theories on generations and later studies often use his paper as a basis. However, this has neither guided researchers toward common definitions for generations nor allowed definitive guidance on where to divide generations. Five primary issues that arise with generational literature will be discussed. First, the lack of empirical work will be discussed. Next, the difficulty of using generation as a construct will be examined followed by the difficulties in dividing populations into generations. Following this, the relatively recent use of generations in North America will be discussed. Finally, the two different views of generations will be discussed along with Mannheim's concept of the "generational unit".

Unlike the organizational commitment literature, the generational literature is a relatively immature area of research. There is little empirical research that has been 
performed in the area. Much of the literature in the area is based on public opinion or is found in practitioners' journals. Those based on public opinion are often biased toward the generation of the author (e.g. Cherrinton, 1977; Cooper 1990; Howe \& Strauss, 1993) while those in practitioners' journals tend to present solutions to the "problems of generations" rather than determining whether or not a "problem" actually exists (e.g. Bertholf \& Loveless, 2001; Bova \& Kroth, 2001; Buckley et al., 2001; Charrier, 2000; Fong, 2001; Weston, 2001). The empirical research attempts to remain unbiased and focus on the generations themselves but most has no connection to organizational issues. Those empirically based articles that do examine organizational issues tend to focus on one generation rather than comparing two or more. In addition, those articles that do focus on one generation, tend to make implications regarding the other generation. For example, Burke (1994a and 1994b) looked at recent graduates and compared across genders with the implication that he was comparing Generation $\mathrm{X}$ to the Baby Boomers even though he does not have any research provided on Baby Boomers.

There are inherent difficulties in using generations as a construct. There is the pervasive question of whether or not the differences in values and behaviors exhibited by a generation are due to the social location (place) and generational location (time) (Laufer \& Bengston, 1974), which defines the generation according to Mannheim (1952), or whether it is due more to the age and life cycle stage of the individuals. This difficulty is highlighted in the opening paragraphs of this thesis where two generations are being 
discussed with apparently similar values and behaviors as today's generations, but in a very different time period.

A third difficulty that occurs when examining the concept of a generation is the division of individuals into their respective generations. The guidelines on what constitutes a generation are vague, as mentioned above. Generations cannot simply be divided into a "parent" generation and a "child" generation based on the general estimate of a life-span of 20 to 30 years (Mannheim, 1952). Births exist on a continuum so it is impossible to determine a year where the "parent" generation ends and the "child" generation begins (Lyons, 2003). The generations of interest in this study, Generation X and Baby Boomers, are often divided based on the Baby Boom and begins with the boom in the birthrate and ends with the end of the boom. However, this ignores the social environment except for the impacts of such a large cohort and, therefore, according to some definitions is still imperfect. The challenge individuals have in dividing these generations, which may appear simple, can be seen in Tables 2.2 and 2.3 where the generations are all defined with slightly different years marking the beginning and the end of different generations. This adds a further difficulty to later research as the studies cannot be compared as easily as if they all used the same boundaries.

An additional weakness in the literature is the lack of generational literature in North America prior to the mid-1960s. This is the time when the term "generation gap" was coined to distinguish between the apparent differences in values and behaviors 
between the two primary generations at the time: the Baby Boomers and their parents (Washburn, 2000). As there is little previous literature on which to compare current generations, and only one other perceived "gap" that has been discussed, the comparison of subsequent generations is difficult. This furthers the difficulties noted above regarding the generation construct and whether it exists or is just the manifestation of the young behaving as the young have always behaved and of their parents behaving as their parents have always behaved but in a different social context. It also presents the question of whether or not researchers will continue to look at generation as a construct once the Baby Boom generation ceases to exist. This is particularly true if there are no events significant enough to define the social context of a new generation such as the end of a World War or the rapid pace of technological innovation.

The final, and probably the most significant, critique of the literature is that there remains an inconsistency in the definition of generation. There are two approaches to identifying a generation. The first, called the cohort approach, uses generations to distinguish between different age groups. This, according to Laufer and Bengston (1974) has "emptied the concept of generation of its active political meaning and sought to treat generational location as a social category similar to sex, race, or religion" (Laufer \& Bengston, 1974, p.184). Therefore, the cohort approach may relate more to the life cycle stage of individuals of a certain age than to an actual social force as suggested by Mannheim (1952). The social forces approach is more closely tied to Mannheim's (1952) original definition of generations. According to Mannheim's definition, a 
generation exists when a generation unit organizes itself to change the political, social, economic or cultural system that is in place. The age group, or part of the age group, acts collectively toward these goals and the rest of the generation is swept along into the change with this generational unit (Laufer and Bengston, 1974).

This research rectified these difficulties in the generation literature by providing empirical research in an area where the majority of the research is theory driven. This allowed the research to remain objective while focusing on organizational issues that are frequently discussed in both current and older literature with no basis in research. 


\section{Theoretical Framework}

As mentioned above, the purpose of this thesis is to determine if there are generational differences in organizational commitment. Two generations will be examined: the Baby Boom Generation and Generation X. In this section, the research questions are presented to help put the research framework in context. The research framework for the thesis will then be presented. Finally, operational definitions are provided for all the variables examined in the research.

\subsection{Research Questions}

This thesis will address the following research questions:

- Is organizational commitment associated with generational membership?

Specifically, how do the levels of organizational commitment reported by

employed Baby Boomers compare to those reported by employed members of Generation X?

- What impact do gender, life cycle stage (i.e. marital and parental status), tenure in the organization, industry sector of employment and job type (professionals, managers and non-managers who are not professionals) have on the relationship between organizational commitment and generational membership?

- How effective a predictor of organizational commitment is generational cohort?

- How effective a predictor of organizational commitment is generational cohort compared to age? 
- Can we identify sub-cohorts within the Baby Boomer and Generation X groupings with respect to organizational commitment?

Supplemental questions were added to the research based on the literature in the area. These were considered because although they are not related to the generation of the respondents, they may help elucidate the organizational commitment construct. These include:

- What is the relationship between gender and organizational commitment?

- What is the relationship between lifecycle stage and organizational commitment when gender is controlled for?

- What is the relationship between job type and organizational commitment when gender is controlled for?

- What is the relationship between industry sector and organizational commitment when gender is controlled for?

- What is the relationship between tenure and organizational commitment when gender is controlled for?

- What impact does the organization of employment have on organizational commitment when the other covariates are controlled for?

\subsection{The Research Framework}

The Research Framework presented below (Figure 3.1) has been developed based on the literature presented in the previous chapter. It seeks to help define the relationship 105 
between organizational commitment and the generation to which an individual belongs. As noted previously, this linkage is based on the premise that the generation to which an individual belongs affects their level of organizational commitment. Gender, life cycle stage, industry sector, job type, tenure and organization of employment have been presented as covariates in this relationship as research in the area suggests they may be related to organizational commitment, as discussed below. 
Figure 3.1- The Research Framework

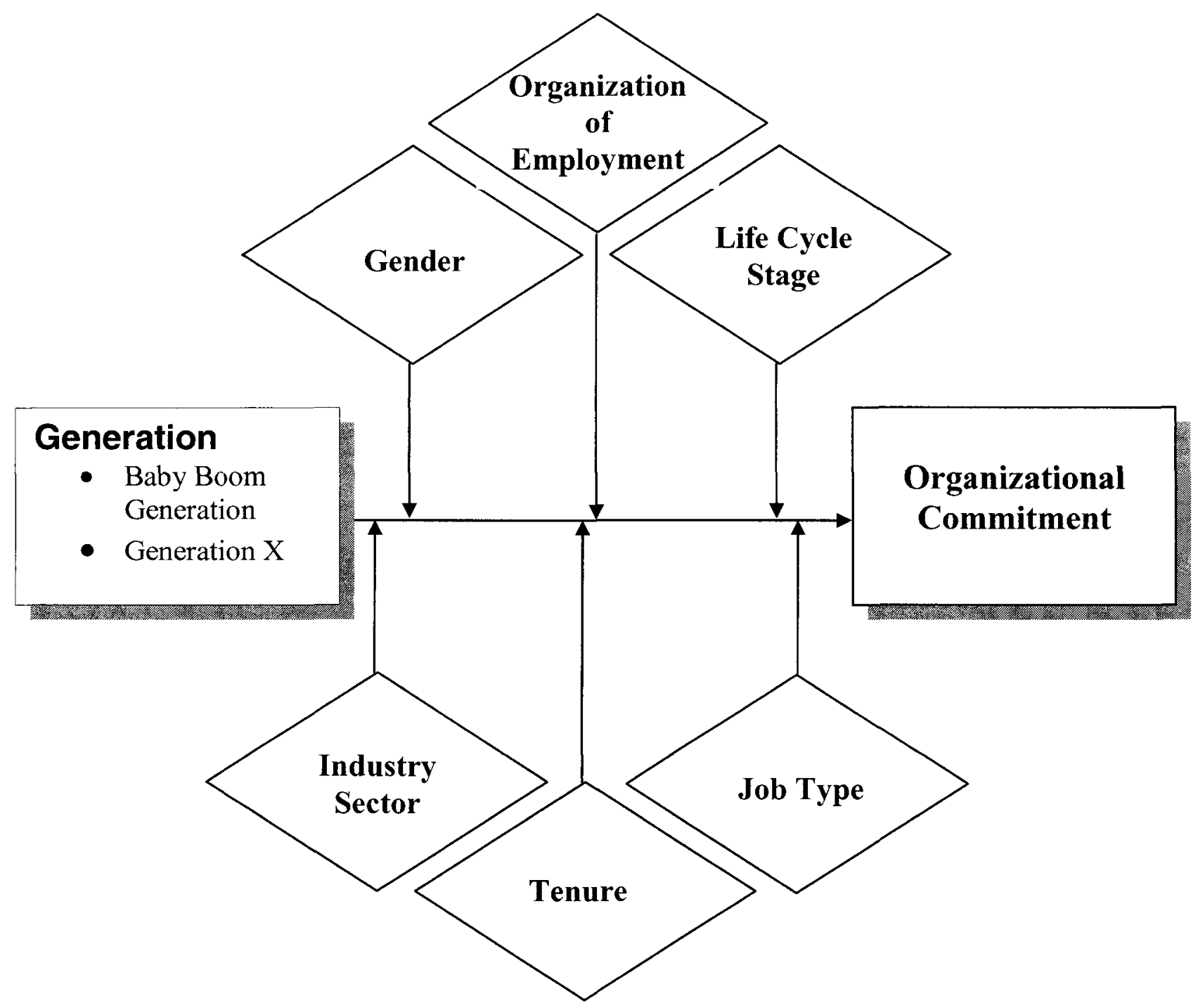

\subsection{Variables}

\subsubsection{Independent Variable}

The independent variable that was studied is organizational commitment.

Organizational commitment, as defined above, is "the relative strength of an individual's 
identification with and involvement in a particular organization" (Mowday et al., 1982, p. 27).

\subsubsection{Explanatory Variable}

The explanatory variable used to study organizational commitment was generation. This is a categorical variable representing the two largest and most visible generations in the current workforce: the Baby Boom Generation and Generation X. This study examines whether or not a relationship between these two variables exists. Previous research demonstrates a high correlation between organizational commitment and age (Swailes, 2002; Mathieu \& Zajac, 1990). Age divisions, however, are done according to five- or ten-year blocks and they are not based on any defining features other than year of birth. Given the social context of generations, it is expected that they would predict a construct like organizational commitment better than age. In addition, much of the literature shows that there is a difference (or at least the perception of a difference) between the generations with respect to organizational commitment (e.g. Howe \& Strauss, 1993; Tulgan, 2000; Washburn, 2000; Adams, 1997). This research seeks to prove or disprove the perception that generational differences extend to the area of organizational commitment.

The literature (Adams, 1997; Paulin \& Riordon, 1998) provided a sound argument for dividing the generations into subgroups. Accordingly, each generation was divided into three categories. This decision was based on the fact that authors, such as Smola and 
Sutton (2002), spoke of those born early in the generation, late in the generation or in the middle of the generation.

\subsubsection{Covariates}

George and Mallory (2003) define a covariate as "a variable that has substantial correlation with the dependent variable and is included in an experiment as an adjustment of the results for differences existing among subjects prior to the experiment" (p. 370). Five covariates are included in the model: gender, industry sector, job type, tenure and life cycle stage as literature demonstrates that each is correlated with organizational commitment. Details on each are given below.

\subsubsection{Gender}

Gender is a categorical variable consisting of two groups: males and females. Elizur (1994) reports that results in existing literature on gender differences in work values are inconclusive. Research specifically on organizational commitment found similarly inconclusive results with respect to gender. Some studies show that women are less, some show they are equally and some find they are more committed than men (Mowday et al., 1982; Vinkenburg et al., 2000; Mathieu \& Zajac, 1990). A meta-analysis performed by Lankau and Skandura (1997) had similar findings when examining organizational commitment specifically. They listed approximately equal numbers of 
empirically tested results that found women to be more committed than men, less committed than men and equally as committed as men ${ }^{2}$.

It is important to determine whether or not there are actual differences in the levels of organizational commitment of men and women for several reasons. First, as addressed by Bruning and Snyder (1983) developing strategies for increasing the commitment level of one gender may, in fact, lead to sexism or perceived differences between the genders where no differences in commitment exist. Research that only examines one gender or does not report findings where there are no differences between genders may propagate lower levels of organizational commitment due to a self-fulfilling prophecy (Bruning \& Snyder, 1983; Lefkowitz, 1994). Lefkowitz (1994) emphasizes that reported differences between men and women can encourage stereotypes, particularly that women are less committed, when a different perception may be developed if all the research were presented, including those cases where no differences were found. Rather than simply encouraging organizations to develop programs that encourage organizational commitment in one gender or the other, gender-based discrimination may even increase based on these reports (Lefkowitz, 1994). As research provides inconsistent evidence on the relationship between generation and organizational commitment (Powell, 1990), it must continue to be examined in depth.

\footnotetext{
${ }^{2}$ Studies that found women to be more committed than men were reported by Angle and Perry, 1981; Baugh, 1990; Gould, 1975; Grusky, 1966; Hrebiniak and Alutto, 1972; and Bielby and Bielby, 1988; studies that found women to be less committed than men were reported by Aranya et al., 1986; Chusmis, 1982; Euchs, 1971; and Graddick and Farr, 1983; and studies that found no difference in commitment level between genders were reported by Fry and Grenfeld, 1980; Cromie, 1981; Stevens, Beyer and Trice, 1978; and Bruning and Snyder, 1983
} 
The second, and most convincing, reason that the possible relationship between gender and organizational commitment must be examined is the large number of women in the workforce. In 2001, women comprised forty-seven percent of the Canadian labour force (Statistics Canada, 2002a). Twenty-five percent of families relied on women's earnings for at least half of the family income and fifty percent of families relied on women's earnings for between twenty-five and forty-nine percent of total earnings (Vanier Institute, 1997). Women continue to enter the workforce and currently make up almost half of the workforce yet it has not been determined whether or not they differ from men on their levels of organizational commitment. Therefore, it is important to determine whether differences exist and, if so, what impact they may have.

There are a variety of explanations given by researchers as to why women may be less, equally or more committed to the organization than men. The most notable explanation is that many researchers do not account for moderators on this relationship. Such moderators may include differing opportunities for women and men in the organization, the jobs women are more likely to hold and the caregiver responsibilities that individuals may have. Two models have been proposed to explain the different results for impacts of gender on organizational commitment: a job model and a gender model (Loscocco, 1990; Feldberg \& Glenn, 1979; Aven et al., 1993). The job model proposes that women and men are equally committed to the organization while the gender model suggests that women and men differ in their levels of organizational commitment. 
The job model (or situational model) of organizational commitment suggests that gender does not influence organizational commitment but rather the work experiences of an individual inspires organizational commitment. This suggests that treating male and female employees equally may invoke equal levels of organizational commitment and the differences in research may be accountable to discrimination (Aven et al., 1993). The gender model is based on the assumption "that women accept family roles as the chief source of their identity and fulfillment, leading to a different orientation to work from men, for whom work is paramount" (Loscocco, 1990, p. 155). It seeks to explain why women have lower levels of organizational commitment and why some believe that women are predisposed to have lower levels of organizational commitment than men (Aven et al., 1993). As research has partially supported both models, this study will present research on both models as well as some evidence that women have higher levels of commitment than men. First, research that women are more committed than men will be presented. This will be followed by research findings that women have less organizational commitment than men and, finally, research that finds that women and men are equally committed to the organization.

In 1990, Mathieu and Zajac performed a meta-analysis that correlated gender and organizational commitment. This study found that women tend to have more attitudinal commitment than men, although the magnitude of the difference was small (Mathieu \& Zajac, 1990). Much of the research today that argues that women are likely to be more 
committed to the organization than men ignores the magnitude of the difference but still uses this finding as evidence (e.g. Kacmar et al., 1999; Ik-Whan \& Banks, 2004). Mowday et al. (1982) also presented findings that women were more committed than men by examining four previous studies. Explanations offered as to why the organizational commitment levels of women may be higher include primarily reasons that would contribute to continuance commitment and not to affective commitment (Aven et al., 1993). These arguments are based on Grusky's (1966) research that noted that women had more "sunk costs" (side bets) in an organization because of the effort required for a woman to gain respect in an organization compared to men or that women do not have the same mobility as men which causes increased continuance commitment to their own organization (Aven et al., 1993; Mathieu and Zajac, 1990).

Several studies have found women to be less committed to the organization than men. Aven et al., (1993), identify several studies that have found women to be less attitudinally committed than men and Chusmir (1982) identifies the stereotype of many managers that women are less committed. Many of the reasons identified for this conclusion follow the same rationale as the gender model explained above. Women are still expected to be the primary caretakers at home which includes taking primary responsibility for the family, the children and the home itself (Bhagat \& Chassie, 1981; Reed et al., 1994, Burke, 1994a; Burke, 1994b; Marsden et al., 1993). The conflict between this role and her role within the organization may cause role overload and if the woman is unable to find stability between the two roles, according to Reed et al. (1994), she is likely to return to the family role. Chusmir (1982) also identifies this conflict 
between women's roles in society and suggests that not only the expectations of society but women themselves contribute to the problem of trying to excel at both roles. However, the pressures to succeed at their societally determined gender-role may cause them to exit the labour force. This echoes Kanter's (1977) belief that sex-role stereotyping may emphasize the family role over the work role. If the woman does not leave the labour force, as is increasingly happening, she may disengage from work and become less committed (Chusmir, 1982).

Many studies have also found evidence to support the job model of gender and organizational commitment. They have found evidence that women and men are equally committed to the organization (Aven et al., 1993; Chusmir, 1982; Russ \& McNeilly, 1995; Ik-Whan \& Banks, 2004; Singh et al., 2004). However, this relies on men and women receiving equitable opportunities in the workforce (Aven et al., 1993). Even with equitable opportunities, there is still the possibility of a difference as women generally have higher levels of environmental stress (Chusmir, 1982). Chusmir (1982) also notes that gender-role conflict may only come into play if men and women in an organization have identical job circumstances, which is unlikely. Allen et al. (1999) seem to agree with this idea because their findings indicate that women felt they were underpaid and taken for granted with respect to men.

Controlling for job-related variables has a great impact on gender related findings for organizational commitment (Singh et al., 2004). Various researchers have found that 
when job-related variables are not controlled for, a difference between levels of organizational commitment is more likely to be perceived (Singh et al., 2004; Skandura \& Lankau, 1997). Other variables that influence the relationship include age, tenure, education, income and occupational level (Skandura \& Lankau, 1997; Bruning \& Snyder, 1983; Lefkowitz, 1994)

A final perception regarding gender and organizational commitment may be as a result of women's career paths. Women are more likely to have different career patterns with more career breaks following child-birth (Healy, 1999). Some managers and researchers share the view that women may be less committed to the organization because they are on the "Mommy Track" (Aven et al., 1993). Whereas men's career development is relatively continuous, women's career development can be disjointed because of interruptions for childbearing and childrearing. These interruptions are considered by some to cause lower levels of commitment (van der Velde et al., 2003). Bielby and Bielby (1988) identify one possible effect these interruptions may have on women's careers. Time taken out of the labour force by women for childbearing will not increase their marketability while men, if they do take time out of the labour force, often do so for schooling or military service which will both increase their marketability (Bielby \& Bielby, 1988). This may result in women being in lower level positions than men, which, as noted above, has a possible effect on the relationship between gender and organizational commitment. 
The above discussion demonstrates that there is little agreement on whether or not there are gender differences in organizational commitment. However, many researchers agree that if men and women do not have the same levels of organizational commitment, it is likely due to factors that moderate the relationship between gender and organizational commitment as noted above. It is therefore important to include gender as a covariate so that if a generational effect is found in organizational commitment, we know that it is due to generation and not due to gender. Because so many studies show that there is a difference, it must be included as a covariate. In addition to the above, in the initial study, Higgins and Duxbury (2002) found that women were over-represented in the sample (with women comprising $55 \%$ of the sample but only $47 \%$ of the labour force). Therefore, to generalize the findings from this research to the employed Canadian population, gender must be controlled for.

\subsubsection{Industry Sector}

Industry sector is the second covariate considered in this analysis. Industry sector is operationalized in this study to include: private-sector, public-sector and not-for-profit sector (i.e. health care, education and protective services). This is the same definition used by Higgins and Duxbury (2002). Higgins and Duxbury (2002) found a relationship between industry sector and commitment when gender was controlled for. This may be due to differences in:

- attitudes and aspirations of employees (Boyne, 2002);

- managerial styles; 
- human resource practices;

- performance measures and rewards;

- goal specification (Goulet \& Frank, 2002);

- type of jobs;

- working conditions;

- consequences of failure; and/or

- job security (Higgins and Duxbury, 2002; Goulet \& Frank, 2002).

Goulet and Frank (2002), for example, observed that private-sector employees were most committed to their organization followed by not-for-profit employees. Public sector employees were found to have the lowest level of organizational commitment. They note, however, that earlier literature suggests that public sector and not-for-profit sector employees are likely to be more committed due to the intrinsic rewards of their jobs and the increased job security in their positions (Goulet \& Frank, 2002). However, some earlier research finds that private-sector organizations are better at encouraging organizational commitment than public-sector organizations for the same differences listed above (Buchanan, 1974b). Other, slightly more recent, research found either public-sector employees to be more committed to the organization than private-sector employees or no significant difference (Balfour \& Wechsler, 1991; Kline \& Peters, 1991; Steinhaus \& Perry, 1996). In more current research, Boyne (2002) argues that it is difficult for public employees to see the connection between their contributions and their organization's success, which may decrease the intrinsic rewards and cause them to have 
lower levels of organizational commitment. Alatrista and Arrowsmith (2004) suggest that not-for-profit employees tend to have lower rates of pay which affects their levels of organizational commitment unless very strong human resource practices for motivation and commitment are in place. Duxbury and Higgins (2003) found similar results to those found by Goulet and Frank (2002). Duxbury and Higgins (2003) found that privatesector employees were the most committed to their organization followed by not-forprofit and public-sector employees. They also suggest that sector of employment and job type are likely to have a greater influence on organizational commitment than gender and life cycle stage (Duxbury and Higgins, 2003). In this study, the fact that public sector workers were older, on average, than private sector or not-for-profit sector employees provides further support for its inclusion as a covariate in this analysis. For these reasons, industry sector must be considered a possible confound when examining the relationship between generational cohort and organizational commitment.

\subsubsection{Job Type}

Job type is the third covariate considered in this analysis. In order to examine this variable, job type was operationalized to include three alternatives: managers, professionals and non-managers who are not professionals. Within this variable, only full-time employees were studied as part-time employees or temporary employees are expected to have vastly different levels of organizational commitment (Tansky \& Gallagher, 1997; Gakoric \& Tetrick, 2003). 
Duxbury and Higgins (2003), using the original dataset for this thesis, found that males in managerial and professional roles had higher levels of organizational commitment (with 54.1 percent saying they had high commitment) than those who were neither managers nor professionals (with only 46.2 percent saying they had high commitment). The same study suggested that an employee's level of organizational commitment was more dependent on the type of work being done and the work environment than on external demands (Duxbury \& Higgins, 2003). As job type has already been determined to affect organizational commitment in this sample, it must be considered a confound for this study. Support for this decision can be found in the literature.

Managers and professionals have been found to have higher levels of organizational commitment (Wang \& Armstrong, 2004). This is possibly because of increased flexibility and personal control over their work conditions despite having higher perceived levels of job-stress (Duxbury \& Higgins, 2003). Based on the differences in the positions and rewards experienced by managers and professionals compared to non-managers who are not professionals, job type should help predict commitment (Higgins \& Duxbury, 2002) as people are likely to have a higher level of commitment to an organization that provides them with both intrinsic and extrinsic rewards (West, 2004; Young et al., 1998). 
Although the study performed by Higgins and Duxbury (2002) did not examine professionals and managers separately, the current study also considers that there may be differing levels of organizational commitment experienced between employees in these different job types. Wang and Armstrong (2004) found managers to have higher levels of organizational commitment than non-managers. In the 2002 study by Higgins and Duxbury, they also found that technical workers and professionals did not differ on their levels of organizational commitment and the only differences found were between managers and professionals and those in other positions. Examining the relationship between the groups will provide further insight as professionals may have increased mobility due to the education and training required to obtain their position. As the literature indicates that higher levels of education may be related to organizational commitment (Higgins \& Duxbury, 2002), the additional training of professionals may increase their levels of organizational commitment.

\subsubsection{Tenure}

Tenure refers to the number of years an employee has maintained employment in his or her current organization. Since tenure in the organization has been found to correlate significantly with organizational commitment (Mowday et al., 1982) it needs to be included as a covariate during data analysis. This decision is supported by the fact that tenure is also likely linked to generational membership as older employees have been in the workforce longer and may therefore have more tenure in the organization than those who are younger. Tenure in this analysis is a continuous variable ranging from 
one to thirty-five years with the current employer. Those with less than one year of tenure in their current organization are not included in this study as some research has found that organizational commitment in the first year of employment may not be consistent with later organizational commitment, as noted above (Meyer \& Allen, 1988; Werbel \& Gould, 1984).

\subsubsection{Life Cycle Stage}

Life cycle stage is also included as a covariate in this analysis. Inclusion of this variable in the analysis adds to the body of knowledge in the area by responding to the criticism, noted earlier, that much of the commitment research is based on an outdated conceptualization of "family" (i.e. the traditional family with a male breadwinner). Canadian employees now have more responsibilities outside of work as families have changed over time (Duxbury \& Higgins, 2003). The "typical family" is now a dualincome family and there are more single parent families which are typically headed by women (Higgins \& Duxbury, 2002). As noted by Jans (1989), high organizational involvement may preclude involvement in other life roles (such as marital and parental roles). This is because family life and work life cannot be considered separately since each of these aspects of an individual's life will intrude on the other (Jans, 1989). Employees in dual income families do not have the option of segregating their work role and their family role as women are now facing increasing work demands and men are taking a more significant role in child-rearing (Higgins \& Duxbury, 2002). It would 
therefore follow that when involvement or commitment in other life roles is high, organizational commitment may necessarily be lower.

As described by Higgins and Duxbury (2001, p. 17), life cycle stage can be "determined by age and normative life events (e.g. marriage, children)". Marriage and parenthood are typically used to operationalize lifecycle because they represent significant, measurable, life roles of an individual that are distinct from their work life role and, therefore, might affect an individual's level of organizational commitment.

In this study, both marriage and parenthood were considered to determine in which life cycle stage the individual belongs. Life cycle stage was operationalized in this study using the typology proposed by Gutek et al. (1981): single non-parents, single parents, married/partnered non-parents and married/partnered parents (see Figure 3.2). Although Gutek et al.'s typology was originally developed for the study of women, in this thesis, it has been extended to include both men and women.

Figure 3.2 - A typology of working women (Gutek et al., 1981, p. 9)

\begin{tabular}{|c|c|c|c|}
\hline & & \multicolumn{2}{|c|}{ Dependents } \\
\hline & & No & Yes \\
\hline \multirow{2}{*}{$\begin{array}{l}\text { Sole } \\
\text { support }\end{array}$} & No & $\begin{array}{l}\text { Group 1: } \\
\text { Married } \\
\text { No children }\end{array}$ & $\begin{array}{l}\text { Group 3: } \\
\text { Married } \\
\text { Children }\end{array}$ \\
\hline & Yes & $\begin{array}{l}\text { Group 2: } \\
\text { Not married } \\
\text { No children }\end{array}$ & $\begin{array}{l}\text { Group 4: } \\
\text { Not married } \\
\text { Children }\end{array}$ \\
\hline
\end{tabular}


It should be noted that in this thesis Groups 1 and 3 were operationalized to include only dual income couples (i.e. both partners work full time outside the home) who both worked 37 hours or more per week. This was done to reduce the possible impact that time in work could have on commitment. For example, married or partnered couples in a "traditional" relationship in which only one partner works may have a higher need for income. This may cause attachments to the organization that are independent from organizational commitment. Alternatively, part-time employees may have very different levels of commitment than their peers who work full-time (Higgins \& Duxbury, 2002).

The research literature can be used to support the decision to control for marital status and parental status. A number of studies have found that marital status and parental status have an impact on organizational commitment. For example, Mellor et al. (2001) have found evidence to suggest that both marital status and number of children may affect organizational commitment. They report that marriage may increase organizational commitment by increasing the resources an individual has to cope with life outside of work while the presence of children may decrease organizational commitment by limiting the time and energy for work involvement (Mellor et al., 2001). For example, a spouse can help an individual care for their children, thereby allowing the employee to focus on work. Other researchers have found similar results regarding the impact of marriage on an individual's level of organizational commitment (Mathieu \& Zajac, 1990; Hrebiniak \& Alutto, 1972; Kacmar et al., 1999; Jans, 1989). Hrebiniak and Alutto (1972) 
suggest that this may be due to different expectations of the work relationship based on marital status.

Those with parental responsibilities may have more demands on their time than those without (Higgins \& Duxbury, 2002) which may affect their levels of commitment. There exists a common belief that parents are likely to be less committed to the organization as they are more committed to other aspects of their lives and have more demands on their time (Korabik \& Rosin, 1995; Higgins \& Duxbury, 2002; Aryee \& Debrah, 1992). As noted previously, however, little empirical work exists in this area to support or refute this contention (Aryee \& Debrah, 1992).

In this study the conceptualization of life cycle stage is extended to include single parents. This was done to help elucidate the relationship between commitment and being a single parent, an area that is relatively unexplored at this point in time. There are a number of reasons why such research is timely. First, single parents can be considered to be in a relatively unique family situation in that they have particular challenges associated with demands of both work and their home lives while they lack the emotional and financial support of a partner (Higgins \& Duxbury, 2002). Unfortunately, the relationship between single parents and organizational commitment has been found to be somewhat contradictory in the literature. For example, while Eaton (2001) found that single parents, along with employees with a homemaker as a spouse, had the highest levels of commitment. Coyne (2002) observed that single parents were more committed 
to the needs of their children than to the organization. Second, the number of single parent families is increasing in Canada, making the commitment levels of this group of greater importance to Canadian employers. The number of lone parent families in Canada increased by 173,680 between the years of 1996 and 2001 with totals of 1,137,510 and 1,311,190 respectively (Statistics Canada, 2002c). This caused the percentage of lone parent families to increase from 14.5 percent of families in 1996 to 15.7 percent of families in 2001 . This makes lone parent families the fastest growing segment of the Canadian population. The examination of the commitment levels of single parents will be a major contribution of this thesis as few empirical studies exist in this area.

\subsubsection{Organization of Employment}

The final covariate in this analysis is organization of employment. The need to control for organization of employment in this analysis of organizational commitment is supported by the fact that a number of studies show a strong relationship between employment practices and organizational commitment (Ngo \& Tsang, 1998; Agarwala, 2003; Guzzo \& Noonan, 1994; Haar \& Spell, 2004). Other researchers have found that the organization of employment can increase employees' commitment to the organization by aligning individuals' career goals with company goals, by focusing on the relationships with employees, by redesigning work to give more variety and autonomy (Johnson, 2005), and by increasing communication in the organization (Manion, 2004). Human resource practitioners, in particular, can affect organizational commitment by 
incorporating mentoring programs into the organization (Payne \& Huffman, 2005), by promoting public recognition of employee accomplishments (West, 2004) and by establishing clear job descriptions with clear roles for employees (Manion, 2004).

Every organization is different in terms of its relationship with its employees, its reward programs, the type of work performed and its human resource initiatives. As these initiatives are considered to affect organizational commitment, every organization may engender differing levels of organizational commitment (Haar \& Spell, 2004; Virick et al., 2004; Manion, 2004). Therefore, to determine whether the difference in organizational commitment exists due to the generation itself or whether it is outweighed by the differences between the organizations, generations must be examined within individual organizations. 


\section{$4 \quad$ Methodology}

This chapter examines the methodology used to study the research questions listed in the previous chapter. First, the sample examined in this thesis is discussed. Next, the procedure for the analysis of the research data is outlined. Finally, the validity of the data is discussed including the testing of assumptions.

\subsection{Sample}

The research sample used in this study is taken from the 2001 National Work-Life Conflict Study conducted by Linda Duxbury and Chris Higgins. The sample for the 2001 study was developed in the following way (Duxbury \& Higgins, 2001). Public, private and not-for-profit organizations were obtained from a mailing list of organizations with more than 500 employees provided by Dun and Bradstreet. The final sample of qualifying organizations consisted of 2978 organizations of which 1482 were public sector or not-for-profit and 1496 were private sector. Letters of introduction were sent to the Chief Executive Officer (CEO)/Deputy Minister and the Head of Human Resources explaining the purpose of the study and inquiring if the organization was interested in participating (Duxbury \& Higgins, 2001). Organizations that expressed interest were given additional information. Ultimately, 100 organizations or $3.4 \%$ of the total sample were selected to participate in the study. The sample included 40 private sector organizations, 22 public sector organizations and 38 not-for-profit organizations (Higgins 
\& Duxbury, 2002). The total sample was used to examine all the primary research questions and the first five supplementary questions.

Approximately 120,000 questionnaires were distributed by the organizations themselves and retrieved by their mailrooms in an anonymous manner. A response rate of $26 \%$ was achieved, resulting in 31,571 usable responses. Given the length of the questionnaire (twelve pages expected to take 30 to 60 minutes to complete) and the inability to send a reminder, this response rate is considered acceptable (Higgins \& Duxbury, 2002). The survey (see Appendix F for relevant sections) included nine sections: your job; your manager; time management; work, family and personal life; work arrangements; work environment; family; physical and mental health; and "information about you".

For the purpose of this thesis, the sample will be reduced to those individuals possessing the following characteristics: belong to either the Baby Boom Generation or Generation X (aged between 20 and 53 in 2000), be full time employees and either be single with no children, single with children, married/partnered with no children or married/partnered with children. As noted previously, the sample was further restricted to couples where both partners were employed full-time outside the home and employees who had worked in their current organization for at least one year. 
The final supplementary question used the four largest organizations in this study to determine the impact the organization of employment has on organizational commitment. These organizations were chosen because they had sufficiently high sample sizes to test the complete model shown in Figure 3.1. These organizations have sample sizes of $1276,969,1039$ and 2061 and belong to the public sector, the public sector, the not-for-profit sector and the private sector, respectively.

Finally, in order to determine the average tenure in the organization, several deletions had to be made to the data. Several data were necessarily false due to the fact that the tenure of the individual in the organization exceeded the age of the individual. This was either due to false responses from the sample or data entry errors. As only individuals aged 20 to 54 are being examined and individuals who have worked at the organization less than a year are not being examined (as mentioned above), individuals who have worked in their organization for one year or less or more than forty years were removed from the sample for this calculation.

The final sample consisted of 15461 individuals aged 20 to 54 at the time of the study. Of these, 11609 respondents $(75.1 \%)$ were from the Baby Boom Generation and $3852(24.9 \%)$ were from Generation X. Males represented $41.1 \%$ of the sample and females comprised the remaining $58.9 \%$ of the sample. Sixty percent of the sample was married with children, $16 \%$ was married with no children, $15 \%$ was single with no children and $10 \%$ of the sample comprised of single parents. In terms of industry sector, 
$48 \%$ belong to the public sector, $21 \%$ to the private sector and $31 \%$ for the not-for-profit sector. Non-manager/non-professionals made up $50 \%$ of the sample for job type, $34 \%$ of the sample comprised of professionals and $16 \%$ of the respondents were managers. The mean tenure for the entire sample was 14 years.

\subsubsection{Variable Measurement}

The following section examines how each of the variables used in the model were measured by the survey found in Appendix F.

\subsubsection{Dependent Variable}

Organizational commitment was measured using the OCQ, developed by Mowday et al. (1982). The data reported in this thesis was collected by Duxbury and

Higgins (2001) as part of their National Study on Work, Family and Lifestyle (see Section 4.1 for more of a discussion of their data). The study by Duxbury and Higgins (2003) found that the Cronbach's alpha for organizational commitment was 0.90 . Therefore, the reliability of this measure is very high and useful for this study.

\subsubsection{Independent Variable}

Respondents born between the years 1947 and 1964 were included in the group as Baby Boomers and respondents born between the years 1965 and 1980 were included in the group as members of Generation X. Respondents were classified into generations based on their years of birth, which were used to calculate their ages at the time of the 
research. Respondents who listed their ages as being between 36 and 53 (in the questionnaire from 2000) will be considered Baby Boomers and those respondents who listed their ages as being between 20 and 35 (in the questionnaire from 2000) will be considered members of Generation X.

The graph of fertility rates of women shown in Chapter 2 (Figure 2.6) was used to divide the generations into subgroups (see Appendix E). First, bold lines were placed at the beginning and end of each generation $(1947,1964$ and 1980) to view the graph in terms of generations. Next, two methods were used to identify possible subgroups. Method one involved dividing each generational cohort into three approximately equal groups with respect to years. For the second method, the chart in Appendix E was examined to determine where peaks, valleys and points of inflection occurred with respect to birth rate. The first group of Baby Boomers (Early Baby Boomers) was determined to finish at the end of the fastest increase in births (1952). The subgroup for Middle Baby Boomers began at this point and ended just prior to the sharp decline in the number of births in 1958. Late Baby Boomers were deemed to occur from 1958 to 1964 in a period of high, yet declining, births. By definition Generation X began with the sharpest decline in birth rates in 1965. This year, would therefore also demark the Early Generation X group. The birth years for Early Generation X ended where the number of births stabilized, briefly in 1969. Middle Generation X is defined to begin in 1969 and end in 1974 , the time when the birth rate again began to stabilize. The Late Generation X subcohort begins in 1974 when the Middle Generation X subcohort ends and ends in 
1980, the year that this study defines as the end of the Generation X cohort. Appendix E shows this breakdown of the sub-cohorts in dotted lines.

The years dividing the sub-cohorts were then translated into the ages of individuals at the time of the study (2000) and generation sub-cohorts were broken down into six groups. Generation X consisted of Late Generation Xers (aged 20 to less than 26), Middle Generation Xers (aged 26 to less than 31) and Early Generation Xers (aged 31 to less than 36). The Baby Boomer Generation consisted of Late Baby Boomers (aged 36 to less than 42), Middle Baby Boomers (aged 42 to less than 48) and Early Baby Boomers (aged 48 to less than 53) as shown in Table 4.1.

Table 4.1 - Generational Sub-cohorts

\begin{tabular}{|l|l|}
\hline \multicolumn{1}{|c|}{ Age } & \multicolumn{1}{c|}{ Group } \\
\hline 20 to less than 26 & Late Generation Xers \\
\hline 26 to less than 31 & Middle Generation Xers \\
\hline 31 to less than 36 & Early Generation Xers \\
\hline 36 to less than 42 & Late Baby Boomers \\
\hline 42 to less than 48 & Middle Baby Boomers \\
\hline 48 to less than 53 & Early Baby Boomers \\
\hline
\end{tabular}

\subsubsection{Covariates}

Gender is a categorical variable consisting of two groups: males and females. It was simply measured, as can be seen in Appendix F, by asking respondents to state whether they are male or female. 
The respondent's job type was determined by asking the individual to identify whether his or her work was managerial, professional, technical, administrative, clerical, retail, production, other or homemaker. The responses were then divided into three categories: managerial, professional and non-managers who are not professionals. The managerial and professional categories were the same as the respondent's answer and the final category consisted of all answers other that managerial, professional or homemaker.

The original researchers, Duxbury and Higgins, coded the industry sector to which an individual belonged. Organizational membership was determined based on the identification number given to that particular questionnaire. Organizations were then coded as being either from the public sector, the private sector or the not-for-profit sector. These organizations were simply grouped into their industry sectors based on this coding.

Tenure was requested in the questionnaire by simply asking the individual how many years they have worked for the organization. Other than the adjustments listed above for responses that were necessarily incorrect, the number of years the individual indicated was used as their tenure within the organization.

The respondent's life cycle stage was determined in a similar manner by asking the individual for his or her marital and parental statuses. This allowed individuals to be placed in one of four categories according to their answers: single non-parents (including 
individuals who are single, divorced or widowed), single parents, married non-parents and married parents.

\subsubsection{Non-response Analysis}

Non-response or missing data occurs when the individual being sampled does not provide the information required by the survey (Groves et al., 2002). For the purposes of this study, when an individual did not respond to all the questions on the questionnaire that are required for the analysis, this was considered non-response. For example, those individuals who did not answer the question regarding their age could not be placed in appropriate generational categories necessary for this study and any remaining responses were not usable. Therefore, their record would show missing data. Non-response can cause difficulties if it is not missing at random, because it can be correlated with certain attitudes (Tabachnick \& Fidell, 1983). For example, if organizational commitment answers were missing from many public sector employees, the lack of an answer may demonstrate an underlying attitude (i.e. lack of organizational commitment) that could bias the findings.

The sample was examined to determine what steps to take in the event of nonresponses. Although most of the questions were answered by most of the respondents, it is important to verify that there was no systemic pattern for those individuals who didn't answer certain questions. Tabachnick and Fidell (1983) suggest testing the mean difference between the values that are missing and those that are present. Since the 
responses without ages were unusable for the purposes of this study, the only other variable that could be tested for the mean difference was organizational commitment. Unfortunately, the mean score for organizational commitment clearly cannot be determined in cases where this question was not answered.

Tabachnick and Fidell (1983) suggest that "if only a few units of data are missing from a large data set, the problems created are not so serious and almost any procedure for handling them should yield similar results" (Tabachnick \& Fidell, 1983, p. 68). As Stevens (1996) describes groups larger than 200 as a very large sample size, this data set qualifies as a large data set. Little and Rubin (1983) suggest the removal of partially observed cases due to the categorical nature of some of the variables included in the framework and the large sample size (see also Tabachnick and Fidell, 1983 and Stevens, 1996). The large sample size enables the removal of partially observed cases because there are still ample records upon which to base the analysis. Specifically, if respondents did not respond to questions on the independent or dependent variables (age to determine generation or any of the organizational commitment questions), their entire response was removed from the dataset prior to the analysis. Without either one of these variables, the analysis could not be properly performed.

As traditional methods of testing the mean differences between the missing data and the present data are impossible to calculate, the data was examined to determine whether a significant proportion of the sample was missing values for the variables of 
interest. The proportion of missing data for members of Generation X and Baby Boomers was compared to ensure that one group was no more likely to skip a question than the other. All organizational commitment questions were answered by $98.0 \%$ of respondents with similar results $(98.6 \%$ and $97.8 \%$ for members of Generation $X$ and Baby Boomers respectively). Of all the cross-tabulations of the intervening variables, job type had the lowest response rate $(97.5 \%)$ with response rates for both generations being similar $(97.6 \%$ and $97.4 \%$ for members of Generation $X$ and Baby Boomers, respectively).

As these percentages do not differ significantly, we can assume that no response bias exists with respect to the key variables of interest. Therefore, as previously mentioned, those individuals who did not answer all the organizational commitment questions and the age question were not included in this study. After removing records with non-response on key variables, the final sample for this thesis would still be considered extremely large as it consisted of 15461 respondents.

\subsection{Analysis}

This section explains the analyses used in this thesis to answer the research questions. First, statistical and practical significance will be examined in order to provide a framework for the analyses. The ANOVAs, ANCOVAs and regressions used to answer the primary research questions were then discussed. Next, the methods used to explore 
the supplementary research questions were discussed. Finally, assumptions required for the statistical techniques were explained and tested.

\subsubsection{Statistical and Practical Significance}

Due to the large sample size, it is necessary to examine both the statistical and the substantive (or practical) significance of all the findings. The probability of rejecting a false null hypothesis (power) is dependent on the $\alpha$ level chosen, the sample size and the effect size. With a very large sample size, which Stevens (1996) describes as groups larger than 200 , there is a high likelihood that effects will be declared statistically significant at the .05 level of significance. The implication of this for this study (sample size of $n=15461$ ) is that all statistically significant differences must be examined to determine whether or not the difference in means is large enough to be practically significant (Stevens, 1996).

Stevens (1996), proposes three methods for determining practical significance. These are:

1. confidence intervals

2. effect size measures

3. measures of association

Confidence intervals for the difference in the population means were examined first, to determine whether or not there was the possibility of a practically significant 
difference. Stevens (1996) suggests that a "reasonable" difference in the values between the two groups must exist for there to be practical significance. To remain conservative in this study, differences of more than 0.1 were considered to have possible practical significance.

When the difference in means was found to be statistically significant, Cohen's effect size measure (or Cohen's d) was used to compare the two groups (Baby Boomers and members of Generation X) on the number of standard deviations that separate them (Stevens, 1996).

Measures of association are recommended by Stevens (1996) to be used with caution. They examine the amount of variance explained by the model $\left(\mathrm{R}^{2}\right)$. However, in some cases a model explaining ten percent of the variance may be practically significant while in others much larger percentages of the variance must be explained in order to be practically significant (Stevens, 1996). Therefore, the variance explained by the model will be examined but with caution.

\subsubsection{Analysis for Research Question 1}

In order to test the first research question as to whether organizational commitment is associated with generational membership, a one-way ANOVA was performed. One-way ANOVA was chosen because there is one dependent variable (generation) and one independent variable (organizational commitment) being examined. 
Prior to performing the ANOVA itself, the ANOVA assumptions will be addressed. Namely, that the observations are normally distributed on the dependent variable of each group, that there is homogeneity of variance, and that the observations are independent (Stevens, 1996). A discussion of how this was done can be found in Section 4.2.7.

\subsubsection{Analysis for Research Question 2}

One-way analysis of covariance (ANCOVA) will be used (see Appendix G) in order to examine the differences in levels of organizational commitment between Baby Boomers and members of Generation $\mathrm{X}$ when accounting for the covariates (research question 2),. According to Tabachnick and Fidell (1983), "One-way analysis of covariance is designed to assess the effects of one independent variable (groups) on a single dependent variable after the effects of one or more other potential independent variables (covariates) are accounted for (p.55)". In the model presented for this study, there is one independent variable in the relationship of interest (generation) that is composed of two groups: the Baby Boom Generation and Generation $\mathrm{X}$ and one dependent variable (organizational commitment). The covariates are five of the six remaining variables presented previously: gender, tenure, life cycle stage, job type, and industry sector. As only tenure is a continuous variable, the categorical variables must be broken into "dummy variables" as suggested by Stevens (1996). See Appendix H for a description of how and why dummy variables are used. Organization of employment is examined in a later research question in order to properly test its impact on organizational commitment. Practical significance was then tested as described above. 
Prior to performing the ANCOVA, it was necessary to determine if all assumptions or requirements underlying its use were met. Specifically, the ANOVA assumptions listed above had to be addressed in addition to ANCOVA assumptions. These assumptions are that there is a linear relationship between the dependent variable and covariates, that there is a homogeneity of regression slopes, and that the covariate is measured without error (Stevens, 1996). Tabachnick and Fidell (1983) also addressed the issue of multicollinearity which had to be resolved prior to proceeding with the ANCOVA and is described below.

\subsubsection{Analysis of Research Questions 3 and 4}

The third research question, regarding the ability of generation to predict organizational commitment, will be tested using hierarchical regression. The significance of the model and the $\mathrm{R}^{2}$ value describing how much of the variance in organizational commitment is explained by the model was used to determine how well generation predicts organizational commitment. An additional test was performed to compare the predictive abilities of age (as a continuous variable) and generation.

The assumptions associated with regression were tested prior to this analysis being run. The regression model assumes that "errors are independent and follow a normal distribution with constant variance" (Stevens, 1996, p. 92). This assumption was checked by examining the scatterplot of the standardized residuals compared to the 
predicted values and checking for random scatter. If the scatterplot has a concentration of values along the center with random scatter around it in an approximate rectangular shape, the assumptions of normality, linearity and homoscedasticity of residuals are considered met (Tabachnick and Fidell, 1983).

Hierarchical regression was used as follows. Organizational commitment and the five primary covariates were first entered into the model. Generation was then added to the model and the $\mathrm{R}^{2}$ and significance were examined. To compare the predictive ability of generation versus age, generation was removed from the model and age added. The significance of the model including age was then examined as well as the $\mathrm{R}^{2}$ value. The $\mathrm{R}^{2}$ and significance of the model including generation and the model including age were then compared to see which explained more of the variance on organizational commitment.

\subsubsection{Analysis of Research Question 5}

ANCOVA was also used to determine whether or not organizational commitment differs significantly between sub-cohorts within the generations (research question 5). There continues to be one dependent variable (organizational commitment) as well as one independent variable (generational cohort) and the same five primary covariates (gender, tenure, industry sector, job type and life cycle stage). Three ANCOVAs will be run, one representing the Baby Boomer Generation, one representing Generation $\mathrm{X}$ and one representing both generations. The first ANCOVA represents the three Baby Boomer 
groups: Early Baby Boomers, Middle Baby Boomers and Late Baby Boomers. The second represents the three Generation X groups: Early Generation Xers, Middle Generation Xers and Late Generation Xers. The third includes all six groups of subcohorts. The breakdown of the sub-cohorts can be seen in Table 4.1. The statistical results are discussed in chapter 5 with a reflection on statistical significance compared to practical significance as determined by the values of Cohen's $d$ and $R^{2}$ described above.

\subsubsection{Analysis of Supplementary Research Questions 1 to 5}

After cleaning the dataset, several sets of analyses were done in order to describe the sample with respect to the variables of interest: gender ( $\%$ male, $\%$ female), life cycle stage (\% single with no children, $\%$ single with children, $\%$ married with no children, $\%$ married with children), industry sector ( $\%$ public sector, $\%$ private sector, $\%$ not-forprofit sector), job type ( $\%$ manager, $\%$ professional, $\%$ non-managers who are not professionals), tenure (mean and standard deviation) and organizational commitment (mean and standard deviation). For each of these variables, analyses were done using the total sample as well as two sub-samples which were created based on the generational membership of the respondent (Generation $\mathrm{X}$ and Baby Boom).

\subsubsection{Analysis of Supplemental Research Question 6}

Finally, analyses will be performed to determine whether the impact of generation on organizational commitment can be seen more clearly when accounting for the 
organization of employment (supplemental research question 6). As noted previously only four of the organizations that participated in the study have large enough n's to permit testing of the full model. These four organizations have sample sizes of 1276 , 969,1039 and 2061 and belong to the public sector, the public sector, the not-for-profit sector and the private sector, respectively. An ANCOVA was performed on each of the four organizations to examine the impact of the four remaining covariates (without industry sector) on the model that included organization of employment, generation, and organizational commitment

\subsubsection{Assumption Testing}

This section outlines methods used to test the assumptions required for the use of ANCOVA. Tests used to determine whether multicollinearity exists in this sample are presented first. This is followed by a discussion of other tests required by ANCOVA.

\subsubsection{Multicollinearity}

Each of the ANOVAs, the ANCOVAs and the regressions assume that there is no multicollinearity between the variables. Multicollinearity (moderate to high correlations among the predictor variables) produces difficulties for researchers by reducing the amount of the variance that can be explained by the explanatory variables because two or more variables may be measuring the same thing (Stevens, 1996). Multicollinearity can cause three problems for researchers (Stevens, 1996).

1. It limits the size of $\mathrm{R}$ (and $\mathrm{R}^{2}$ ) because the same variance on the dependent variable is explained by two or more predictor variables. 
2. It makes determining the importance of predictors difficult if they're highly correlated with another, or a combination of other, predictors which gives false results

3. It increases the variances of the regression coefficients which also give false results in the analysis

Several methods for checking for multicollinearity in a data set exist. In this thesis, the recommendations of Stevens (1996) and Tabachnick and Fidell (1983) were followed. They suggest:

1. Examining the Pearson correlations

2. Examining the squared multiple correlations for the predictors

The Pearson correlations between all the variables in the model were calculated first to determine whether or not any of the variables were significantly related. Franzblau (1958) describes intercorrelations of less than .40 as being relatively low and intercorrelations of more than .80 as being high (see Table 4.1).

Table 4.1 - Pearson Correlation Ranges (Franzblau, 1958)

\begin{tabular}{|l|l|}
\hline Pearson Correlation & Level of correlation \\
\hline $0-0.2$ & None or negligible \\
\hline $0.2-0.4$ & Low degree \\
\hline $0.4-0.6$ & Moderate degree \\
\hline $0.6-0.8$ & Marked degree \\
\hline $0.8-1$ & High level \\
\hline
\end{tabular}


The Pearson correlations are shown in Table 4.2. All correlations are significant (other than the correlation between life cycle stage and industry sector), which is due to the large sample size rather than multicollinearity. The remainder of the intercorrelations are considered to be low or negligible. Therefore, it can be concluded from these findings that little multicollinearity exists in this dataset and no variables are considered redundant.

Table 4.2 - Pearson correlations between variables

\begin{tabular}{|l|l|l|l|l|}
\hline & $\begin{array}{l}\text { Life } \\
\text { Cycle } \\
\text { Stage }\end{array}$ & $\begin{array}{l}\text { Industry } \\
\text { Sector }\end{array}$ & Tenure & Job Type \\
\hline $\begin{array}{l}\text { Life Cycle } \\
\text { Stage }\end{array}$ & 1 & .010 & $.159 * *$ & $-.087^{* *}$ \\
\hline $\begin{array}{l}\text { Industry } \\
\text { Sector }\end{array}$ & & 1 & $.056^{* *}$ & $-.077^{* *}$ \\
\hline Tenure & & & 1 & $-.062^{* *}$ \\
\hline Job Type & & & & 1 \\
\hline
\end{tabular}

To check this conclusion, the squared multiple correlations for each of the predictors were calculated. Whereas Pearson correlations show the simple correlation between two variables, a squared multiple correlation is a linear relationship between that variable and all remaining variables. The squared multiple correlation (SMC) is obtained by performing a series of multiple regressions. In each multiple regression, a different variable is used as the dependent variable and all others are used as the independent variable (Tabachnick \& Fidell, 1983). The tolerance level of the variable is calculated as 1 minus the SMC for that variable. Low tolerances (values near 0 ) demonstrate a high 
level of multicollinearity and high tolerances (values near 1) demonstrate a low level of multicollinearity (Tabachnick \& Fidell, 1983). The tolerances of the explanatory variables used in this analysis are shown in Table 4.3. When Table 4.3 is examined, it is clear that the tolerances for all variables in this study are suitably high. The lowest values are .700 , which is a sufficiently high tolerance (Stevens, 1996).

Table 4.3 - Tolerance of explanatory variables

\begin{tabular}{|l|l|l|l|l|l|l|}
\hline $\begin{array}{l}\text { Dependent } \\
\text { Variable }\end{array}$ & \multicolumn{5}{|l|}{ Independent Variable } \\
\hline & Generation & Gender & Tenure & $\begin{array}{l}\text { Life Cycle } \\
\text { Stage }\end{array}$ & $\begin{array}{l}\text { Industry } \\
\text { Sector }\end{array}$ & Job Type \\
\hline Generation & & .958 & .945 & .956 & .986 & .964 \\
\hline Gender & .721 & & .920 & .990 & .988 & .700 \\
\hline Tenure & .925 & .989 & & .964 & .922 & .963 \\
\hline $\begin{array}{l}\text { Life Cycle } \\
\text { Stage }\end{array}$ & .983 & .967 & .727 & & .957 & .721 \\
\hline $\begin{array}{l}\text { Industry } \\
\text { Sector }\end{array}$ & .969 & .702 & .964 & .722 & & .920 \\
\hline Job Type & .700 & .981 & .717 & .924 & .988 & \\
\hline
\end{tabular}

As both the tolerance levels and the correlation levels of the predictor variables are acceptable, we can determine that multicollinearity will not cause problems in this data set.

\subsubsection{2 - Verification of Assumptions}

Section 4.2.8.2 discusses a variety of assumptions that were proved or disproved when examining the sample. 


\subsection{Assumptions Associated with ANOVA}

For all ANOVAs three assumptions were tested: that the observations are normally distributed on the dependent variable of each group, that there is homogeneity of variance, and that the observations are independent (Stevens, 1996). The data was first examined for the assumptions regarding the ANOVA between organizational commitment and generation. The histogram of organizational commitment revealed a normal distribution. This finding is consistent with the central limit theorem which states "the sum of independent observations having any distribution whatsoever approaches a normal distribution as the number of observations increases" (Stevens, 1996, p.242). Stevens continued by saying that at 50 observations there is an approximation of normality. As the number of observations in this study is 15461 , the central limit theorem helps confirm the normality of this sample.

Testing the assumption of homogeneity of variances was slightly more difficult due to the nature of the data. Levene's test of homogeneity of variances was used with a significance level of .01 . This test found a p-value of .003 meaning that the null hypothesis (that the variances of the groups are equal) is rejected. Therefore, the sizes of the groups need to be examined with respect to their variances (Stevens, 1996). Baby Boomers comprised the larger group $(n=11609)$ and Generation $X$ comprised the smaller group $(\mathrm{n}=3852)$. When the variances were examined for both groups, it was found that the large group (Baby Boomers) had a variance of .640 and the small group (members of Generation X) had a variance of .604. Stevens (1996) notes that when the 
larger group has a larger variance, the $F$ statistic is conservative and the actual $\alpha$ is smaller than the level of significance. Therefore, the tests will be more conservative than the noted $\alpha=.01$. The ratio between the largest (Baby Boomers) and smallest (Generation X) group sizes is less than 4:1 which also ensures that the ANOVA is robust to differences in variances.

With respect to the final assumption, the sample can be considered to be independent as treatments (the questionnaires) were individually administered (Stevens, 1996).

\subsection{Additional Assumptions Associated with ANCOVA}

For all ANCOVAs three additional tests were performed to determine whether there is a linear relationship between the dependent variable and covariates, whether there is a homogeneity of regression slopes, and whether the covariate is measured without error (Stevens, 1996). The first three assumptions for the ANCOVA were determined when testing for the ANOVA above and all were found to be acceptable. Next, residual plots were examined to test the assumption of linearity between the dependent variable and covariates. They confirmed that the assumption held. The same is true of the reliability of the covariates due to their demographic nature as variables such as gender and age are unlikely to be falsely reported (Tabachnick \& Fidell, 1983). When examining the homogeneity of regression slopes, however, the assumption did not hold true as there is an interaction variable that is significant between generation and tenure 
(see Table 4.3) and between generation and two of the life cycle stage dummy variables.

As noted before, the association between generation and tenure is to be expected. The second violation could not, however, be predicted from the literature.

Table 4.4 - Significance of interaction terms

\begin{tabular}{|l|l|l|}
\hline \multicolumn{1}{|c|}{ Interaction } & \multicolumn{1}{c|}{$\boldsymbol{F}$} & \multicolumn{1}{c|}{ Significance } \\
\hline Generation * Gender & .310 & .578 \\
\hline Generation * Tenure & 29.381 & .000 \\
\hline Generation * Industry Sector Dummy 1 & .065 & .799 \\
\hline Generation * Industry Sector Dummy 2 & 3.660 & .056 \\
\hline Generation * Job Type Dummy 1 & .1 .053 & .305 \\
\hline Generation* Job Type Dummy 2 & 1.094 & .296 \\
\hline Generation* Life Cycle Stage Dummy 1 & 21.411 & .000 \\
\hline Generation * Life Cycle Stage Dummy 2 & .180 & .835 \\
\hline Generation * Life Cycle Stage Dummy 3 & 18.608 & .000 \\
\hline
\end{tabular}

According to Hutcheson and Sofroniou (1999), the more the homogeneity of regression slopes assumption is violated, the more conservative ANCOVA becomes and the more likely Type I errors (accepting a false null hypothesis) become.

The three ANCOVAs testing the existence of sub-cohorts were tested for the assumptions in the same way as the earlier ANCOVAs. First, histograms showed that each of the three datasets had normal distributions although they were slightly negatively skewed. Given the existence of the central limit theorem as described above, we can treat these as normally distributed samples. Levene's test for homogeneity of variance found that the variances were equal at a $\mathrm{p}=.01$ level of significance for the Generation $\mathrm{X}$ subcohorts and for all sub-cohorts together (p-values of .345 and .013 respectively). This meant the null hypothesis of equal variances could not be rejected. It was found, 
however, that the variances were not equal when only Baby Boomer sub-cohorts were examined. For the same reasons as above (robustness, conservativeness) it was deemed acceptable to continue with the ANCOVA.

Residual plots found that the assumption of linearity between the dependent variable and covariates held. The same is true of the reliability of the covariates, as explained earlier. Due to the lack of homogeneity of regression experienced in these observations, the same considerations will be given as above when examining the results.

Finally, when examining the data within each of the four organizations, all ANCOVA assumptions were found to have the same results as previously reported. Although the sample sizes were smaller when using this subset of the data, they were still sufficiently large (more than 50 responses in each) for the central limit theorem to apply. The histograms showed normal distributions that were slightly negatively skewed similar to the histograms for the subcohorts of generations. Levene's test for homogeneity of variance found $\mathrm{p}$-values of $.944, .006, .744$ and .605 for each of the four organizations indicating that the variances were equal at a $\mathrm{p}=.01$ level of significance. The assumption of linearity between the dependent variable and the covariates was shown in the residual plots for all four organizations. The homogeneity of regression assumption did not hold and will have to be considered when examining the results of the output. 


\subsection{Assumptions Associated with Regression}

The regressions used to compare the predictive ability of age on organizational commitment and generation on organizational commitment will be tested for the assumption that the errors are independent and normal with a constant variance. In order to test the assumption for the regressions, scatterplots of the standardized residuals compared to the predicted values were examined. As the plots showed random scatter, the errors were found to be independent with a normal distribution and constant variance. Therefore, all assumptions for these tests were met. 


\section{Results}

This chapter presents the results of the statistical analyses that were performed to elucidate the five research questions presented in this thesis. First, the characteristics of the sample are presented. Next, each research question is examined and the related statistics discussed.

\subsection{Sample Characteristics}

The final sample size for this study consisted of 15461 individuals aged 20 to 54 at the time of the study. This section provides a framework for the study by describing the survey sample in terms of the related demographic characteristics.

As previously mentioned, 11609 respondents (75.1\%) were from the Baby Boom Generation and $3852(24.9 \%)$ were from Generation X. The Canadian Labour Force as a whole is made up of entrants other than Baby Boomers and Generation X. When these others are excluded, (see Appendix I) Baby Boomers make up approximately ${ }^{3} 61 \%$ of the paid labour force and members of Generation X make up 39\% of the paid labour force in the 2001 Statistics Canada census (Statistics Canada, 2003). Therefore, members of Generation $\mathrm{X}$ are over represented in this sample and Baby Boomers are under represented in this study.

\footnotetext{
${ }^{3}$ Due to the age divisions by five-year intervals in the Statistics Canada report, individuals 35 and 36 years of age were included as Baby Boomers and not members of Generation X.
} 


\subsubsection{Gender}

Tables 5.1 and 5.2 show the sample broken down by generation and gender and then further broken down by the variables of interest. Tenure is not included as a number value for this table as the number of respondents with tenure is a meaningless statistic. The sample consisted of $41.1 \%$ males $(n=6356)$ and $58.9 \%$ females $(n=9094)$. The Canadian labour force consists of 53\% males and 47\% females (Statistics Canada, 2004). Although this dataset is from 2001, the percentage of males and females in the workforce has not changed significantly. Therefore, in this sample, men are under represented and women are over represented. This must be considered because if organizational commitment is highly related to gender, the findings of this study will be impacted. This gender imbalance provides further justification for the inclusion of gender as a covariate in this model.

Within the Baby Boom Generation, 43.7 percent $(n=5062)$ of respondents were male and 56.3 percent $(n=6533)$ were female. Within Generation $X,(n=1290) 33.5$ percent of respondents were male and 66.5 percent $(n=2557)$ were female. Again, this supports the need to control for gender in the analysis, as the sample is not representative of the population.

\subsubsection{Life Cycle Stage}

As mentioned previously, life cycle stage is operationalized to include four categories: individuals who are not married and have no children, individuals who are not 
married and have children, individuals who are married and have no children and individuals who are married and have children. When examining the total sample, almost 60 percent of the sample was married with children $(58.4 \%)$. The percentage of individuals who were married with no children or single with no children was similar at 16 percent and 15 percent respectively. Only one in ten of the individuals in the sample were single parents. These data were consistent with the proportions found in Canada's workforce (Higgins \& Duxbury, 2002).

When examining the generations separately, differences were found across the generations. Twenty-five percent of Generation X was single and had no children while only 12 percent of Baby Boomers fell into this category. This is understandable as some members of Generation $\mathrm{X}$ are below the age when one generally gets married or has children. Five percent of Generation X consists of single parents compared to just over 12 percent of Baby Boomers. This is also logical as Baby Boomers are more likely to have children due to their ages and are also more likely to be divorced (Kiechel, 1989). Thirty-two percent of Generation $\mathrm{X}$ are married with no children although only eleven percent of Baby Boomers are in this same position. Since younger members of Generation $\mathrm{X}$ are likely to be newlyweds who have not yet decided to have children, it makes sense that this would comprise the second largest category for this generation. Finally, the largest percentage of individuals were married with children. Almost 40 percent of Generation X was married with children and 65 percent of Baby Boomers. 
Again, the association between life cycle stage and generation supports the decision to control for this variable in the analyses.

\subsubsection{Industry Sector}

For the purpose of this study, individuals were considered to work in three industries. These were: the public sector, the private sector and the not-for-profit sector. When examining the total sample, 48 percent, 21 percent and 31 percent of the sample belonged to the public sector, the private sector and the not-for-profit sector respectively. Statistics for the Canadian Labour Force do not use the same categorization so this cannot be compared to the population. The public sector is comprised of 1654 members of Generation X (22.2\%) and 5797 Baby Boomers (77.8\%). Of these, 44.6 per cent are men and 55.4 per cent are women. Members of Generation X make up 33.1 per cent $(n=$ 1057) of the private sector sample while Baby Boomers comprise the remaining 66.9 per cent. Of these, men comprise 32.6 per cent of the private sector and 67.4 percent are women. Finally, the not-for-profit sector is comprised of $1135(23.7 \%)$ members of Generation X and 3651 (76.3\%) Baby Boomers. Males make up 41.3 per cent of the notfor-profit sample and females comprise 58.7 percent.

\subsubsection{Job Type}

Tables 5.1 and 5.2 also summarize the job type of the respondents from the sample. The data is grouped by job type (manager, professional, non-manager/nonprofessional) and generation. Non-manager/non-professionals made up the largest 
proportion of the sample -50 percent. One in three (34 percent) of the respondents worked in professional positions. Finally, managers made up the smallest proportion of the sample (only 16 percent of respondents were managers). This is slightly disproportional to the Canadian work force at the time of the study. Just over 10 percent of the Canadian workforce in 2001 were managers, 16 percent were professionals and non-managers/non-professionals made up the remaining 74 percent. Therefore, nonmanagers who are not professionals are under represented in this study and the other two groups are over represented (Statistics Canada, 2002f). This again supports the need to control for job type in the analysis. Of those in the public sector, 55.1 percent were male and 44.9 percent were female. This compares to the private sector with 43.8 percent men and 56.2 percent women and to the not-for-profit sector with 34.7 percent men and 65.3 percent women. 
Table 5.1 - Sample by Generation and Gender (n)

\begin{tabular}{|c|c|c|c|c|c|c|c|}
\hline & \multicolumn{6}{|c|}{ Generation } & \multirow[b]{3}{*}{ Total (n) } \\
\hline & \multicolumn{3}{|c|}{ Generation X } & \multicolumn{3}{|c|}{ Baby Boomers } & \\
\hline & Male & Female & Total & Male & Female & Total & \\
\hline Gender & 1290 & 2557 & 3847 & 5062 & 6533 & 11595 & 15442 \\
\hline \multicolumn{8}{|l|}{$\begin{array}{l}\text { Life Cycle } \\
\text { Stage }\end{array}$} \\
\hline $\begin{array}{l}\text { Single/no } \\
\text { children }\end{array}$ & 340 & 632 & 972 & 426 & 907 & 1333 & 2305 \\
\hline $\begin{array}{l}\text { Single/ } \\
\text { children }\end{array}$ & 53 & 147 & 200 & 413 & 1004 & 1417 & 1617 \\
\hline $\begin{array}{l}\text { Married } \\
\text { (partnered)/ } \\
\text { no children }\end{array}$ & 364 & 854 & 1218 & 502 & 779 & 1281 & 2499 \\
\hline $\begin{array}{l}\text { Married } \\
\text { (partnered)/ } \\
\text { children }\end{array}$ & 533 & 924 & 1457 & 3721 & 3843 & 7564 & 9021 \\
\hline \multicolumn{8}{|l|}{$\begin{array}{l}\text { Industry } \\
\text { Sector }\end{array}$} \\
\hline $\begin{array}{l}\text { Public } \\
\text { Sector }\end{array}$ & 669 & 982 & 1651 & 2649 & 3140 & 5789 & 7440 \\
\hline $\begin{array}{l}\text { Private } \\
\text { Sector }\end{array}$ & 294 & 761 & 1055 & 745 & 1389 & 2134 & 3189 \\
\hline $\begin{array}{l}\text { Not-for- } \\
\text { profit } \\
\text { Sector }\end{array}$ & 325 & 810 & 1135 & 1652 & 1995 & 3647 & 4782 \\
\hline \multicolumn{8}{|l|}{ Job Type } \\
\hline Managerial & 164 & 238 & 402 & 1220 & 889 & 2109 & 2511 \\
\hline Professional & 511 & 988 & 1499 & 1801 & 1981 & 3782 & 5281 \\
\hline $\begin{array}{l}\text { Neither } \\
\text { Managerial } \\
\text { nor } \\
\text { Professional }\end{array}$ & 615 & 1331 & 1946 & 2041 & 3663 & 5704 & 7650 \\
\hline
\end{tabular}


Table 5.2 - Sample by Generation and Gender (\%)

\begin{tabular}{|c|c|c|c|c|c|c|}
\hline & \multicolumn{4}{|c|}{ Generation } & \multirow{2}{*}{\multicolumn{2}{|c|}{ Total }} \\
\hline & \multicolumn{2}{|c|}{ Generation X } & \multicolumn{2}{|c|}{ Baby Boomers } & & \\
\hline & Male & Female & Male & Female & Male & Female \\
\hline Gender & 33.5 & 66.5 & 43.7 & 56.3 & 41.1 & 58.9 \\
\hline \multicolumn{7}{|l|}{$\begin{array}{l}\text { Life Cycle } \\
\text { Stage }\end{array}$} \\
\hline $\begin{array}{l}\text { Single/no } \\
\text { children }\end{array}$ & 35.0 & 65.0 & 32.0 & 68.9 & 33.2 & 66.8 \\
\hline $\begin{array}{l}\text { Single/ } \\
\text { children }\end{array}$ & 26.5 & 73.5 & 29.1 & 70.9 & 28.8 & 71.2 \\
\hline $\begin{array}{l}\text { Married } \\
\text { (partnered)/ } \\
\text { no children }\end{array}$ & 29.9 & 70.1 & 39.2 & 60.8 & 34.7 & 65.3 \\
\hline $\begin{array}{l}\text { Married } \\
\text { (partnered)/ } \\
\text { children }\end{array}$ & 36.6 & 63.4 & 49.2 & 50.8 & 41.2 & 58.8 \\
\hline \multicolumn{7}{|l|}{$\begin{array}{l}\text { Industry } \\
\text { Sector }\end{array}$} \\
\hline $\begin{array}{l}\text { Public } \\
\text { Sector }\end{array}$ & 40.5 & 59.5 & 45.8 & 54.2 & 44.6 & 55.4 \\
\hline $\begin{array}{l}\text { Private } \\
\text { Sector }\end{array}$ & 27.9 & 72.1 & 34.9 & 65.1 & 32.6 & 67.4 \\
\hline $\begin{array}{l}\text { Not-for- } \\
\text { profit } \\
\text { Sector }\end{array}$ & 28.6 & 71.4 & 45.3 & 54.7 & 41.3 & 58.7 \\
\hline \multicolumn{7}{|l|}{ Job Type } \\
\hline Managerial & 40.8 & 59.2 & 57.8 & 42.2 & 54.3 & 45.7 \\
\hline Professional & 34.1 & 65.9 & 47.6 & 52.4 & 44.9 & 55.1 \\
\hline $\begin{array}{l}\text { Neither } \\
\text { Managerial } \\
\text { nor } \\
\text { Professional }\end{array}$ & 31.6 & 68.4 & 35.8 & 64.2 & 34.9 & 65.1 \\
\hline
\end{tabular}




\subsubsection{Tenure in the organization and generation}

The mean tenure in the organization for respondents was approximately fourteen years. The means and standard deviations of years in the organization for Baby Boomers and members of Generation X are reported in Table 5.3. As can be seen, the average tenure for members of Generation $\mathrm{X}$ is six years and the average tenure for Baby Boomers is sixteen years. This result is to be expected as Baby Boomers have been in the labour force for more years than members of Generation X.

There is no substantive difference between the mean tenure of males and females within Generation X. Male members of Generation X have a mean tenure of 6.36 years while female members have a mean tenure of 6.52 years. Within the Baby Boom Generation, females have slightly lower tenure with a mean of 15.32 years compared to a mean of 16.92 years for males. This is likely because of time off for maternity leave as more individuals in this generation are parents.

Table 5.3 - Mean tenure in the organization by generation and gender

\begin{tabular}{|l|r|r|r|r|r|r|r|}
\hline & \multicolumn{6}{|c|}{ Generation } & \\
\hline & \multicolumn{3}{|c|}{ Generation X } & \multicolumn{3}{c|}{ Baby Boomers } & Total \\
\hline & \multicolumn{1}{|c|}{ Male } & \multicolumn{1}{|c|}{ Female } & \multicolumn{1}{c|}{ Total } & \multicolumn{1}{c|}{ Male } & \multicolumn{1}{c|}{ Female } & \multicolumn{1}{c|}{ Total } & \\
\hline Mean & 6.36 & 6.52 & 6.47 & 16.92 & 15.32 & 15.96 & 13.17 \\
\hline $\begin{array}{l}\text { Standard } \\
\text { Deviation }\end{array}$ & 3.85 & 3.99 & 3.95 & 8.45 & 7.80 & 8.10 & 8.34 \\
\hline
\end{tabular}




\subsubsection{Sub-cohorts}

In order to examine the sub-cohorts within the generations, the six categories are examined: Late Generation X, Middle Generation X, Early Generation X, Late Baby Boomers, Middle Baby Boomers and Early Baby Boomers (see Table 5.4). Of the members of Generation X, 362 respondents belong to the late sub-cohort, 1297 belong to the middle sub-cohort and 2193 belong to the early sub-cohort. The Baby Boomers are divided into sub-cohorts as follows: 3890 respondents are in the late sub-cohort, 4230 respondents are in the middle sub-cohort and 3489 respondents are in the early subcohort. With such large sample sizes for each sub-cohorts the data can be subdivided this way and still provide significant results. In addition, the large sample sizes enable the covariates to be examined within the sub-cohort analysis.

Table 5.4 - Sample size by sub-cohort

\begin{tabular}{|l|c|c|}
\hline \multicolumn{1}{|c|}{ Sub-Cohort } & N & \% of sample \\
\hline Late Generation X & 362 & 2.3 \\
\hline Middle Generation X & 1297 & 8.4 \\
\hline Early Generation X & 2193 & 14.2 \\
\hline Late Baby Boomers & 3890 & 25.2 \\
\hline Middle Baby Boomers & 4230 & 27.4 \\
\hline Early Baby Boomers & 3489 & 22.6 \\
\hline Total & 15461 & $100.1^{*}$ \\
\hline
\end{tabular}

* total does not add up to $100 \%$ due to rounding 
Table 5.5 - Mean organizational commitment by sub-cohort

\begin{tabular}{|l|l|l|}
\hline Sub-cohort & Mean & $\begin{array}{l}\text { Standard } \\
\text { Deviation }\end{array}$ \\
\hline Late Generation X & 3.56 & .752 \\
\hline Mid Generation X & 3.50 & .790 \\
\hline Early Generation X & 3.47 & .774 \\
\hline Late Baby Boomers & 3.45 & .778 \\
\hline Mid Baby Boomers & 3.49 & .803 \\
\hline Early Baby Boomers & 3.49 & .820 \\
\hline
\end{tabular}

\subsection{Sample Characteristics with respect to Organizational Commitment}

This section will examine the frequencies as well as the mean and the standard deviation for organizational commitment in order to provide an overview of the results. Each of the covariates will be examined with respect to organizational commitment (the results from the OCQ) and generation. See Table 5.6 for a summary of the mean scores of organizational commitment for each variable. 
Table 5.6 - Mean value of organizational commitment

\begin{tabular}{|c|c|c|c|c|c|c|c|c|c|c|}
\hline & \multicolumn{8}{|c|}{ Organizational Commitment } & & \\
\hline & \multicolumn{4}{|c|}{ Generation X } & \multicolumn{4}{|c|}{ Baby Boomers } & \multirow{2}{*}{\multicolumn{2}{|c|}{ Total }} \\
\hline & \multicolumn{2}{|c|}{ Male } & \multicolumn{2}{|c|}{ Female } & \multicolumn{2}{|c|}{ Male } & \multicolumn{2}{|c|}{ Female } & & \\
\hline & Mean & $\begin{array}{l}\text { Std } \\
\text { Dev } \\
\end{array}$ & Mean & $\begin{array}{l}\text { Std } \\
\text { Dev }\end{array}$ & Mean & $\begin{array}{l}\text { Std } \\
\text { Dev }\end{array}$ & Mean & $\begin{array}{l}\text { Std } \\
\text { Dev } \\
\end{array}$ & Mean & $\begin{array}{l}\text { Std } \\
\text { Dev } \\
\end{array}$ \\
\hline Gender & & & & & & & & & & \\
\hline Male & 3.41 & .803 & $\mathrm{n} / \mathbf{a}$ & $\mathrm{n} / \mathrm{a}$ & 3.45 & .815 & $\mathrm{n} / \mathrm{a}$ & $\mathrm{n} / \mathrm{a}$ & 3.44 & .813 \\
\hline Female & $\mathrm{n} / \mathrm{a}$ & $\mathrm{n} / \mathrm{a}$ & 3.52 & .761 & $\mathrm{n} / \mathrm{a}$ & $\mathrm{n} / \mathrm{a}$ & 3.50 & .788 & 3.50 & .780 \\
\hline $\begin{array}{l}\text { Life Cycle } \\
\text { Stage }\end{array}$ & & & & & & & & & & \\
\hline $\begin{array}{l}\text { Not married } \\
\text { (partnered)/ } \\
\text { no children }\end{array}$ & 3.32 & .854 & 3.53 & .779 & 3.26 & .793 & 3.40 & .785 & 3.40 & .801 \\
\hline $\begin{array}{l}\text { Not married } \\
\text { (partnered)/ } \\
\text { children }\end{array}$ & 3.26 & .702 & 3.54 & .812 & 3.44 & .832 & 3.54 & .799 & 3.50 & .807 \\
\hline $\begin{array}{l}\text { Married } \\
\text { (partnered)/ } \\
\text { no children }\end{array}$ & 3.44 & .756 & 3.52 & .753 & 3.31 & .860 & 3.40 & .811 & 3.43 & .798 \\
\hline $\begin{array}{l}\text { Married } \\
\text { (partnered)/ } \\
\text { children }\end{array}$ & 3.48 & .805 & 3.51 & .750 & 3.49 & .804 & 3.53 & .777 & 3.51 & .788 \\
\hline $\begin{array}{l}\text { Industry } \\
\text { Sector }\end{array}$ & & & & & & & & & & \\
\hline $\begin{array}{l}\text { Public } \\
\text { Sector }\end{array}$ & 3.33 & .790 & 3.50 & .736 & 3.32 & .802 & 3.48 & .764 & 3.41 & .781 \\
\hline $\begin{array}{l}\text { Private } \\
\text { Sector }\end{array}$ & 3.45 & .785 & 3.54 & .797 & 3.59 & .754 & 3.57 & .807 & 3.56 & .791 \\
\hline $\begin{array}{l}\text { Not-for- } \\
\text { profit } \\
\text { Sector } \\
\end{array}$ & 3.55 & .829 & 3.53 & .760 & 3.59 & .827 & 3.47 & .809 & 3.53 & .810 \\
\hline Job Type & & & & & & & & & & \\
\hline Managerial & 3.64 & .683 & 3.75 & .650 & 3.74 & .734 & 3.72 & .697 & 3.72 & .710 \\
\hline Professional & 3.43 & .830 & 3.49 & .751 & 3.41 & .801 & 3.41 & .785 & 3.42 & .789 \\
\hline $\begin{array}{l}\text { Neither } \\
\text { Managerial } \\
\text { nor } \\
\text { professional }\end{array}$ & 3.34 & .800 & 3.51 & .781 & 3.32 & .832 & 3.49 & .800 & 3.44 & .809 \\
\hline
\end{tabular}


As can be seen by Table 5.6, commitment scores are all in the range of 3.25 to 3.75. In other words, respondents report moderate levels of commitment as assessed using the OCQ. Given that all the means are close, differences were examined for each covariate to see whether there were significant differences in commitment that could be associated with each covariate.

The data in Table 5.6 indicate that women report higher levels of commitment than men, regardless of their generational membership. A t-test was used to determine if results from this gender difference in commitment levels was statistically significant. Results from this analysis are given in Table 5.7. This analysis indicates that, in this sample, women report statistically higher levels of commitment than men $(p=.000)$. Since the gender distribution in the sample was not representative of the population, it must be controlled for in order to prevent it from skewing the results. Therefore, twoway ANOVAs between gender and each of the other covariates were used to determine whether or not organizational commitment levels are associated with job type, industry sector, life cycle stage or tenure.

Table 5.7 - T-test for differences between genders

\begin{tabular}{|l|l|l|l|c|}
\hline & $\begin{array}{c}\text { Equal } \\
\text { variances }\end{array}$ & \multicolumn{1}{|c|}{ t-statistic } & Significance & Difference \\
\hline Gender & No $(\mathrm{p}=.000)$ & -4.679 & .000 & $\square$ \\
\hline
\end{tabular}

Life cycle stage was examined for the whole sample in a two-way ANOVA with organizational commitment as the dependent variable and both gender and life cycle 163 
stage as independent variables. The results are listed in Table 5.8 below. As significant differences in commitment were found between life cycle stages and the interaction term (gender x life cycle stage) was not significant (see Table 5.9), a follow-up Scheffé test was performed for pairwise comparisons of the lifecycle stages. These results are listed in Table 5.10 below. The Scheffé test indicates that individuals who are single with no children have significantly lower levels of commitment than individuals who are married with children. No other significant between group differences were found. This is somewhat surprising given that the research in this area has shown that individuals who are single with children have lower levels of organizational commitment. This result will be further examined in the discussion section.

A two-way ANOVA with gender and sector as independent variables and organizational commitment as the dependent variable was used to see if commitment varied with sector. Results are shown in Table 5.8. This analysis indicates that commitment varies with sector and gender (i.e. the interaction term was significant at the $p=.01$ level of significance) as shown in Table 5.9. Respondents in the public sector had significantly lower levels of organizational commitment than their counterparts in the private sector and the not-for-profit sector (see Table 5.11). No differences were found in the mean organizational commitment between respondents in the private sector and the not-for-profit sector. This finding will be further explored in the discussion section. 
The two-way ANOVA examining the relationship of job type and gender with organizational commitment (see Table 5.8) also found a significant difference between the means of groups within the job type variable. The interaction term (see Table 5.9) was not significant. Table 5.10 shows that the means of organizational commitment were significantly different between managers and professionals and between managers and those who were neither managers nor professionals. Managers were found to have significantly higher levels of organizational commitment, regardless of gender, than either professionals or non-managers who are not professionals. No significant difference was found between professionals and those who were neither managers nor professionals. This finding is particularly interesting given that most researchers examine either professionals and non-professionals or managers and non-managers. This result will be discussed in the Chapter 6 .

Table 5.8 - Differences in organizational commitment between groups within gender

\begin{tabular}{|l|l|l|l|c|}
\hline & \multicolumn{1}{|c|}{ F-statistic } & Significance & $\mathbf{R}^{2}$ & Difference \\
\hline $\begin{array}{l}\text { Life cycle } \\
\text { stage }\end{array}$ & 9.705 & .000 & .012 & $\square$ \\
\hline $\begin{array}{l}\text { Industry } \\
\text { Sector }\end{array}$ & 10.065 & .000 & .013 & $\square$ \\
\hline Job Type & 35.081 & .000 & .027 & $\square$ \\
\hline
\end{tabular}


Table 5.9 - Interactions on organizational commitment between gender and covariates

\begin{tabular}{|l|r|r|}
\hline Interaction & F & Sig. \\
\hline Gender*Tenure & 1.213 & .191 \\
\hline Gender*Industry Sector Dummy 1 & 7.587 & .006 \\
\hline Gender*Industry Sector Dummy 2 & 2.265 & .132 \\
\hline Gender*Job Type Dummy 1 & 2.008 & .157 \\
\hline Gender*Job Type Dummy 2 & 5.279 & .022 \\
\hline Gender*Life Cycle Stage Dummy 1 & .765 & .382 \\
\hline Gender*Life Cycle Stage Dummy 3 & .116 & .733 \\
\hline
\end{tabular}

Table 5.10 - Scheffé results for significant organizational commitment differences within covariates

\begin{tabular}{|c|c|c|c|c|c|}
\hline Covariate & Group 1 & Group 2 & $\begin{array}{l}\text { Mean } \\
\text { Difference }\end{array}$ & Significance & Difference \\
\hline \multirow{6}{*}{$\begin{array}{l}\text { Life } \\
\text { Cycle } \\
\text { Stage }\end{array}$} & $\begin{array}{l}\text { Single/no } \\
\text { children }\end{array}$ & $\begin{array}{l}\text { Single/ } \\
\text { children }\end{array}$ & .95 & .408 & $x$ \\
\hline & $\begin{array}{l}\text { Single/no } \\
\text { children }\end{array}$ & $\begin{array}{l}\text { Married/ no } \\
\text { children }\end{array}$ & -.08 & .330 & $x$ \\
\hline & $\begin{array}{l}\text { Single/no } \\
\text { children }\end{array}$ & $\begin{array}{l}\text { Married/ } \\
\text { children }\end{array}$ & $-.17 *$ & .000 & $\nabla$ \\
\hline & $\begin{array}{l}\text { Single/ } \\
\text { children }\end{array}$ & $\begin{array}{l}\text { Married/ no } \\
\text { children }\end{array}$ & -1.04 & .330 & $x$ \\
\hline & $\begin{array}{l}\text { Single/ } \\
\text { children }\end{array}$ & $\begin{array}{l}\text { Married/ } \\
\text { children }\end{array}$ & -1.12 & .262 & $x$ \\
\hline & $\begin{array}{l}\text { Married/ } \\
\text { no children }\end{array}$ & $\begin{array}{l}\text { Married/ } \\
\text { children }\end{array}$ & -.08 & .171 & $x$ \\
\hline $\begin{array}{l}\text { Industry } \\
\text { Sector }\end{array}$ & $\begin{array}{l}\text { Private } \\
\text { Sector }\end{array}$ & $\begin{array}{l}\text { Not-for- } \\
\text { profit sector }\end{array}$ & .05 & .438 & $x$ \\
\hline \multirow[t]{3}{*}{ Job Type } & Managerial & Professional & $.32^{*}$ & .000 & $\bar{\nabla}$ \\
\hline & Managerial & $\begin{array}{l}\text { Neither } \\
\text { managerial } \\
\text { nor } \\
\text { professional }\end{array}$ & $.28^{*}$ & .000 & $\nabla$ \\
\hline & Professional & $\begin{array}{l}\text { Neither } \\
\text { managerial } \\
\text { nor } \\
\text { professional }\end{array}$ & -.04 & .404 & $x$ \\
\hline
\end{tabular}

*significant at the .05 level of significance 
Figure 5.1 - Organizational Commitment Means for Industry Sectors by Gender

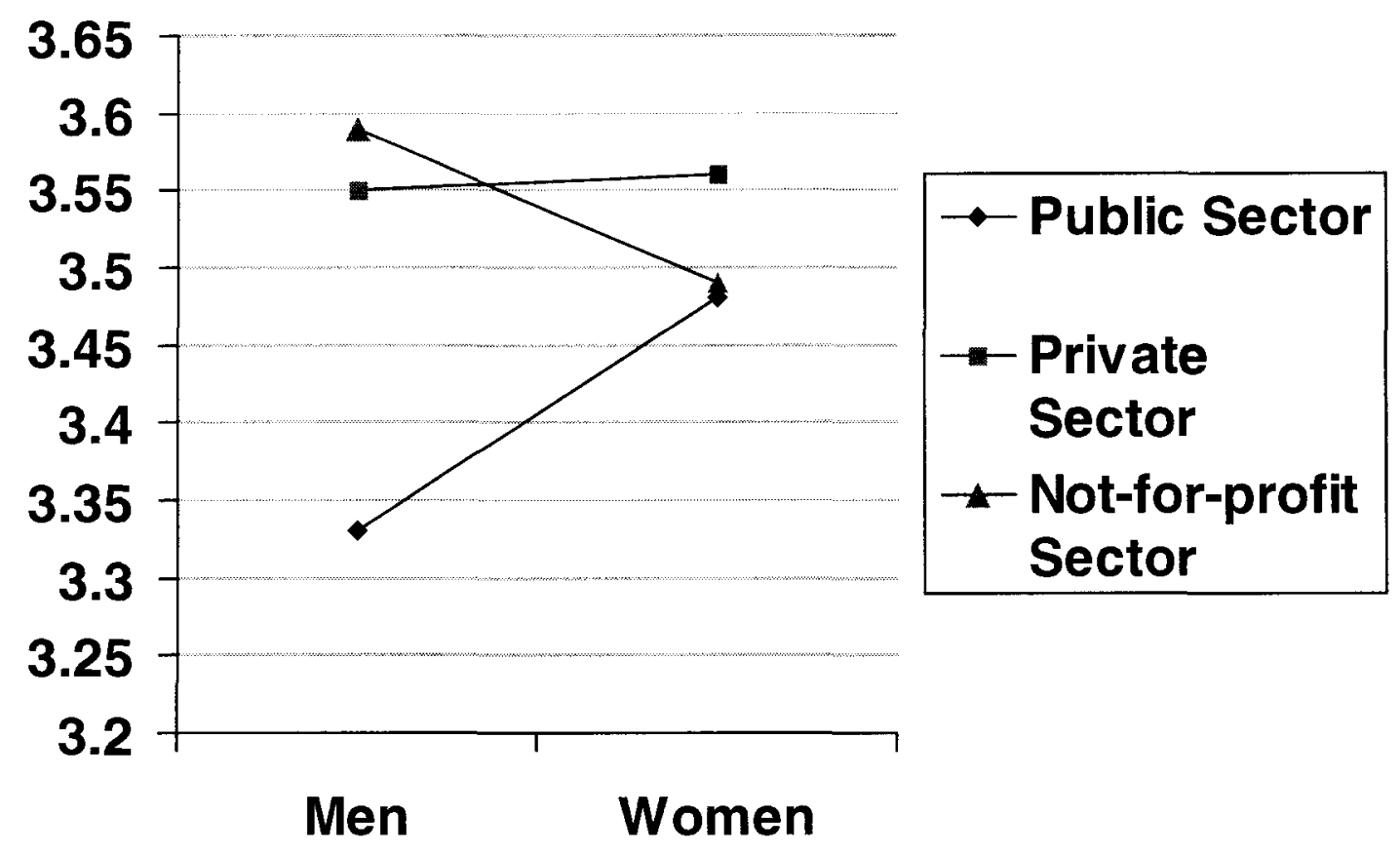

\subsection{Commitment Differences Between Generational Cohorts}

The following section examines the results of each of the statistical tests performed to determine the relationship between organizational commitment and the generational cohorts or sub-cohorts as specified in the Research Questions.

\subsubsection{Research Question 1}

An examination of the mean organizational commitment seen in Table 5.6 (p.162) between the generations does not reveal any obvious generational differences. A oneway ANOVA was performed, as described in chapter 4, to determine whether or not there 167 
was a statistically significant difference between the means of the two generations. The results are seen in Table 5.11, below.

Table 5.11 - ANOVA Between Generation and Organizational Commitment

\begin{tabular}{|l|l|l|l|l|}
\hline Source & $\begin{array}{l}\text { Type III Sum } \\
\text { of Squares }\end{array}$ & Mean Square & F & Sig. \\
\hline $\begin{array}{l}\text { Corrected } \\
\text { Model }\end{array}$ & .344 & .344 & .545 & .460 \\
Intercept & 140195.507 & 140195.507 & 222264.83 & .000 \\
Generation & .344 & .344 & .545 & .460 \\
Error & 9750.901 & .631 & & \\
Total & 196813.124 & & & \\
Corrected Total & 9751.245 & & & \\
\hline
\end{tabular}

R Squared $=.000$

The main effect for generation was not significant at the .01 level of significance.

This indicates that organizational commitment does not differ significantly between Baby Boomers and members of Generation $X$ when no other factors are considered.

\subsubsection{Research Question 2}

The results in Table 5.12 show results for the ANCOVA including organizational commitment as the dependent variable, generation as the independent variable and gender, tenure, life cycle stage (dummy coded), industry sector (dummy coded) and job type (dummy coded) as covariates. 
Table 5.12 - ANCOVA Between Generation and Organizational Commitment

\begin{tabular}{|l|l|l|l|l|}
\hline Source & $\begin{array}{l}\text { Type III Sum } \\
\text { of Squares }\end{array}$ & Mean Square & F & Sig. \\
\hline Corrected Model & 308.611 & 30.861 & 50,453 & .000 \\
Intercept & 8024.732 & 8024.732 & 13119.197 & .000 \\
Generation & .436 & .436 & .713 & .399 \\
Gender & 19.913 & 19.913 & 32.554 & .000 \\
Tenure & 14.941 & 14.941 & 24.426 & .000 \\
Industry Sector & 48.525 & 48.525 & 79.331 & .000 \\
Dummy 1 & & .771 & 1.261 & .262 \\
Industry Sector & .771 & 164.876 & 269.546 & .000 \\
Dummy 2 & 164.876 & 1.613 & 2.637 & .104 \\
Job Type Dummy 1 & 1.613 & 21.945 & 35.877 & .000 \\
Job Type Dummy 2 & 21.945 & .007 & .012 & .913 \\
Life Cycle Stage & & & \\
Dummy 1 & .007 & 17.206 & 28.129 & .000 \\
Life Cycle Stage & & & \\
Dummy 2 & 17.206 & .612 & & \\
Life Cycle Stage & & & \\
Dummy 3 & 9372.752 & & \\
Error & 195252.337 & & & \\
Total & 9681.363 & & & \\
Corrected Total & & & \\
\hline R Squared 0.032 & & & \\
\hline
\end{tabular}

R Squared $=0.032$

While the main effects for gender, tenure, industry sector (dummy variable 1), job type (dummy variable 1) and life cycle stage (dummy variables 1 and 3) were significant at the .01 level of significance, the main effect for generation remained insignificant when variables associated with organizational commitment in the literature were included to reduce confounds. An examination of the $\mathrm{R}^{2}$ value shows that only 3.2 percent of the variance in the level of organizational commitment was explained by the model including the covariates. 


\subsubsection{Research Question 3}

A regression model with organizational commitment and generation, gender, tenure, life cycle stage, job type and industry sector as predictors, was found to be statistically significant at a $\mathrm{p}<.01$ level of significance (Table 5.13). An $\mathrm{R}^{2}$ of .031 indicates that the variables in this model account for only 3.1 percent of the variance around organizational commitment.

Table 5.13 - Regression: Generation and covariates

\begin{tabular}{|l|r|r|r|r|r|}
\hline Model & $\begin{array}{l}\text { Sum of } \\
\text { Squares }\end{array}$ & Df & \multicolumn{1}{l|}{$\begin{array}{l}\text { Mean } \\
\text { Square }\end{array}$} & F & Sig. \\
\hline Regression & 308.611 & 10 & 30.861 & 50.453 & .000 \\
\hline Residual & 9372.752 & 15323 & .612 & & \\
\hline Total & 9681.363 & 15333 & & & \\
\hline
\end{tabular}

R Squared $=.032$ (Adjusted R Squared $=.031$ )

Table 5.14- Regression with Beta values

\begin{tabular}{|c|c|c|c|c|c|}
\hline \multirow[t]{2}{*}{ Variables } & \multicolumn{2}{|c|}{$\begin{array}{c}\text { Unstandardized } \\
\text { Coefficients }\end{array}$} & \multirow{2}{*}{$\begin{array}{c}\begin{array}{c}\text { Standardized } \\
\text { Coefficients }\end{array} \\
\beta\end{array}$} & \multirow[t]{2}{*}{$\mathbf{t}$} & \multirow[t]{2}{*}{ Sig. } \\
\hline & $\beta$ & $\begin{array}{l}\text { Std. } \\
\text { Error }\end{array}$ & & & \\
\hline Constant & 3.490 & .032 & & 110.762 & .000 \\
\hline Industry Sector Dummy 1 & -.133 & .015 & -.084 & -8.907 & .000 \\
\hline Industry Sector Dummy 2 & -.021 & .019 & -.011 & -1.123 & .262 \\
\hline Job Type Dummy 1 & .301 & .018 & .140 & 16.418 & .000 \\
\hline Job Type Dummy 2 & -.024 & .015 & -.014 & -1.624 & .104 \\
\hline Life Cycle Dummy 1 & -.113 & .019 & -.051 & -5.990 & .000 \\
\hline Life Cycle Dummy 2 & -.002 & .021 & -.001 & -.109 & .913 \\
\hline Life Cycle Dummy 3 & -.098 & .019 & -.046 & -5.304 & .000 \\
\hline Gender & .076 & .013 & .047 & 5.706 & .000 \\
\hline Tenure & -.004 & .001 & -.046 & -4.942 & .000 \\
\hline Generation & -.015 & .017 & -.008 & -.844 & .399 \\
\hline
\end{tabular}


The standardized coefficients show the magnitudes of each of the variables relative to their contribution to the dependent variable. Because they are standardized, they can be compared. Examining Table 5.14 shows that job type has the most significant contribution of the variables to organizational commitment, as the job type dummy variable is significant with a standardized $\beta$ of .140 . Industry sector has the next most significant contribution to organizational commitment although it contributes just over half as much explanatory power as the job type dummy variable with a standardized $\beta$ of -.084 . Life cycle stage, gender and tenure all contribute very little to our understanding of organizational commitment. These predictors, while significant, are not substantive. Finally, it is important to note that generation is not a significant predictor of organizational commitment.

\subsubsection{Research Question 4}

As noted earlier, three regressions were run to compare the ability of age versus generation to predict organizational commitment. The dependent variable in all three cases was organizational commitment. The first regression model included all covariates and the generational variable as independent variables. The second model excluded generation as a predictor (i.e. only the covariates were used as independent variables). In the third model, age was added as a dependent variable to the model which also included all covariates. The results of these analyses are shown in Table 5.15. 
While all three models are significant at the $\mathrm{p}<.01$ level of significance, all three have the same $\mathrm{R}^{2}$ value. This suggests that not only does age not contribute anything to the model over generation but also tells us that neither age nor generation add anything to our ability to predict organizational commitment above what is contributed for by the five covariates. Furthermore, the $\mathrm{R}^{2}$ value of only .032 indicates that none of the variables considered in this analysis are good predictors of organizational commitment.

Table 5.15 - Regression: Hierarchical regression

\begin{tabular}{|l|l|r|r|r|r|r|}
\hline Model & & $\begin{array}{l}\text { Sum of } \\
\text { Squares }\end{array}$ & \multicolumn{1}{l|}{ df } & $\begin{array}{l}\text { Mean } \\
\text { Square }\end{array}$ & F & \multicolumn{1}{l|}{ Sig. } \\
\hline \multirow{3}{*}{1} & Regression & 308.611 & 10 & 30.861 & 50.453 & $.000^{\mathrm{a}}$ \\
\cline { 2 - 8 } & Residual & 9372.752 & 15323 & .612 & & \\
\cline { 2 - 8 } & Total & 9681.362 & 15333 & & & \\
\hline \multirow{3}{*}{2} & Regression & 308.175 & 9 & 34.242 & 55.981 & $.000^{\mathrm{b}}$ \\
\cline { 2 - 8 } & Residual & 9373.187 & 15324 & .612 & & \\
\cline { 2 - 8 } & Total & 9681.363 & 15333 & & & $.000^{\mathrm{C}}$ \\
\hline \multirow{3}{*}{3} & Regression & 308.195 & 10 & 30.819 & 50.383 & \\
\cline { 2 - 8 } & Residual & 9373.168 & 15323 & .612 & & \\
\cline { 2 - 8 } & Total & 9681.363 & 15333 & & & \\
\hline
\end{tabular}

a. R Squared $=.032$ (Adjusted R Squared $=.031)$

b. R Squared $=.032$ (Adjusted R Squared $=.031)$

c. R Squared $=.032$ (Adjusted R Squared $=.031$ )

The standardized $\beta$ 's in Table 5.16 are consistent with those seen in Table 5.14 and support the idea that only job type and industry sector are substantive predictors of organizational commitment. In this study, life cycle stage, gender and tenure are significant, but not substantive, predictors of organizational commitment. 
Table 5.16 - Regression 2: Standardized Coefficients for all three models

\begin{tabular}{|c|c|c|c|}
\hline Model & Variable & $\begin{array}{c}\text { Standardized } \\
\beta \\
\end{array}$ & Sig. \\
\hline \multirow[t]{11}{*}{1} & Constant & & .000 \\
\hline & Industry Sector Dummy 1 & -.084 & .000 \\
\hline & Industry Sector Dummy 2 & -.011 & .262 \\
\hline & Job Type Dummy 1 & .140 & .000 \\
\hline & Job Type Dummy 2 & -.014 & .104 \\
\hline & Life Cycle Dummy 1 & -.051 & .000 \\
\hline & Life Cycle Dummy 2 & -.001 & .913 \\
\hline & Life Cycle Dummy 3 & -.046 & .000 \\
\hline & Gender & .047 & .000 \\
\hline & Tenure & -.046 & .000 \\
\hline & Generation & -.008 & .399 \\
\hline \multirow[t]{10}{*}{2} & Constant & & .000 \\
\hline & Industry Sector Dummy 1 & -.084 & .000 \\
\hline & Industry Sector Dummy 2 & -.011 & .272 \\
\hline & Job Type Dummy 1 & .140 & .000 \\
\hline & Job Type Dummy 2 & -.014 & .105 \\
\hline & Life Cycle Dummy 1 & -.050 & .000 \\
\hline & Life Cycle Dummy 2 & -.001 & .882 \\
\hline & Life Cycle Dummy 3 & -.044 & .000 \\
\hline & Gender & .047 & .000 \\
\hline & Tenure & -.049 & .000 \\
\hline \multirow[t]{11}{*}{3} & Constant & & .000 \\
\hline & Industry Sector Dummy 1 & -.084 & .000 \\
\hline & Industry Sector Dummy 2 & -.010 & .278 \\
\hline & Job Type Dummy 1 & .140 & .000 \\
\hline & Job Type Dummy 2 & -.014 & .104 \\
\hline & Life Cycle Dummy 1 & -.049 & .000 \\
\hline & Life Cycle Dummy 2 & -.001 & .872 \\
\hline & Life Cycle Dummy 3 & -.044 & .000 \\
\hline & Gender & .047 & .000 \\
\hline & Tenure & -.050 & .000 \\
\hline & Age & .002 & .858 \\
\hline
\end{tabular}




\subsubsection{Research Question 5}

As mentioned in chapter 4, a set of two-way ANOVAs (organizational commitment by each sub-cohort) was performed to examine if organizational commitment was associated with the generational sub-cohort membership. This was done to determine whether any difference on organizational commitment levels existed between the sub-cohorts.

Table 5.17 - ANOVA: Generation X Sub-cohorts and Organizational Commitment

\begin{tabular}{|c|c|c|c|c|}
\hline Source & $\begin{array}{l}\text { Type III Sum } \\
\text { of Squares }\end{array}$ & Mean Square & $\mathbf{F}$ & Sig. \\
\hline $\begin{array}{l}\text { Corrected } \\
\text { Model }\end{array}$ & 3.169 & 1.585 & 2.719 & .066 \\
\hline Intercept & 4074.556 & 4074.556 & 6991.731 & .000 \\
\hline $\begin{array}{l}\text { Generation } X \\
\text { Dummy } 1\end{array}$ & 2.763 & 2.763 & 4.742 & .030 \\
\hline $\begin{array}{l}\text { Generation X } \\
\text { Dummy } 2\end{array}$ & 1.072 & 1.072 & 1.839 & .175 \\
\hline Error & 556.543 & .583 & & \\
\hline Total & 12176.702 & & & \\
\hline Corrected Total & 559.713 & & & \\
\hline
\end{tabular}

R Squared $=.006$ (Adjusted R Squared $=.004)$

The ANOVA for the Generation X sub-cohorts is seen in Table 5.17. There was no significant difference on organizational commitment between the generational subcohorts for Generation $\mathrm{X}$ at the .01 level of significance. The $\mathrm{R}^{2}$ is .006 meaning that the model including these variables explains only 0.6 percent of the variance in organizational commitment. 
Similar findings were obtained for the Baby Boomer sub-cohorts (see Table 5.18). There was no significant difference found between the levels of organizational commitment reported by the three sub-cohorts of the Baby Boomers. The $\mathrm{R}^{2}$ value of .001 shows that the Baby Boom sub-cohorts do not explain any of the variance in organizational commitment.

Table 5.18 - ANOVA: Baby Boomer Sub-cohorts and Organizational Commitment

\begin{tabular}{|c|c|c|c|c|}
\hline Source & $\begin{array}{l}\text { Type III Sum } \\
\text { of Squares }\end{array}$ & Mean Square & $\mathbf{F}$ & Sig. \\
\hline $\begin{array}{l}\text { Corrected } \\
\text { Model }\end{array}$ & 1.710 & .855 & 1.315 & .269 \\
\hline Intercept & 19863.663 & 19863.663 & 30542.383 & .000 \\
\hline $\begin{array}{l}\text { Baby Boomer } \\
\text { Dummy } 1\end{array}$ & .833 & .833 & 1.281 & .258 \\
\hline $\begin{array}{l}\text { Baby Boomer } \\
\text { Dummy } 2\end{array}$ & .070 & .070 & .107 & .743 \\
\hline Error & 1491.935 & .650 & & \\
\hline Total & 29240.722 & & & \\
\hline Corrected Total & 1493.645 & & & \\
\hline
\end{tabular}

R Squared $=.001$ (Adjusted R Squared $=.000$ )

A final ANOVA, which included all six sub-cohorts from both the Baby Boom Generation and Generation X, is given in Table 5.19. Again, no significant differences were found between any of the sub-cohorts on their reported levels of organizational commitment at the .01 level of significance. 
Table 5.19 - ANOVA: All Sub-cohorts and Organizational Commitment

\begin{tabular}{|c|c|c|c|c|}
\hline Source & $\begin{array}{l}\text { Type III Sum } \\
\text { of Squares }\end{array}$ & Mean Square & $\mathbf{F}$ & Sig. \\
\hline $\begin{array}{l}\text { Corrected } \\
\text { Model }\end{array}$ & 4.910 & .982 & 1.557 & .169 \\
\hline Intercept & 1616.078 & 1616.078 & 2563.190 & .000 \\
\hline $\begin{array}{l}\text { All Sub-cohorts } \\
\text { Dummy } 1\end{array}$ & 1.475 & 1.475 & 2.340 & .126 \\
\hline $\begin{array}{l}\text { All Sub-cohorts } \\
\text { Dummy } 2\end{array}$ & .121 & .121 & .193 & .661 \\
\hline $\begin{array}{l}\text { All Sub-cohorts } \\
\text { Dummy } 3\end{array}$ & .711 & .711 & 1.128 & .288 \\
\hline $\begin{array}{l}\text { All Sub-cohorts } \\
\text { Dummy } 4\end{array}$ & .833 & .833 & 1.322 & .250 \\
\hline $\begin{array}{l}\text { All Sub-cohorts } \\
\text { Dummy } 5\end{array}$ & .070 & .070 & .111 & .740 \\
\hline Error & 2048.478 & .630 & & \\
\hline Total & 41417.425 & & & \\
\hline Corrected Total & 2053.388 & & & \\
\hline
\end{tabular}

R Squared $=.002$ (Adjusted R Squared $=.001$ )

\subsubsection{Research Question 5 with covariates}

A set of three ANCOVAs was performed to examine the generational sub-cohorts with the covariates. This was done to determine whether any difference on organizational commitment levels could be found between the sub-cohorts when the covariates were controlled for.

Table 5.20 shows an ANCOVA which examines only the Generation X subcohorts. There was no significant difference on organizational commitment between the generational sub-cohorts for Generation $\mathrm{X}$ at the .01 level of significance. The $\mathrm{R}^{2}$ is .051 which means that the model explains 5.1 percent of the variance around organizational 
commitment. However, as the Generation $\mathrm{X}$ sub-cohorts are not significant, the $\mathrm{R}^{2}$ can be largely attributed to the impact of the covariates.

Table 5.20 - ANCOVA: Generation X Sub-cohorts and Organizational Commitment with Covariates

\begin{tabular}{|c|c|c|c|c|}
\hline Source & $\begin{array}{l}\text { Type III Sum } \\
\text { of Squares }\end{array}$ & Mean Square & $\mathbf{F}$ & Sig. \\
\hline Corrected Model & 28.425 & 2.584 & 4.590 & .000 \\
\hline Intercept & 418.549 & 418.549 & 743.521 & .000 \\
\hline Generation X & .601 & .601 & 1.068 & .302 \\
\hline Dummy 1 & & & & \\
\hline Generation $X$ & .054 & .054 & .095 & .758 \\
\hline Dummy 2 & & & & \\
\hline Gender & 3.042 & 3.042 & 5.405 & .202 \\
\hline Tenure & 8.780 & 8.780 & 15.598 & .000 \\
\hline Job Type Dummy 1 & 5.288 & 5.288 & 9.394 & .002 \\
\hline Job Type Dummy 2 & .460 & .460 & .817 & .366 \\
\hline Industry Sector & 2.359 & 2.359 & 4.190 & .041 \\
\hline Dummy 1 & & & & \\
\hline Industry Sector & .649 & .649 & 1.153 & .283 \\
\hline Dummy 2 & 2226 & 2026 & & 017 \\
\hline $\begin{array}{l}\text { Life Cycle Stage } \\
\text { Dummy } 1\end{array}$ & 2.226 & 2.226 & 3.954 & .047 \\
\hline Life Cycle Stage & 3.469 & 3.469 & 6.163 & .013 \\
\hline Dummy 2 & & & & \\
\hline Life Cycle Stage & 2.899 & 2.899 & 5.149 & .023 \\
\hline Dummy 3 & & & & \\
\hline Error & 529.716 & .563 & & \\
\hline Total & 12123.460 & & & \\
\hline Corrected Total & 558.141 & & & \\
\hline
\end{tabular}

R Squared $=0.051$ (Adjusted R Squared $=.040$ )

Tables 5.21 and 5.22 show similar results to the ANCOVA shown in Table 5.20 with the model containing Baby Boom sub-cohorts (Table 5.21) and the model containing all generational sub-cohorts (Table 5.22). Each of the ANCOVAs shows that 
there is no significant difference in the generational sub-cohorts, when controlling for the covariates.

Table 5.21 - ANCOVA: Baby Boom Sub-cohorts and Organizational Commitment with Covariates

\begin{tabular}{|c|c|c|c|c|}
\hline Source & $\begin{array}{l}\text { Type III Sum } \\
\text { of Squares }\end{array}$ & Mean Square & $\mathbf{F}$ & Sig. \\
\hline Corrected Model & 63.689 & 5.790 & 9.259 & .000 \\
\hline Intercept & 1115.159 & 1115.159 & 1783.328 & .000 \\
\hline Baby Boomer & .720 & .720 & 1.151 & .283 \\
\hline Dummy 1 & & & & \\
\hline Baby Boomer & .037 & .037 & .059 & .807 \\
\hline Dummy 2 & & & & \\
\hline Gender & 5.420 & 5.420 & 8.667 & .003 \\
\hline Tenure & 1.528 & 1.528 & 2.444 & .118 \\
\hline Job Type Dummy 1 & 24.588 & 24.588 & 39.321 & .000 \\
\hline Job Type Dummy 2 & .807 & .807 & 1.291 & .256 \\
\hline $\begin{array}{l}\text { Industry Sector } \\
\text { Dummy } 1\end{array}$ & 6.594 & 6.594 & 10.545 & .001 \\
\hline $\begin{array}{l}\text { Industry Sector } \\
\text { Dummy } 2\end{array}$ & .031 & .031 & .050 & .823 \\
\hline $\begin{array}{l}\text { Life Cycle Stage } \\
\text { Dummy } 1\end{array}$ & 11.380 & 11.380 & 18.198 & .000 \\
\hline $\begin{array}{l}\text { Life Cycle Stage } \\
\text { Dummy } 2\end{array}$ & .184 & .184 & .295 & .587 \\
\hline $\begin{array}{l}\text { Life Cycle Stage } \\
\text { Dummy } 3\end{array}$ & 2.425 & 2.425 & 3.877 & .049 \\
\hline Error & 1418.862 & .625 & & \\
\hline Total & 29065.116 & & & \\
\hline Corrected Total & 1482.551 & & & \\
\hline
\end{tabular}

R Squared $=0.043$ (Adjusted R Squared $=.038$ ) 
Table 5.22 - ANCOVA: All Sub-cohorts and Organizational Commitment with Covariates

\begin{tabular}{|l|l|l|l|l|}
\hline Source & $\begin{array}{l}\text { Type III Sum } \\
\text { of Squares }\end{array}$ & Mean Square & F & Sig. \\
\hline $\begin{array}{l}\text { Corrected Model } \\
\text { Intercept }\end{array}$ & 82.326 & 5.880 & 9.666 & .000 \\
Sub-cohort & 764.287 & 764.287 & 1256.255 & .000 \\
$\begin{array}{l}\text { Dummy 1 } \\
\text { Sub-cohort }\end{array}$ & 1.614 & 1.614 & 2.652 & .103 \\
$\begin{array}{l}\text { Dummy 2 } \\
\text { Sub-cohort }\end{array}$ & .142 & .142 & .233 & .629 \\
$\begin{array}{l}\text { Dummy 3 } \\
\text { Sub-cohort }\end{array}$ & 1.126 & .884 & 1.452 & .228 \\
$\begin{array}{l}\text { Dummy 4 } \\
\text { Sub-cohort }\end{array}$ & .016 & 1.126 & 1.850 & .174 \\
$\begin{array}{l}\text { Dummy 5 } \\
\text { Gender }\end{array}$ & 7.744 & .016 & .025 & .873 \\
Tenure & 4.044 & 7.744 & 12.728 & .000 \\
Job Type Dummy 1 & 30.865 & 4.044 & 6.646 & .010 \\
Job Type Dummy 2 & 1.119 & 30.865 & 50.733 & .000 \\
Industry Sector & 8.959 & 1.119 & 1.840 & .175 \\
$\begin{array}{l}\text { Dummy 1 } \\
\text { Industry Sector }\end{array}$ & .104 & 8.959 & 14.725 & .000 \\
$\begin{array}{l}\text { Dummy 2 } \\
\text { Life Cycle Stage }\end{array}$ & 11.611 & .104 & .171 & .680 \\
$\begin{array}{l}\text { Dummy 1 } \\
\text { Life Cycle Stage }\end{array}$ & 2.583 & 11.611 & 19.084 & .000 \\
$\begin{array}{l}\text { Dummy 2 } \\
\text { Life Cycle Stage }\end{array}$ & 5.687 & 2.583 & 4.245 & .002 \\
$\begin{array}{l}\text { Dummy 3 } \\
\text { Error }\end{array}$ & 1958.392 & .608 & 9.348 & \\
$\begin{array}{l}\text { Total } \\
\text { Corrected Total }\end{array}$ & 41188.576 & 2040.718 & & \\
\hline R Squared & & & \\
\hline
\end{tabular}

R Squared $=0.040$ (Adjusted R Squared $=.036$ ) 


\subsubsection{Supplemental Research Question 6}

In order to examine the impact of the sixth covariate, specific organization, ANCOVAs were performed on four individual organizations as mentioned in chapter 4 . It should be noted that the covariate for industry sector was removed for these analyses as each organization could only belong to one of the three sector categories. The ANCOVAs are presented in Appendix $\mathrm{J}$ (see summary in Table 5.23).

The first organization was a public sector organization. In this organization, the only significant main effects (at the .01 level of significance) were for gender, tenure and one of the job type dummy variables. There was no significant difference on organizational commitment between the generations. The $\mathrm{R}^{2}$ is .051 meaning that the model including these variables explains 5.1 percent of the variance in organizational commitment.

The second organization also operated in the public sector. Once again, the main effect for generation is not significant with a p-value of .191. In this case only gender (significant at $\mathrm{p}<.01$ ) and one of the life cycle stage dummy variables (significant at $\mathrm{p}<.01$ ) were significantly associated with commitment. In this organization, the $\mathrm{R}^{2}$ value is .035 signifying that the model accounts for only 3.5 percent of the variance around organizational commitment.

Appendix J shows the ANCOVA obtained within the not-for-profit sector. The generation to which an individual belongs remains insignificant at the .01 level of 
significance with a p-value of .298. The significant main effects in this sample are job type (dummy 1) and life cycle stage (dummy 1). Neither gender nor tenure were significant at the. 01 level of significance. The $\mathrm{R}^{2}$ is .077 showing that this model accounts for 7.7 percent of the variance on organizational commitment.

The final specific organization examined is a private sector firm. Results obtained with this organization are shown in Appendix J. The main effects for this model show that, again, there is no significant difference on measures of organizational commitment between the two generations of interest (at the .01 level of significance). The only main effect that is statistically significant in this specific organization is job type. The $\mathrm{R}^{2}$ value for this model is .041 showing that 4.1 percent of the variance around organizational commitment is explained by this model. 
Table 5.23 - Significance Levels of Organizational Membership Results

\begin{tabular}{|c|c|c|c|c|c|}
\hline & $\begin{array}{l}\text { Organization } \\
\text { 1: Public } \\
\text { Sector } \\
\end{array}$ & $\begin{array}{l}\text { Organization } \\
\text { 2: Public } \\
\text { Sector }\end{array}$ & $\begin{array}{l}\text { Organization } \\
\text { 3: Not-for- } \\
\text { profit Sector }\end{array}$ & $\begin{array}{l}\text { Organization } \\
\text { 4: Private } \\
\text { Sector } \\
\end{array}$ & $\begin{array}{l}\text { Total } \\
\text { Sample }\end{array}$ \\
\hline Generation & $\begin{array}{l}\text { Not } \\
\text { significant }\end{array}$ & $\begin{array}{l}\text { Not } \\
\text { significant }\end{array}$ & $\begin{array}{l}\text { Not } \\
\text { significant }\end{array}$ & $\begin{array}{l}\text { Not } \\
\text { significant }\end{array}$ & $\begin{array}{l}\text { Not } \\
\text { significant }\end{array}$ \\
\hline Gender & $p<.01$ & $p<.01$ & $\begin{array}{l}\text { Not } \\
\text { significant }\end{array}$ & $\begin{array}{l}\text { Not } \\
\text { significant }\end{array}$ & $p<.01$ \\
\hline Tenure & $\mathrm{p}<.01$ & $\begin{array}{l}\text { Not } \\
\text { significant }\end{array}$ & $\begin{array}{l}\text { Not } \\
\text { significant }\end{array}$ & $\begin{array}{l}\text { Not } \\
\text { significant }\end{array}$ & $\mathrm{p}<.01$ \\
\hline $\begin{array}{l}\text { Job Type } \\
\text { Dummy } 1 \\
\end{array}$ & $\mathrm{p}<.01$ & $\begin{array}{l}\text { Not } \\
\text { significant }\end{array}$ & $\mathrm{p}<.01$ & $\mathrm{p}<.01$ & $\mathrm{p}<.01$ \\
\hline $\begin{array}{l}\text { Job Type } \\
\text { Dummy } 2\end{array}$ & $\begin{array}{l}\text { Not } \\
\text { significant }\end{array}$ & $\begin{array}{l}\text { Not } \\
\text { significant }\end{array}$ & $\begin{array}{l}\text { Not } \\
\text { significant }\end{array}$ & $\begin{array}{l}\text { Not } \\
\text { significant }\end{array}$ & $\begin{array}{l}\text { Not } \\
\text { significant }\end{array}$ \\
\hline $\begin{array}{l}\text { Life Cycle } \\
\text { Stage } \\
\text { Dummy } 1 \\
\end{array}$ & $\begin{array}{l}\text { Not } \\
\text { significant }\end{array}$ & $\mathrm{p}<.01$ & $\mathrm{p}<.01$ & $\begin{array}{l}\text { Not } \\
\text { significant }\end{array}$ & $\mathrm{p}<.01$ \\
\hline $\begin{array}{l}\text { Life Cycle } \\
\text { Stage } \\
\text { Dummy } 2 \\
\end{array}$ & $\begin{array}{l}\text { Not } \\
\text { significant }\end{array}$ & $\begin{array}{l}\text { Not } \\
\text { significant }\end{array}$ & $\begin{array}{l}\text { Not } \\
\text { significant }\end{array}$ & $\begin{array}{l}\text { Not } \\
\text { significant }\end{array}$ & $\begin{array}{l}\text { Not } \\
\text { significant }\end{array}$ \\
\hline $\begin{array}{l}\text { Life Cycle } \\
\text { Stage } \\
\text { Dummy } 3\end{array}$ & $\begin{array}{l}\text { Not } \\
\text { significant }\end{array}$ & $\begin{array}{l}\text { Not } \\
\text { significant }\end{array}$ & $\begin{array}{l}\text { Not } \\
\text { significant }\end{array}$ & $\begin{array}{l}\text { Not } \\
\text { significant }\end{array}$ & $\mathrm{p}<.01$ \\
\hline $\begin{array}{l}\text { Industry } \\
\text { Sector } \\
\text { Dummy } 1 \\
\end{array}$ & $\mathrm{n} / \mathrm{a}$ & $\mathrm{n} / \mathrm{a}$ & $\mathrm{n} / \mathrm{a}$ & $\mathrm{n} / \mathrm{a}$ & $\mathrm{p}<.01$ \\
\hline $\begin{array}{l}\text { Industry } \\
\text { Sector } \\
\text { Dummy } 2 \\
\end{array}$ & $\mathrm{n} / \mathrm{a}$ & $\mathrm{n} / \mathrm{a}$ & $\mathrm{n} / \mathrm{a}$ & $\mathrm{n} / \mathrm{a}$ & $\begin{array}{l}\text { Not } \\
\text { significant }\end{array}$ \\
\hline
\end{tabular}




\section{Discussion of Results}

This chapter discusses the findings of this thesis based on the analysis found in chapter 5. This section begins with a discussion of results associated with each research question presented in Chapter 3. Next, section 6.2 discusses the supplemental research questions.

\subsection{Discussion of Primary Research Questions}

This thesis sought to determine if organizational commitment varied with generational membership. Specifically, do Baby Boomers report significantly different levels of organizational commitment than those who are members of Generation X? A number of different analyses were done to answer this question including ANOVA, ANVOCA and regression. In none of these cases did we observe a significant association between generation and organizational commitment. Furthermore, the analysis could not explain a substantive part of the variance in organizational commitment even when the covariates were included in the model.

The initial ANOVA from Table 5.10 shows that there is no significant difference in levels of organizational commitment at the $\mathrm{p}<.01$ level of significance (Research Question 1). This finding is surprising for several reasons. First, generation is determined by age and according to Becker (1960), age and tenure should be associated. 
As Becker (1960) acknowledged, you would expect tenure to have a significant impact on an individual's level of organizational commitment. However, as a variety of authors have noted, members of Generation $\mathrm{X}$ are expected to have lower levels of organizational commitment because, as children, they saw their Baby Boomer parents laid off and were influenced by this experience. When examining this observation from a different perspective, the Baby Boomer parents themselves were laid off. This could be expected to lower their levels of organizational commitment due to a change in their organizational values. In other words, the organizational environment lowered the organizational commitment levels of Baby Boomers as well as Generation X employees.

The question then becomes, if empirically there is no difference in commitment between Baby Boomers and members of Generation X, why do so many members of the general public perceive that the two are connected? There are several possible explanations for these findings. First, this research was performed through self-reported questionnaires. It is possible that the entire perception of one being committed to the organization is different for members of Generation X and Baby Boomers. Members of Generation X may see themselves as highly committed while the same levels of commitment in Baby Boomers may be perceived by the Baby Boomers themselves as lower levels of commitment. The general public may also be using behavior to identify the level of organizational commitment of individuals. Although members of Generation $\mathrm{X}$ and Baby Boomers may be equally committed, they may be perceived as having differing levels of organizational commitment based on their behaviors. A member of 
Generation $\mathrm{X}$, as suggested by the literature, may be very committed to the organization but take all their vacation and weekends off which may be perceived by Baby Boomers as lower commitment. However, the affective commitment they feel toward the organization may be equal.

Another possibility is that there is no actual difference between the organizational commitment levels of the two generations but cognitive dissonance has caused the perception. If people pay attention to the cues that support their perceptions and ignore any cues that contradict them, their original opinions will be confirmed. Therefore, the general public may draw erroneous conclusions using only the data that is available to them in the media and cognitive dissonance may result in their conclusions being erroneously confirmed.

The five covariates have an impact on organizational commitment as all are significantly related to organizational commitment at the .01 level of significance (Research Question 2). However, generation remains statistically insignificant after these covariates have been accounted for. When the model is used in a regression with only the covariates, only 3.2 percent of the variance in organizational commitment is accounted for. The majority of this variance was explained by job type, which explained more than one percent of the variance. Industry sector, gender, life cycle stage and tenure were not practically significant in terms of their relationship to organizational 
commitment. This suggests that something other than personal characteristics explains most of the variance around organizational commitment.

As mentioned above, the model including generation is not an effective predictor of organizational commitment (Research Question 3). The regression model shows that neither generation nor age add to the model. The lack of a change in the $\mathrm{R}^{2}$ value of the regression further emphasizes that generation is not significantly related to organizational commitment. The amount of the variance that was explained by the model was, therefore, explained by the covariates. Job type explained the majority of this variance and industry sector had a moderate contribution. Gender, life cycle stage and tenure were all significantly related to organizational commitment statistically but not substantively and cannot be used to predict any of the variance.

When examining generational sub-cohorts, as defined for this study, within organizational commitment (Research Question 5), there is no evidence of the existence of sub-cohorts. This also suggests that something other than personal characteristics strongly influences organizational commitment. As described in the literature review, each generation is hypothesized to have various sub-cohorts. Each of these sub-cohorts is expected to have different values. Since there is no connection between either generation and organizational commitment or generational sub-cohorts and organizational commitment, it appears that organizational commitment is not primarily based on generational values. If sub-cohorts had been found to be significant predictors of 
organizational commitment, the generations, as they were defined, would clearly need re-examination as the smaller sub-cohorts would be finding differences that were not found between generations, violating the definition of a generation as a group with similar values.

\subsection{Discussion of Supplemental Research Questions}

When examining the relationship between gender and organizational commitment (Supplemental Research Question 1), the descriptive statistics indicate that women have higher levels of organizational commitment than men. However, when gender is considered in association with the other covariates in this study, this gender difference in organizational commitment appears to be largely due to the much higher levels of organizational commitment of women in the public service sector sample. The ANCOVA shows that while gender is significantly associated with organizational commitment, this difference is not substantive. Regression results support this observation. Other than in the public service, gender was not found to be associated with organizational commitment levels of employees. These differences shed light on the mixed findings in the literature as they suggest that these differences will be observed in some samples and not others.

When examining the four life cycle stages (Supplemental Research Question 2), the descriptive statistics show that parents have higher levels of organizational commitment than those without children whether they are single or married. It appears 
based on these statistics that parental status has a positive impact on organizational commitment while marital status has no significant impact. When life cycle stage was considered in two-way ANOVAs with gender and organizational commitment, a significant difference was only found between individuals who were married with children and individuals in the three other life stages. Notably, individuals who are married with children have higher levels of organizational commitment by more than .1 of a point on the Likert-type scale. No difference was found between any of the other groups when they were examined in pairwise comparisons. This is surprising as single parents were expected to have different levels of commitment than other employees according to the literature and because the literature proposed that individuals who were married with children were more likely to have conflicting commitments that would reduce their level of commitment in the organization. However, it may be considered that when individuals only have one of the two factors examined in life cycle stage (are either married or have children but not both), they continue to have more flexibility for movement. Individuals who are married with children may have less flexibility and choose to remain in the same organization due to this. Although this appears to be primarily continuance commitment, this is not necessarily true. Once individuals have decided to remain with an organization, the simple act of making the decision and feeling tied to the organization may encourage the individual to search for reasons that the organization is worth committing to (i.e. cognitive dissonance). Such a process could perhaps help them overcome some of the barriers listed in the commitment process earlier in this paper. 
Within job type (Supplemental Research Question 3), one of the three groups has a significantly different mean organizational commitment than the other two. This is the management group, which has a mean that is statistically significantly higher (at 3.72 ) than both professionals (at 3.42) and the group that contains neither managers nor professionals (at 3.44). As these differences are both higher than .1 point on the Likerttype scale, this also shows that they may be practically significant as well. This further supports Wang and Armstrong's research showing that managers have a higher level of commitment than non-managers (2004). Managers may be expected to have higher levels of commitment because they have more authority and autonomy and they are better able to help mould the organizational culture. They may also have benefits associated with their position that further bond them to the organization. It is somewhat surprising that professionals do not have higher levels of organizational commitment than non-professionals who are not managers. It would be expected that professionals might have some of the same benefits as managers such as more autonomy in the workplace. However, professionals may also feel more freedom to leave an organization based on their levels of education and salary. Managers are also more likely to support the values and ideals of the organization as Gouldner (1960) mentions that global commitment is both to the organization and to upper management.

When examining the mean levels of organizational commitment across industry sectors (Supplemental Research Question 4), it was found that there was only a statistically significant difference when comparing other industries to the public sector. 
Mean organizational commitment does not differ between private sector employees and not-for-profit sector employees but both are statistically different than public sector employees. Public sector employees tend to have lower levels of organizational commitment with a mean score of 3.41 compared to the private and not-for-profit scores of 3.56 and 3.53 , respectively. As this is greater than a .1 point difference, this may be considered a practical difference. This is true despite the human resource practices in the public sector that would tend to support continuance commitment such as the benefits, pension plan and job security.

One consideration is that the public sector has nothing concrete to commit to. The not-for-profit sector may commit to the ideal of the organization (for example, police officers may be committed to the ideal of public safety that is engendered by the police force). Private sector employees also have something to commit to as overall organizational commitment is often to the ideas and ideals of senior management. However, the "employer" of the public sector may change at the drop of a ballot. As governments change, the senior management changes, and the ideals of the organization change. Moreover, policies may change and projects can be easily dropped as goals of the government change. Private sector firms have concrete goals: to increase market share, to make a profit or to produce a better product or service. Not-for-profit sector firms also have concrete goals of helping the public in a concrete way: improving their health, improving their safety or improving their education. However, public service firms are more reliant on following the policies of whichever government is in office, 
regardless of how far removed that government may seem in their daily activities. It is difficult to commit to the ideas of senior managers when you work in a division of a division of a department that seems indirectly related to those actually setting the agenda.

Another consideration is that the public sector may adapt to the environment more slowly due to its size and entrenched hierarchy and that the current methods in place to reward, motivate and make individuals feel connected to the organization may be outdated or non-existent. Recent downsizing and public opinion of the public sector may be factors causing individuals in the public sector to report lower levels of organizational commitment. Examining this result from a different perspective shows that the private sector and the not-for-profit sector display tendencies toward higher levels of commitment than the public sector. This may be the case in the private sector because employees tend to have better pay and a more flexible organizational hierarchy. The notfor-profit sector would also be expected to have higher levels of organizational commitment as the organizations tend to exist to help society, which is likely to cause intrinsic rewards and a high affective attachment.

The significant interaction between gender and industry sector also has some interesting implications. This interaction is the result of men and women in the public service having significantly different levels of organizational commitment. This may be because of the nature of the public service. There is legislated equality in terms of pay for work, security of employment and other issues that may be of more concern to 
women than men. The public service also offers better benefits than most private sector employers which is of more interest to women as they are more likely to need maternity leave and, as found in the literature review, are more likely to take time off work with their children. As mentioned above, there are a variety of reasons that public service members may be less committed to the organization than employees in other industry sectors. For women, benefits and working arrangements may balance out these drawbacks to cause them to have similar commitment levels to employees from other sectors. Men may not consider these benefits and working arrangements as critical to them and the drawbacks of public service employment may outweigh these in their levels of commitment to the organization.

Tenure explains less of the variance around organizational commitment than the other covariates which can be seen in the ANCOVAs as well as the regression. This is understandable as tenure is believed to impact continuance commitment rather than affective commitment, which has been measured using the OCQ. Logically, tenure is still related to organizational commitment as individuals who are highly committed to the organization are likely to remain there and, therefore, accumulate more tenure. In the case of affective commitment, we would expect this relationship and hypothesize that affective commitment may be a cause of tenure.

Finally, there was evidence that the organization of employment has a significant impact on organizational commitment as the $\mathrm{R}^{2}$ of the models controlling for 
organizational membership was much higher than the models where organizational membership was not included in this analysis $\left(\mathrm{R}^{2}\right.$ of $7.7 \%$ versus $\mathrm{R}^{2}$ of $\left.3.2 \%\right)$. These results indicate that organization of employment must be considered in any research exploring the prediction of organizational commitment. For example, this one variable was able to explain over one percent more of the variance in this organization than the other covariates. In the other specific organizations, organization of employment was found to explain no more of the variance in the second organization, over 4 percent more of the variance in the third organization and very little more of the variance in the fourth organization than the model including all the other covariates. Not only does this demonstrate that different organizations have very different impacts on an individual's level of organizational commitment but it demonstrates that industry sector does not explain this adequately as the first and second organizations were both from the public sector, the third was from the not-for-profit sector and the fourth was from the private sector.

The finding that different predictors were significant in different organizations has interesting practical applications. Since each of the covariates has a different impact on each organization, it is possibly the human resource policies that the organizations have in place, the organization's culture or other organization-specific influences have the greatest impact on organizational commitment. 


\section{Conclusions}

This chapter will present the conclusions of this thesis as well as its strengths and weaknesses. First, the research conclusions will be discussed. Next, the strengths will be addressed followed by the limitations. Following this, areas for further research will be discussed.

\subsection{Research conclusions}

This research investigated possible differences between Generation $\mathrm{X}$ and the Baby Boom Generation in organizational commitment. The most obvious conclusion from this study is that generation has no significant impact on organizational commitment as it is measured by the OCQ (affective commitment). This implies that either the popular press and the media are misrepresenting differences between the generations, that people see what they look for in others (i.e. that they expect a difference in organizational commitment between the generations so they see that difference), that the concept of generation is flawed or that different generations perceive commitment differently. In addition to this, there was no evidence of the existence of sub-cohorts.

A significant conclusion of this thesis is the impact of both gender and of an individual's life cycle stage on organizational commitment. Gender was found to have a significant but not substantive relationship with organizational commitment. This is an important finding as it supports the idea that gender cannot accurately predict 
organizational commitment, despite the views of some managers. As mentioned in the literature review on gender, many believe that women may have lower levels of commitment due to their family obligations. Because men and women currently share many of the household tasks, this could be extended to suggest that individuals who are either married or who have children are likely to be less committed. However, this does not appear to be the case. Marriage and parenthood together appear to be positively related to organizational commitment although the presence of only one or the other does not appear to have an effect.

Another conclusion of this study is that members of the public service have lower levels of organizational commitment than the private or not-for-profit sectors. This has serious ramifications as members of the public service are at or are reaching retirement age and they will need to attract new employees. Based on some of the OCQ questions such as "I promote my organization to my friends as a great company to work for", a low organizational commitment score suggests that the public service is not likely to be considered an employer of choice. As Baby Boomers move out of the workforce, management in the public service may need to put much greater effort into attracting younger employees than would be necessary if it fostered a higher level of organizational commitment. Also, attracting younger employees may not be sufficient because the lower levels of organizational commitment imply that there may be higher turnover and retention may be a problem in the public service. Employees may leave to go to private sector or not-for-profit sector firms that are considered employers of choice. 
The conclusions regarding job type supported the literature in that managers were found to have higher levels of commitment than non-managers who were not professionals. The additional finding that professionals were significantly less committed to the organization than managers suggests that professionals and managers should be considered separately in future studies. This is not often the case in current studies, which may give skewed results for both groups.

Based on the results of this study, we can conclude that organizational commitment is influenced by factors other than those included here. As these are the factors most often cited in the literature, this is a significant finding as there must be other factors that contribute more significantly. One such factor is organizational membership which provides an additional significant contribution of this study. The inclusion of organization of employment as a covariate contributes more to level of organizational commitment than the other factors examined in this study. The organization of employment has a significant impact on the level of organizational commitment of its employees. In fact, the organization of employment has a significant impact on which covariates are significant in that organization of employment. The different policies, values and cultures of different organizations appear to influence which covariates are relevant to the level of commitment of that organization's employees. This is somewhat intuitive as, for example, if an organization has undergone recent downsizing of its middle management, managers would likely not be found to have higher levels of organizational commitment than non-managers. The addition of this covariate may help 
explain conflicting findings in the literature on the significance of different variables on organizational commitment.

\subsection{Strengths}

Organizational commitment has a well-defined literature but the generation literature is much less well defined. Few empirical studies exist in this area. This research fills a gap in the literature regarding whether or not there is an actual difference in the reported level of organizational commitment between the generations. Empirical evidence from this study shows that there is no link between generations and a key work attitude: organizational commitment. Such a finding has important organizational and academic repercussions.

From an organizational perspective, the research will contribute to managerial decisions in the human resource field as differences between the generations that are empirically significant could have been the basis for changes in human resource policies. The results of this study suggest that when adjusting rewards and other benefits offered by the organization, human resource practitioners must consider factors other than age and generation if the goal is to develop a higher level of organizational commitment.

From an academic perspective, this research has found that future research does not have to control for generation when studying organizational commitment. It also 
sheds some doubt on the construct of generation and how it was operationalized in this study.

Additionally, this research is based on a large sample using good, reliable measures developed by Linda Duxbury and Chris Higgins (2001). Such a large sample would be difficult to obtain as a Master's candidate, due to the resources required for the large number and variety of organizations that agreed to participate in this study. The large sample allows a comprehensive look at this issue and provides the opportunity to control for many possible confounds. This research, therefore, provides results that are relatively generalizable across the Canadian population and thus contribute to the literature.

\subsection{Limitations}

Despite the robust nature of the research instrument, there are inevitably limitations that result. First, the study is cross-sectional in nature. Therefore, it cannot attempt to predict causality but can only demonstrate the relationships between the different variables. The questionnaire required self-reporting which may result in biases. Although organizational commitment is universally measured through self-report and often using the OCQ, it is possible that events occurring immediately prior to the respondent answering the questions may have had an effect on the responses, resulting in a bias. Using the OCQ for this study also means that this thesis will only look at one type of organizational commitment instead of examining each form of organizational 198 
commitment independently. In addition, the results of this research may not be generalizable across small and medium businesses because all of the businesses in the sample are large organizations.

An additional limitation of this study is that it is possible that "middle of the road" answers may have been given which is a common bias and a common problem for researchers. Respondents may have either spent little time on the organizational commitment questions or may not have felt strongly about the questions at the time and may have responded with a score of three or four as a result. This may not be a true reflection of their attitude and may instead reflect their desire to finish the questionnaire more quickly or to avoid choosing any abnormal responses.

As discussed in the critique of the generational literature, there is an inherent difficulty in identifying precise boundaries for each generation. This may be considered a limitation of this study as the lack of findings could conceivably be due to misidentifying the generations.

Finally, due to the use of secondary data, additional information such as ethnicity was unavailable. Other variables, such as education, were not included in this study. In addition, several data were necessarily false due to the fact that the tenure of the individual in the organization exceeded the age of the individual. As the accurate values for these individuals cannot be examined, it is unknown why this occurred. As such, it is 
also unknown whether other individuals may have made similar errors when answering their questionnaires. However, because a small proportion of the sample fell into this category, this is unlikely to influence the results.

\subsection{Suggestions for further research}

Because organizational commitment is considered such an important attitude to management and to workforces, it is recommended that further research be done in this area. This is particularly true because the workplace is changing and, as such, attitudes would be expected to change as well. Since very little of the variance in organizational commitment was explained by the variables examined, it is important to determine what factors can explain organizational commitment more thoroughly. It is possible that more organizational characteristics instead of demographics would better help describe organizational commitment. In order to determine other possible characteristics, interviews would be very insightful. Not only would interviews help determine if there are factors that are not being examined when examining organizational commitment but they would also determine whether the perception of organizational commitment is the same for members of both generations.

This same study should also be performed using Meyer and Allen's Affective Commitment Scale (ACS) to determine whether or not the same findings hold true. It could also be performed using Meyer and Allen's Normative Commitment Scale (NCS) 
and Continuance Commitment Scale (CCS) to determine the impact of generation and the covariates used in this study on the two other forms of organizational commitment.

It should also be considered that the construct of organizational commitment may have changed over time and a new measure should be developed to adequately measure organizational commitment. Although the OCQ is commonly used, it is an older measured that may be outdated given the current environment both at work and at home. New measures should be developed and examined to determine whether they can measure organizational commitment more accurately in today's environment.

It may be interesting to examine other groups that were outside the scope of this study, such as small or medium organizations or contract employees. As companies are increasingly turning to contract employees, more of a difference may be found in the level of organizational commitment in this group. This is particularly true as it is believed that members of Generation X are more likely to belong to this group.

It would also be interesting to determine whether similar findings occur when examining the impact of generation on other organizational attitudes such as job satisfaction. As job satisfaction is frequently linked to organizational commitment, it would be expected that there would be similar findings which in turn would allow future researchers and practitioners to ignore the popular concern of new generations entering the workforce, regardless of its interest to the popular press. 


\section{Bibliography}

Adams, M. (1997). Sex in the snow: Canadian social values at the end of the millennium. Toronto, Ontario: Penguin Books Canada Ltd.

Agarwala, T. (2003). Innovative human resource practices and organizational commitment: an empirical investigation. International Journal of Human Resource Management, 14(2), 175 - 197.

Alatrista, J. and Arrowsmith, J. (2004). Managing employee commitment in the not-forprofit sector. Personnel Review, 33(5), 536 - 548.

Allen, N.J. and Meyer, J.P. (1990). The measurement and antecedents of affective, continuance and normative commitment to the organization. Journal of Occupational Psychology, 63, $1-18$.

Allen, W.R., Drews, R.A., and Ruhe, J.A. (1999). Reasons why college-educated women change employment. Journal of Business and Psychology, 14(1), 77-93.

Alluto, J.A., Hrebiniak, L.G. and Alonso, R.C. (1973). On Operationalizing the Concept of Commitment. Social Forces, 51(4), $448-454$.

Altimus, C. A, and Tersine, R. J. (1973). Chronological Age and Job Satisfaction: The Young Blue-Collar Worker. Academy of Management Journal, 16, 53 - 66.

Aryee, S., and Debrah, Y.A. (1992). An Investigation of the Impact of Family and Career Variables on Organisational Commitment. Australian Journal of Management, $17(2)$.

Aven, F.F., Parker, B. and McEvoy, G.M. (1993). Gender and Attitudinal Commitment to Organizations: A Meta-Analysis. Journal of Business Research, 26(1), 63 - 73.

Bhagat, R.S. and Chassie, M.B. (1981). Determinants of Organizational Commitment in Working Women: Some Implications for Organizational Integration. Journal of Occupational Behaviour, 2(1), $17-30$.

Balfour, D. and Wechsler, B (1991). Commitment, performance, and productivity in public organizations. Public Productivity and Management Review, 14, 355 367.

Barnard, R., Cosgrave, D. and Welsh, J. (1998). Chips \& Pop, Toronto, Ontario: d Code. 
Becker, H.S. (1960). Notes on the Concept of Commitment. American Journal of Sociology, 66(1), $32-40$.

Bengtson, V. L., and Lovejoy, M. C. (1973). Values, Personality, and Social Structure. American Behavioral Scientist, 16, 880-912.

Benkhoff, B. (1997). Disentangling organizational commitment: The dangers of the OCQ for research and policy. Personnel Review, 26(1/2), $114-131$.

Berg, P., Kalleberg, A.L. and Appelbaum, E. (2003). Balancing Work and Family: The Role of High-Commitment Environments. Industrial Relations, 42(2), 168 - 188.

Bergman, B. (2002). After a Marriage Fails. Maclean's, 115(44), 52 - 54.

Bertholf, L. and Loveless, S. (2001). Baby Boomers and Generation X: Strategies to Bridge the Gap. Seminars for Nurse Managers, 9(3), 169 - 172.

Betters-Reed, B.L. and Moore, L.L. (1992) in Sekaran, U. and Leong, F.T.L (eds.) Womanpower, Sage Publications, Inc., Newbury Park, California.

Bielby, D.D. and Bielby, W.T. (1988). She Works Hard for the Money: Household Responsibilities and the Allocation of Work Effort. The American Journal of Sociology, 93(5), $1031-1059$.

Brandwein, R.A., Brown, C.A., and Fox, E.M. (1974). Women and children last: the social situation of divorced mothers and their families, Journal of Marriage and the Family, 36, 498-515.

Brickman, P. (1987). Commitment, Conflict and Caring. Prentice-Hall, Inc. New Jersey.

Bruning, N.S. and Snyder, R.A. (1983). Sex and Position as Predictors of Organizational Commitment. Academy of Management Journal, 26(3), 485 - 491.

Bohen, H., and Viveros-Long, A. (1981). Balancing jobs and family life. Philadelphia: Temple University Press.

Bourne, R.S. (1911). The Two Generations. The Atlantic Monthly. 97 (5), 591 - 598.

Bova, B. and Kroth, M. (2001). Workplace learning and Generation X. Journal of Workplace Learning, 13(2), $57-65$.

Boyne, G. A. (2002). Public and Private Management: What's the difference. Journal of Management Studies, 39(1). 
Bruning, N.S. and Snyder, R.A. (1983). Sex and Position as Predictors of Organizational Commitment. Academy of Management Journal, 26(3), 485 - 491.

Buchanan, B. (1974a). Building Organizational Commitment: The Socialization of Managers in Work Organizations. Administrative Sciences Quarterly, 19(4), 533 546.

Buchanan, B. (1974b). Government Managers, Business Executives, and Organizational Commitment. Public Administration Review, July/August, 339 - 347.

Buckley, M.R., Beu, D.S., Novicevic, M.M. and Sigerstad, T.D. (2001). Managing Generation Next: Individual and Organizational Perspectives. Review of Business, $22(1 / 2), 81-85$.

Burke, R.J. (1994a). Generation X: Measures, sex and age differences. Psychological Reports, 74, $555-562$.

Burke, R.J. (1994b). Career and life values and expectations of university business students. Psychological Reports, 75, $147-160$.

Cambiano, R.L., De Vore, J.B. and Harvey, R.L. (2001). Learning Style Preferences of the Cohorts: Generation X, Baby Boomers, and the Silent Generation. PAACE Journal of Lifelong Learning, 10, pp. $31-39$.

Charrier, K. (2000). Marketing Strategies for Attracting and Retaining Generation X. The Police Chief, December, $45-51$.

Cherrington, D. J. (1977). The Values of Younger Workers. Business horizons, 20(6), 18 -30 .

Cherrington, D. J., Condie, S.J. and England, J.L. (1979). Age and Work Values. Academy of Management Journal, 22(3), 617 - 623.

Cohen, A. (1991). Career stage as a moderator of the relationships between organizational commitment and its outcomes: A meta-analysis. Journal of Occupational Psychology, 64(I), $253-268$.

Cohen, A. (1993). Age and Tenure in Relation to Organizational Commitment: A MetaAnalysis. Basic and Applied Social Psychology, 14(2), 143 - 159.

Cohen, J. (1994). The Earth Is Round ( $p<.05)$. American Psychologist, 49(12), 997 1003. 
Colin, M. and Coy, P. (1999). The Wild New Workforce. Business Week, 6 December, $39-44$.

Comer, C. A. P. (1911). A Letter to the Rising Generation. The Atlantic Monthly, February, $145-154$.

Conger, J.A. (2001). How 'Gen X' Managers Manage In J.S. Osland, D.A. Kolb and I.M. Rubin (Eds.), The Organizational Behavior Reader (pp. 9 - 19). Upper Saddle River, New Jersey: Prentice-Hall, Inc.

Cook, J.D., Hepworth, S.J., Wall, T.D. and Warr, P.B. (1981). The Experience of Work: A Compendium and Review of 249 Measures and their Use. New York, New York: Academic Press.

Cooper, D.S. (1990). "What 25-Year Olds Want," in Fortune. August 27, 42 - 50.

Cooper, M. R., Morgan, B. S., Foley, P.M., and Kaplan, L. B. (1979). Changing Employee Values: Deepening Discontent. Harvard Business Review, 57, 117 125.

Coupland, D. (1992). Generation X: Tales for an Accelerated Culture. New York: St. Martin's Press.

Coyne, B.S. (2002). Has care giving become the new glass ceiling? A cross-cultural comparison of UK/US responses by lone parents with sole care-giving responsibilities. Human Resource Development International, 447 - 466.

Culpepper, R.A. (2000). A test of revised scales for the Meyer and Allen (1991) threecomponent commitment construct. Educational and Psychological Measurement, $60(4), 604-616$.

Currivan, D.B. (1999). The causal order of job satisfaction and organizational commitment in models of employee turnover. Human Resource Management Review, 9(4), 495 - 524.

Deutschman, A. (1999). What 25-Year-Olds Want. Fortune. August 27, $42-50$.

Dickson, J. W. and Buchholz, R.A. (1977). Managerial Beliefs About Work in Scotland and the U.S.A. The Journal of Management Studies, 80-101.

DiNatale, M. and Baraas, S. (2002). The labor force experience of women from 'Generation X'. Monthly Labor Review, March, 3-15. 
Doverspike, D., Taylor, M.A., Shultz, K.S. and McKay, P.F. (2000). Responding to the Challenge of a Changing Workforce: Recruiting Nontraditional Demographic Groups. Public Personnel Management, 29(4), 445 - 459.

Dunham, R.B., Grube, J.A. and Castañeda, M.B. (1994). Organizational Commitment: The Utility of an Integrative Definition. Journal of Applied Psychology, 79(3), $370-380$.

Duxbury, L.E. and Higgins, C. A. (1991). Gender Differences in Work-Family Conflict. Journal of Applied Psychology, 76(1), 60-74.

Duxbury, L. and Higgins, C. (2001). Work-Life Balance in the New Millenium: Where Are We? Where Do We Need To Go? CPRN Discussion Paper.

Duxbury, L. and Higgins, C. (2003). Work-Life Conflict in Canada in the New Millenium: A Status Report. Health Canada report.

Dyer, W. G. and Dyer, J. H. (1984). The $\mathrm{M}^{*} \mathrm{~A}^{*} \mathrm{~S}^{*} \mathrm{H}$ Generation: Implication for Future Organizational Values. Organizational Dynamics, 13, 66 - 79 .

Eaton, S.C. (2001). If You Can Use Them: Flexibility Policies, Organizational Commitment, and Perceived Productivity. John F. Kennedy School of Government, Harvard University, Faculty Research Working Papers Series.

Elizur, D. (1994). Gender and Work Values: A comparative analysis. Journal of Social Psychology, 134(2), $201-212$.

Etzioni, A. (1975). A comparative analysis of complex organizations. New York, New York: The Free Press.

Farrell, O. and Rusbult, C.E. (1981). Exchange variables as Predictors of Job Satisfaction, Job Commitment, and Turnover: The Impact of Rewards, Costs, Alternatives, and Investments. Organizational Behaviour and Human Performance, 28, 78-95.

Feldberg, R. and Glenn, E. (1979). Male and Female: Job Versus Gender Models in the Sociology of Work. Social Problems, 525 - 535.

Finegold, D., Mohrman, S. and Spreitzer, G.M. (2002). Age effects on the predictors of technical workers' commitment and willingness to turnover. Journal of Organizational Behavior, 23, $655-674$.

Fong, R.O. (2001). Retaining generation X'ers in a baby boomer firm. Capital University Law Review, 911 - 921. 
Foot, D.K. (1996). Boom, Bust and Echo. Toronto, Ontario: Stoddart Publishing Co. Ltd.

Fowler, Gregory W. (2003). Stone Throwing in Glass Houses: When Baby Boomers Met Generation X. Popular Culture Review, 13(2), $37-51$.

Franzblau, A. (1958). A Primer of Statistics for Non Statisticians. Harcourt Brace and World: New York.

Gakovic, A., Tetrick, L.E. (2003). Perceived organizational support and work status: a comparison of the employment relationships of part-time and full-time employees attending university classes. Journal of Organizational Behavior, 25(5), 649 667.

Gallie, D., White, M., Cheng, Y. and Tomlinson, M. (1998). Restructuring the Employment Relationship. Oxford, New York: Oxford University Press.

George, D. \& Mallery, P. (2003). SPSS for Windows Step by Step: A Simple Guide and Reference. Boston: Pearson Education, Inc.

Gerard, H.B. (1965). Deviation, conformity, and commitment. In I.D. Steiner \& M. Fishbein (Eds.), Current studies in social psychology (pp. 263-277). New York: Holt, Rinehart \& Winston.

Gibson, J.L. and Klein, S.M. (1970). Employee Attitudes as a Function of Age and Length of Service: A Reconceptualization. Academy of Management Journal, $\mathrm{V}(\mathrm{I}), 411-425$.

Gouldner, H.P. (1960). Dimensions of Organizational Commitment. Administrative Sciences Quarterly, 4(4), $468-490$.

Goulet, L.R. and Frank, M.L. (2002). Organizational Commitment Across Three Sectors: Public, Non-Profit and For-Profit. Public Personnel Management, 31(2), 201 211.

Green, S.B. and Salkind N.J. (2003). Using SPSS for Windows and Macintosh: Analyzing and Understanding Data. Prentice Hall: Upper Saddle River, New Jersey.

Gross, D.M. and Scott, S. (1990). Twenty something: proceeding with caution. Time, July $16,44-50$.

Groves, R.M., Dillman, D.A., Eltinge, J.L., and Little, R.J.A (Eds.) (2002). Survey Non Response (pp. 243 - 257). Wiley, New York. 
Gutek, B. A., Nakamura, C. Y, and Nieva, V. F. (1981). The interdependence of work and family roles. Journal of Occupational Behaviour, 2, 1-16.

Guzzo, R.A. and Noonan, K.A. (1994). Human resource practices as communications and the psychological contract. Human Resource Management, 33(3), 447 - 462.

Haar, J.M. and Spell, C.S. (2004). Programme knowledge and value of work-family practices and organizational commitment. International Journal of Human Resource Management, 15(6), 1040 - 1056.

Hackett, R.D., Bycio, P. and Hausdorf, P.A. (1994). Further Assessments of Meyer and Allen's (1991) Three-Component Model of Organizational Commitment. Journal of Applied Psychology, 79(1), $15-23$.

Hall, J.R. (1988). Social Organization and Pathways of Commitment: Types of Communal Groups, Rational Choice Theory, and the Kanter Thesis. American Sociological Review, 53(5), 679-692.

Hall, D. T. and Richter, J. (1990). Career gridlock: baby boomers hit the wall. Academy of Management Executive, 4(3), $7-22$.

Healy, G. (1999). Structuring Commitments in Interrupted Careers: Career Breaks, Commitment and the Life Cycle in Teaching. Gender, Work and Organization, 6(4).

Herrbach, O. and Mignonac, K. (2004). How organizational image affects employee attitudes. Human Resource Management, 14(4), 76 - 89.

Hessen, C.N. and Lewis, B.J. (2001). Steps You Can Take to Hire, Keep, and Inspire Generation Xers. Leadership and Management in Engineering, Winter, 42 - 44.

Higgins, C. and Duxbury, L. (2002). The 2001 National Work-Life Conflict Study. Public Health Agency report.

Howe, N. and Strauss, W. (1992). The New Generation Gap. The Atlantic Monthly, December, $67-89$.

Howe, N. and Strauss, W. (1993). $13^{\text {th }}$ Gen: Abort, Retry, Ignore, Fail? New York, New York: Vintage Books (A Division of Random House, Inc.).

Hrebiniak, L.G. and Alutto J.A. (1972). Personal and role-related factors in the development of organizational commitment. Administrative Science Quarterly, $555-573$. 
Hutcheson, Graeme and Nick Sofroniou (1999). The multivariate social scientist: Introductory statistics using generalized linear models. Thousand Oaks, CA: Sage Publications.

Hulin, C. (1991). Adaptation, Persistence, and Commitment in Organizations. In M.D. Dunnette and L.M. Hough (Eds.), Handbook of Industrial \& Organizational Psychology (pp. 445 - 505). Palo Alto, California: Consulting Psychologists Press, Inc.

Ik-Whan, G.K. and Banks, D.W. (2004). Factors related to the organizational and professional commitment of internal auditors. Managerial Auditing Journal, $19(5), 606-622$.

Jans, N.A. (1989). Organizational commitment, career factors and career/life stage. Journal of Organizational Behavior, 10, 246 - 266.

Johnson, M.P. (1973). Commitment: A conceptual structure and empirical application. The Sociological Quarterly, 14, 395-406.

Johnson, L.K. (2005). The new loyalty: make it work for your company. Harvard Management Update, 10(3), 3 - 7.

Jurkiewicz, C.L. and Brown, R.G. (1998). GenXers vs. boomers vs. matures: Generational comparisons of public employee motivation. Review of Public Personnel Administration, 18(4), 18 - 37.

Jurkiewicz, C.L. (2000). Generation X and the Public Employee. Public Personnel Management, 29(1), 55-74.

Kacmar, K.M., Carlson, D.S., and Brymer, R.A. (1999). Antecedents and consequences of organizational commitment: a comparison of two scales. Educational and Psychological Measurement, 59(6), 976 - 994.

Kanter, R.M. (1968). Commitment and Social Organization: A Study of Commitment Mechanisms in Utopian Communities. American Sociological Review, 33(4), 499 $-517$.

Kiechel, W. (1989). The Workaholic Generation. Fortune, April 10, 50 - 62.

Kirk, R.E. (1996). Practical Significance: A concept whose time has come. Educational and Psychological Measurement, 56(5), 746 - 759.

Kline, J. and Peters, L. (1991). Behavioral commitment and tenure of new employees: A replication and extension. Academy of Management Journal, 34, 320 - 331. 
Korabik, K. and Rosin, H.M. (1995). The Impact of Children on Women Managers' Career Behavior on Organizational Commitment. Human Resource Management, $34(4), 513-528$.

Krantz, D.H. (1999). The Null Hypothesis Testing Controversy in Psychology. Journal of the American Statistical Association, 44(448), 1372 - 1381.

Lachman, R. and Aranya, N. (1986). Job Attitudes and Turnover Intentions Among Professionals in Different Work Settings. Organization Studies 7(3), 279 - 293.

Lankau, J. J. and Scandura, T. (1997). Relationships of gender, family responsibility, and flexible work hours to organizational commitment and job satisfaction. Journal of Organizational Behavior, 18(4), 377 - 391.

Laufer, R.S. and Bengtson, V.L. (1974). Generations, Aging, and Social Stratification: on the Development of Generational Units. Journal of Social Issues, 30(3), 181 204.

Lefkowitz, J. (1994). Sex-related differences in job attitudes and dispositional variables: Now you see them, ... Academy of Management Journal, 37(2), 323 - 349.

Little, R.J.A. \& Rubin, D.B. (1983). Missing Data in Large Data Sets. Statistical Methods and the Improvement of Data Quality, T. Wright (Ed.). pp. $215-243$.

Locke, Edwin A. (1968). Toward a Theory of Task Motivation and Incentives. Organizational Behavior and Human Performance, 3, 157 - 189.

Lord, A. and Hartley, J. (1998). Organizational Commitment and Job Insecurity in a Changing Public Service Organization. European Journal of Work and Organizational Psychology, 7(3), 341 - 354.

Loscocco, K. (1990). Reactions to Blue-Collar Work: A Comparison of Women and Men. Work and Occupations, $152-177$.

Losyk, B. (1997). Generation X: What They Think and What They Plan to Do. The Futurist, $39-44$.

Lyons, S. (2003). An Exploration of Generational Values in Life and at Work. Doctoral Thesis.

Maccoby, M. (1988). Why Work. New York, New York: Simon and Schuster. 
Mackenzie Davey, K. (1998). Book Review: Commitment in the Workplace: Theory, Research and Application. British Journal of Industrial Relations, V(I), $674-$ 675.

Manion, J. (2004). Strengthening Organizational Commitment: Understanding the Concept as a Basis for Creating Effective Workforce Retention Strategies. The Health Care Manager, 23(2), 167 - 176.

Mannheim, K. (1952). Essays on the Sociology of Knowledge, London: Routledge \& Kegan Paul Ltd.

Masters, W.H. and Johnson, V.E. (1974). The pleasure bond: A new look at sexuality and commitment. Boston: Little, Brown

Mathieu, J. E. and Zajac, D. M. (1990). A Review and Meta-Analysis of the Antecedents, Correlates, and Consequences of Organizational Commitment. Psychological Bulletin, 108, 171 - 194.

Marciniak, J. (2002). The Taming of the Slacker. Brandweek, 43(28), 18.

Marsden, P.V., Kalleberg, A.L. and Cook, C.R. (1993). Gender differences in Organizational Commitment: Influences of Work Positions and Family Roles. Work and Occupations. 20(3), $368-390$.

May, T.M., Korczynski, M. and Frenkel, S.J. (2002). Organizational and occupational commitment: knowledge workers in large corporations. Journal of Management Studies, 39(6), $775-801$.

McGee, G.W. and Ford, R.C. (1987). Two (or More?) Dimensions of Organizational Commitment: Reexamination of the Affective and Continuance Commitment Scales. Journal of Applied Psychology, 72(4), 638 - 642.

Mellor, S., Mathieu, J., Barnes-Farrell, J. and Rogelberg, S. (2001). Employees' nonwork obligations and organizational commitments: a new way to look at the relationship. Human Resource Management, 40(2), 171 - 184.

Meyer, J.P. and Allen, N.J. (1984). Testing the "Side-Bet Theory" of Organizational Commitment: Some Methodological Considerations. Journal of Applied Psychology, 69(3), $372-378$.

Meyer, J.P. and Allen, N.J. (1987). A longitudinal analysis of the early development and consequences of organizational commitment. Canadian Journal of Behavioural Science, 19(2), $199-215$. 
Meyer, J.P. and Allen, N.J. (1988). Links between work experiences and organizational commitment during the first year of employment: A longitudinal analysis. Journal of Occupational Psychology, 61, pp.195 - 209.

Meyer, J.P. and Allen, N.J. (1991). A three-component conceptualization of organizational commitment. Human Resource Management Review, 1(1), 61 89.

Meyer, J.P., Allen, N.J. and Smith, C.A. (1993). Commitment to Organizations and Occupations: Extension and Test of a Three-Component Conceptualization. Journal of Applied Psychology, 69(3), 372 - 378.

Meyer, J.P. and Allen, N.J. (1997). Commitment in the workplace: Theory, research, and application. Thousand Oaks, California: Sage Publications, Inc.

Meyer, J.P., Allen, N.J. and Topolnytsky, L. (1998). Commitment in a Changing World of Work. Canadian Psychology, 39(1-2), 83 - 93.

Miller, C.S. (2000). Selling Variable Life to Generation X. Advisortoday, November, 110 -112 .

Mir, A., Mir, R. and Mosca, J.B. (2002). The New Age Employee: An Exploration of Changing Employee-Organization Relations. Public Personnel Management, $31(2), 187-200$.

Morris J. H. and Sherman J.D. (1981). Generalizability of an Organizational Commitment Model. Academy of Management Journal, 24, 512 - 526.

Mowday, R.T., Porter, L.W. and Steers, R.M. (1982). Employee-organization linkages: The psychology of commitment, absenteeism, and turnover. San Diego, CA: Academic Press.

Mowday, R.T., Steers, R.M. and Porter, L.W. (1979). The Measurement of Organizational Commitment. Journal of Vocational Behavior, 14, $224-247$.

Munk, Nina. (1998). The New Organization Man. Fortune, March 16, $62-82$.

Ngo, H. and Tsang, A.W. (1998). Employment practices and organizational commitment: Differential effects for men and women? International Journal of Organizational Analysis, 6(3), 251 - 266.

Nicholson, W.L., (1983). Analyzing Large Data Sets: A challenge for Statistical Computing in Proceedings of the American Statistical Society: Stat. Comp. Section. $194-199$. 
O'Reilly, C.A. and Caldwell, D.F. (1981). The Commitment and Job Tenure of New Employees: Some Evidence of Postdecisional Justification. Administrative Science Quarterly, 26(?), $597-616$.

O'Reilly, C. and Chatman, J. (1986). Organizational Commitment and Psychological Attachment: The Effects of Compliance, Identification, and Internalization on Prosocial Behavior. Journal of Applied Psychology, 71(3), 492 - 499.

Page, M. and Stevens, A. (2004). The EconomicConsequences of Absent Parents. Journal of Human Resources, 39(1), 80 - 108.

Paulin, G. and Riordon B. (1998). Making it on their own: the baby boom meets Generation X. Monthly Labor Review, February, 10-21.

Payne, S.C. and Huffman, A.H. (2005). A longitudinal examination of the influence of mentoring on organizational commitment and turnover. Academy of Management Journal, 48(1), $158-169$.

Pekala, N (2001). Conquering the Generational Divide. Journal of Property Management, November/December, 1 - 8 .

Popenoe, D. (1996) Life Without Father, New York: The Free Press, p. 6.

Poindexter, P.M. and Lasorsa, D.L. (1999). Generation X: Is its meaning understood? Newspaper Research Journal, 20(4), 28 - 36.

Reed, S.A., Kratchman, S.H., and Strawser, R.H. (1994). Job Satisfaction, Organizational Commitment, and Turnover Intentions of United States Accountants: The Impact of Locus of Control and Gender. Accounting, Auditing \& Accountability Journal, 7(1), $31-58$.

Riketta, M. (2002). Attitudinal organizational commitment and job performance: a metaanalysis. Journal of Organizational Behavior 23, 257 - 266.

Riley, M.W. (1973). Aging and cohort succession: Interpretations and misinterpretations. Public Opinion Quarterly, 37, 35 - 49.

Ritzer, G. and Trice, H.M. (1969). An Empirical Study of Howard Becker's Side-Bet Theory. Social Forces, 47(4), $475-478$.

Rodgers, F.S. and Rodgers, C. (1989). Business and the Facts of Family Life. Harvard Business Review, November-December, $121-131$. 
Romaniuc, A. (1984). Fertility in Canada: From Baby-boom to Baby-bust. Current Demographic Analysis, 1 - 73.

Rosow, I. (1978). What Is a Cohort and Why? Human Development 21, 65 - 75.

Ruch, W. (2000). How to Keep Gen X Employees From Becoming X-Employees. Training and Development, 54(4), $40-43$.

Russ, F.A. and McNeilly, K.M. (1995). Links among Satisfaction, Commitment, and Turnover Intentions: The Moderating Effect of Experience, Gender, and Performance. Journssal of Business Research, 34, 57 - 65.

Ryder, N. B. (1965). The Cohort as a Concept in the Study of Social Change. American Sociological Review, 30(6), $843-861$.

Salancik, G.R. (1977). Commitment and the control of organizational behavior and belief. In B.M. Staw and G.R. Salancik (Eds.), New directions in organizational behavior. Chicago: St. Clair Press.

Scandura, T.A. and Lankau, M.J. (1997). Relationships of gender, family responsibility and flexible work hours to organizational commitment and job satisfaction. Journal of Organizational Behavior, 18, $377-391$.

Scott, J. (2000). Is it a different world from when you were growing up? Generational effects on social representations and child-rearing values. British Journal of Sociology, 51(2), $355-376$.

Schrammel, Kurt. (1998). Comparing the Labor Market Success of Young Adults From Two Generations. Monthly Labor Review, $3-9$.

Shoemaker, D.J., Snizek, W.E. and Bryant, C.D. (1977). Toward a Further Clarification of Becker's Side-Bet Hypothesis as Applied to Organizational and Occupational Commitment. Social Forces, 56(2), $598-603$.

Singh, V. and Vinnicombe, S. (2000). What does "commitment" really mean? Personnel Review, 29(2), $228-258$.

Smola, K.W. and Sutton, C.D. (2002). Generational differences: revisiting generational work values for the new millennium. Journal of Organizational Behavior, 23, $363-382$.

Spencer, A. and Podmore, D. (1987). In a Man's World: Essays on Women in Maledominated professions. Tavistock Publications, London. 
Spencer, B. (1995). Correlations, sample size and practical significance: a comparison of selected psychological and medical investigations. The Journal of Psychology 129(4), $469-475$.

Statistics Canada (2002b). Census families in private householods by framily structure and presence of children, by provinces and territories (2001 Census). 2001 Census of Canada. Ottawa: Statistics Canada.

Statistics Canada (2002c). Age and Sex for Population, for Canada, Provinces, Territories, Census Metropolitan Areas and Census Agglomerations, 2001 Census. 2001 Census of Canada. Ottawa: Statistics Canada.

Statistics Canada (2002d). Population by marital status and sex. Statistics Canada, CANSIM II, table 051-0010.

Statistics Canada (2002e). Average total income by economic family types. Statistics Canada, CANSIM II, table 202-0403.

Statistics Canada (2002f). Occupational skill groups by sex. 2001 Census of Canada. Ottawa: Statistics Canada.

Statistics Canada (2003). Class of Worker (12), Age Groups (10) and Sex (3) for Labour Force 15 Years and Over, for Canada, Provinces, Territories, Census Metropolitan Areas and Census Agglomerations, 2001 Census - 20\% Sample Data. 2001 Census of Canada. Ottawa: Statistics Canada.

Stauffer, D. (1997). For Generation Xers, what counts isn't all work or all play. Management Review, 86(11), 7.

Stebbins, R.A. (1970). On Misunderstanding the Concept of Commitment: A Theoretical Clarification. Social Forces, 48(4), 526 - 529.

Steers, R.M. (1977). Antecedents and Outcomes of Organizational Commitment. Administrative Science Quarterly, 22 (March), 46 - 56.

Steinhaus, C. and Perry, J. (1996). Organizational commitment: Does sector matter? Public Productivity and Management Review, 19, 278 - 288.

Stewart, C. S. (2002). Gen X Rising. Potentials, 35 (9), 22 - 29.

Stevens, J. (1996). Applied Multivariate Statistics for the Social Sciences. Lawrence Erlbaum Associates: Mahwah, New Jersey. 
Sturges, J., Guest, D., Mackenzie Davey, K.(2000). Who's in charge? Graduates' attitudes to and experiences of career management and their relationship with organizational commitment. European Journal of Work and Organizational Psychology, 9(3), 351-370.

Sturges, J., Guest, D., Conway, N. and Mackenzie Davey, K. (2001). What difference does it make? A longitudinal study of the relationship between career management and organizational commitment in the early years at work. Academy of Management Proceedings, V(I), pages.

Subramaniam, N. \& Lokman, M. (2003). A not on work-related values, budget emphasis and managers' organisational commitment. Management Accounting Research 2003 (14), $389-408$.

Svyantek, D.J. \& Ekeberg, S.E. (1995). Strong hypothesis testing in organizations: Alternative approaches to the evaluation or practical significance. The International Journal of Organizational Analysis, 3(4), 361 - 374.

Swailes, S. (2002). Organizational commitment: a critique of the construct and measures. International Journal of Management Reviews, 4(2), 155 - 178.

Tabachnick, B.G. and Fidell, L.S. (1983). Using Multivariate Statistics. New York: Harper \& Row, Publishers, Inc.

Tansky, J.W. and Gallagher, D.G. (1997). The effect of demographics, work status and relative equity on organizational. Canadian Journal of Administrative Sciences, $14(3), 315-327$.

Taormina, R.J. (1999). Predicting employee commitment and satisfaction: the relative effects of socialization and demographics. International Journal of Human Resource Management, 10(6), 1060 - 1076.

Taylor, R. N. and Thompson, M. (1976). Work Value Systems of Young Workers. Academy of Management Journal, 19(4), 522 - 536.

Thomas, L. Eugene. (1974). Generational Discontinuity in Beliefs: An Exploration of the Generation Gap. Journal of Social Issues, 30(3), 1 - 22.

Tulgan, B. (2000). Managing Generation X. New York, New York: W.W. Norton \& Company,

Inc.

Tulgan, Bruce. (1997). Bringing Out the Best in Today's Young People. Management Development Review, 10(3), $92-93$. 
Van der Velde, M.E.G., Bossink, C.J.H., and Jansen, P.G.W. (2003). Gender Differences in the Influence of Professional Tenure on Work Attitudes. Sex Roles, 49(3/4), $153-162$.

Vanier Institute of the Family. (1997). From the Kitchen Table to the Boardroom Table: The Canadian Family and the Workplace. Ottawa: Vanier Institute of the Family.

Vinkenburg, C.J., Jansen, P.G.W. and Koopman, P.L. (2000) in Davidson, M.J. and Burke, R.J. (eds.) Women in Management. SAGE Publications Ltd., London.

Virick, M., Misra, R. \& Czekajewski, A.M. (2004). Diversity Climate: A reality check. Academy of Management Proceedings, 2004.

Wallace, J.E. (1995). Organizational and Professional Commitment in Professional and Nonprofessional Organizations. Administrative Science Quarterly, 40(June), 228 -255 .

Wang, X and Armstrong, A. (2004). An empirical study of PM professionals' commitment to their profession and employing organizations. International Journal of Project Management, 2004(22), 377 - 386.

Washburn, Earl R. (2000). Are You Ready For Generation X? Physician Executive, $26(1), 51-57$.

Watson, N. (2002). Generation Wrecked. Fortune, 146(7), 183 - 188.

Werbel, J.D. and Gould, S. (1984). A Comparison of the Relationship of Commitment to Turnover in Recent Hires and Tenured Employees. Journal of Applied Psychology, 69(4), 687-690.

West, R. (2004). Not just a token gesture. Marketing Week, 27(48), 45 - 46.

Weston, M.J. (2001). Leading into the Future: Coaching and Mentoring Generation X Employees. Seminars for Nurse Managers, 9(3), 157 - 160.

White, B. (2000) in Davidson, M.J. and Burke, R.J. (eds.) Women in Management. SAGE Publications Ltd., London.

Wiener, Y. (1982). Commitment in Organizations: A Normative View. Academy of Management Review, 7(3), 418-428.

Wilkerson, M. \& Olson, M.R. (1997). Misconceptions about sample size, statistical significance, and treatment effect. The Journal of Psychology, 131(6), 627 - 631. 
Young, B.S., Worchel, S. and Woehr, D.J. (1998). Organizational commitment among public service employees. Public Personnel Management, 27(3), 339 - 349.

Zemke, R., Raines, C. and Filipczak, B. (1999). Generations at Work: Managing the Clash of Veterans, Boomers, Xers and Nexters in Your Workplace. New York: AMACOM Books. 

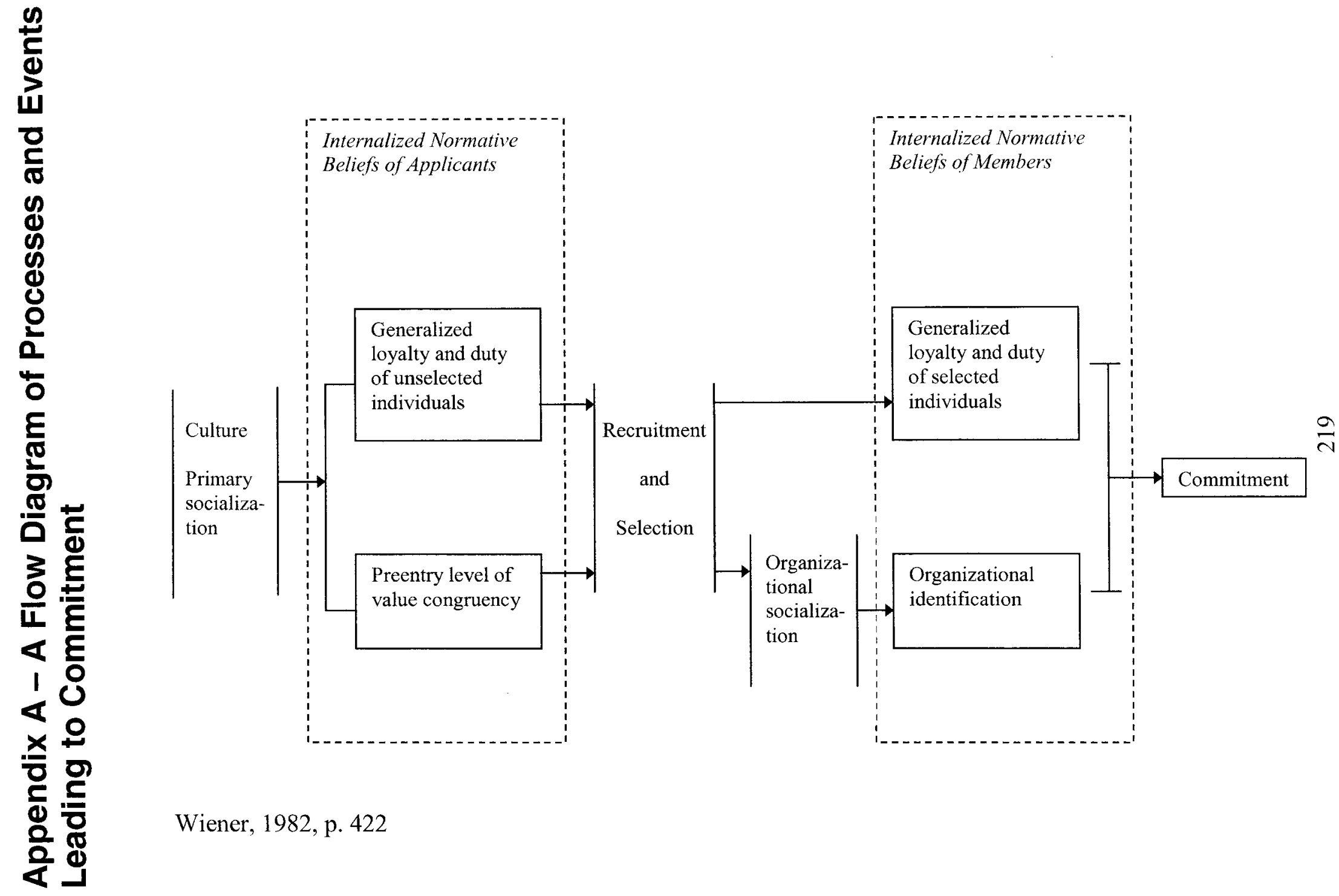
Meyer and Allen, 1991, p. 68

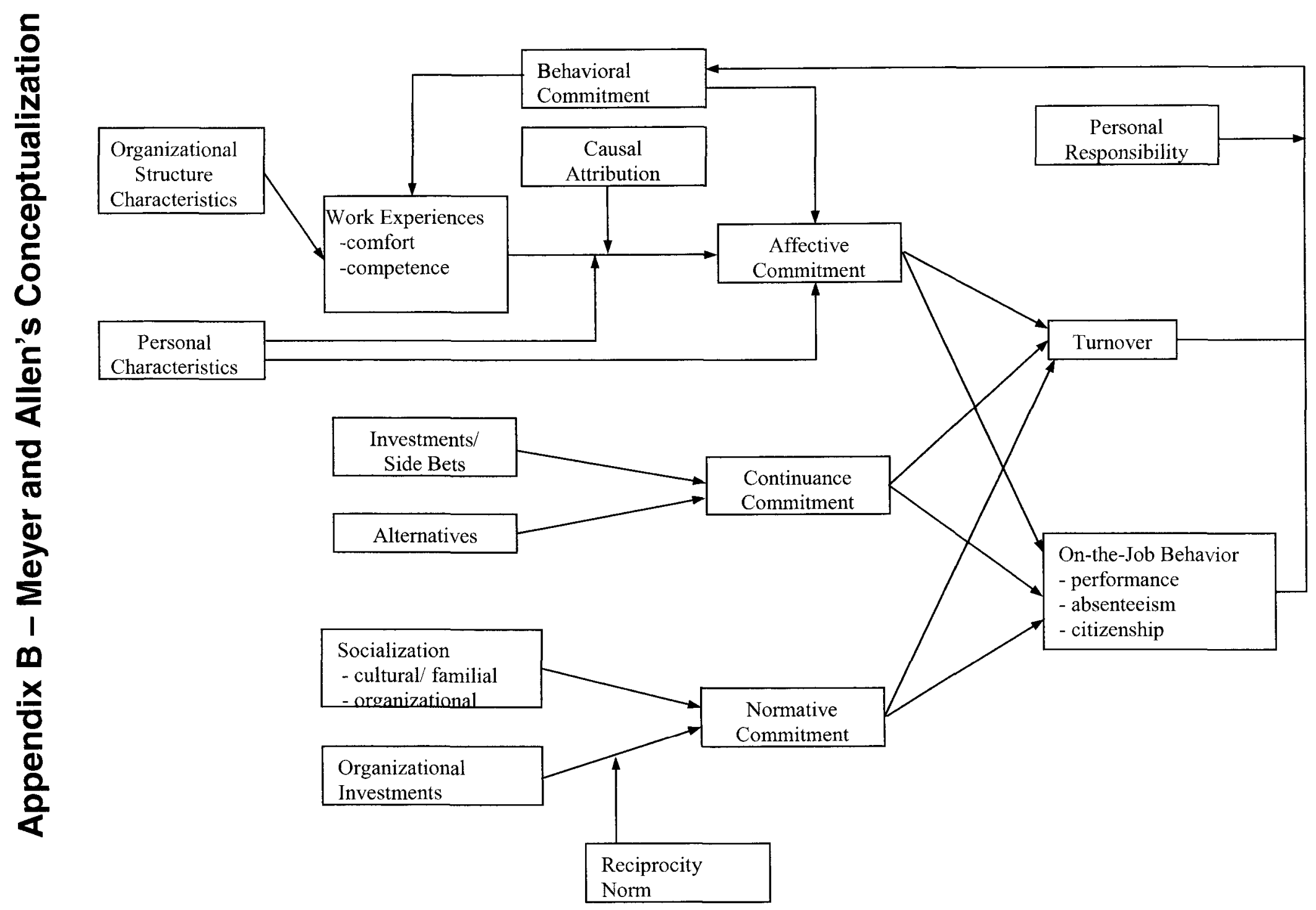


Organizational Commitment Questionnaire (OCQ) (Mowday et al., 1979)

Instructions

Listed below are a series of statements that represent possible feelings that individuals might have about the company or organization for which they work. With respect to your own feelings about the particular organization for which you are now working [company name] please indicate the degree of your agreement or disagreement with each statement by checking one of the seven alternatives below each statement. ${ }^{\text {a }}$

1. I am willing to put in a great deal of effort beyond that normally expected in order to help this organization be successful.

2. I talk up this organization to my friends as a great organization to work for.

3. I feel very little loyalty to this organization. (R)

4. I would accept almost any type of job assignment in order to keep working for this organization.

5. I find that my values and the organization's values are very similar.

6. I am proud to tell others that I am part of this organization.

7. I could just as well be working for a different organization as long as the type of work were similar. (R)

8. This organization really inspires the very best in me in the way of job performance.

9. It would take very little change in my present circumstances to cause me to leave this organization. (R)

10. I am extremely glad that I chose this organization to work for over others I was considering at the time I joined.

11. There's not too much to be gained by sticking with this organization indefinitely. (R)

12. Often, I find it difficult to agree with this organization's policies on important matters relating to its employees. (R)

13. I really care about the fate of this organization.

14. For me this is the best of all possible organizations for which to work.

15. Deciding to work for this organization was a definite mistake on my part. (R)

${ }^{a}$ Responses to each item are measured on a 7-point scale with scale point anchors labeled (1) strongly disagree; (2) moderately disagree; (3) slightly disagree; (4) neither disagree nor agree; (5) slightly agree; (6) moderately agree; (7) strongly agree. An R denotes a negatively phrased and reverse-scored item. 


\section{Appendix D - Meyer and Allen's Three Measures}

(1) represents strongly disagree and (7) represents strongly agree

\begin{tabular}{|c|c|}
\hline \multicolumn{2}{|l|}{ Affective Commitment Scale Items } \\
\hline $\begin{array}{l}\text { 1. I would be very happy to spend the rest of my career with this } \\
\text { organization. }\end{array}$ & 1234567 \\
\hline 2. I enjoy discussing my organization with people outside it. & 1223445667 \\
\hline 3. I really feel as if this organization's problems are my own. & 1223445567 \\
\hline $\begin{array}{l}\text { 4. I think that I could easily become as attached to another } \\
\text { organization as I am to this one. (R) }\end{array}$ & 1234567 \\
\hline 5. I do not feel like 'part of the family' at my organization. (R) & 1223445667 \\
\hline 6. I do not feel 'emotionally attached' to this organization. (R) & 123345567 \\
\hline 7. This organization has a great deal of personal meaning for me. & 1223345567 \\
\hline $\begin{array}{l}\text { 8. I do not feel a strong sense of belonging to my organization. } \\
\text { (R) }\end{array}$ & 123345667 \\
\hline \multicolumn{2}{|l|}{ Continuance commitment Scale items } \\
\hline $\begin{array}{l}\text { 1. I am not afraid of what might happen if I quit my job without } \\
\text { having another one lined up. (R) }\end{array}$ & 12334567 \\
\hline $\begin{array}{l}\text { 2. It would be very hard for me to leave my organization right } \\
\text { now, even if I wanted to. }\end{array}$ & 1234567 \\
\hline $\begin{array}{l}\text { 3. Too much in my life would be disrupted if I decided I wanted } \\
\text { to leave my organization now. }\end{array}$ & 123345567 \\
\hline $\begin{array}{l}\text { 4. It wouldn't be too costly for me to leave my organization now. } \\
\text { (R) }\end{array}$ & 12334567 \\
\hline $\begin{array}{l}\text { 5. Right now, staying with my organization is a matter of } \\
\text { necessity as much as desire. }\end{array}$ & 123345567 \\
\hline $\begin{array}{l}\text { 6. I feel I have too few options to consider leaving this } \\
\text { organization. }\end{array}$ & 12345567 \\
\hline $\begin{array}{l}\text { 7. One of the few serious consequences of leaving this } \\
\text { organization would be the scarcity of available alternatives. }\end{array}$ & 123345667 \\
\hline $\begin{array}{l}\text { 8. One of the major reasons I continue to work for this } \\
\text { organization is that leaving would require considerable } \\
\text { personal sacrifice - another organization may not match the } \\
\text { overall benefits I have here. }\end{array}$ & 122345567 \\
\hline \multicolumn{2}{|l|}{ Normative commitment scale items } \\
\hline $\begin{array}{l}\text { 1. I think that people these days move from company to company } \\
\text { too often. }\end{array}$ & 123345667 \\
\hline $\begin{array}{l}\text { 2. I do not believe that a person must always be loyal to his or her } \\
\text { organization. }\end{array}$ & 12345567 \\
\hline $\begin{array}{l}\text { 3. Jumping from organization to organization does not seem at all } \\
\text { unethical to me. (R) }\end{array}$ & 123345567 \\
\hline $\begin{array}{l}\text { 4. One of the major reasons I continue to work for this } \\
\text { organization is that I believe that loyalty is important and }\end{array}$ & 122345567 \\
\hline
\end{tabular}


therefore feel a sense of moral obligation to remain.

5. If I got another offer for a better job elsewhere I would not feel $\mid \begin{array}{lllllll}1 & 2 & 3 & 4 & 5 & 6 & 7\end{array}$ it was right to leave my organization.

6. I was taught to believe in the value of remaining loyal to one

1223445667 organization.

7. Things were better in the days when people stayed with one organization for most of their careers.

8. I do not think that wanting to be a 'company man' or 'company 1223545667 woman' is sensible anymore. (R) 


\section{Appendix E - Age Chart with Sub-cohorts}

(adapted from Romaniuc, Fertility in Canada: From Baby-boom to Baby-bust: Current Demographic Analysis)

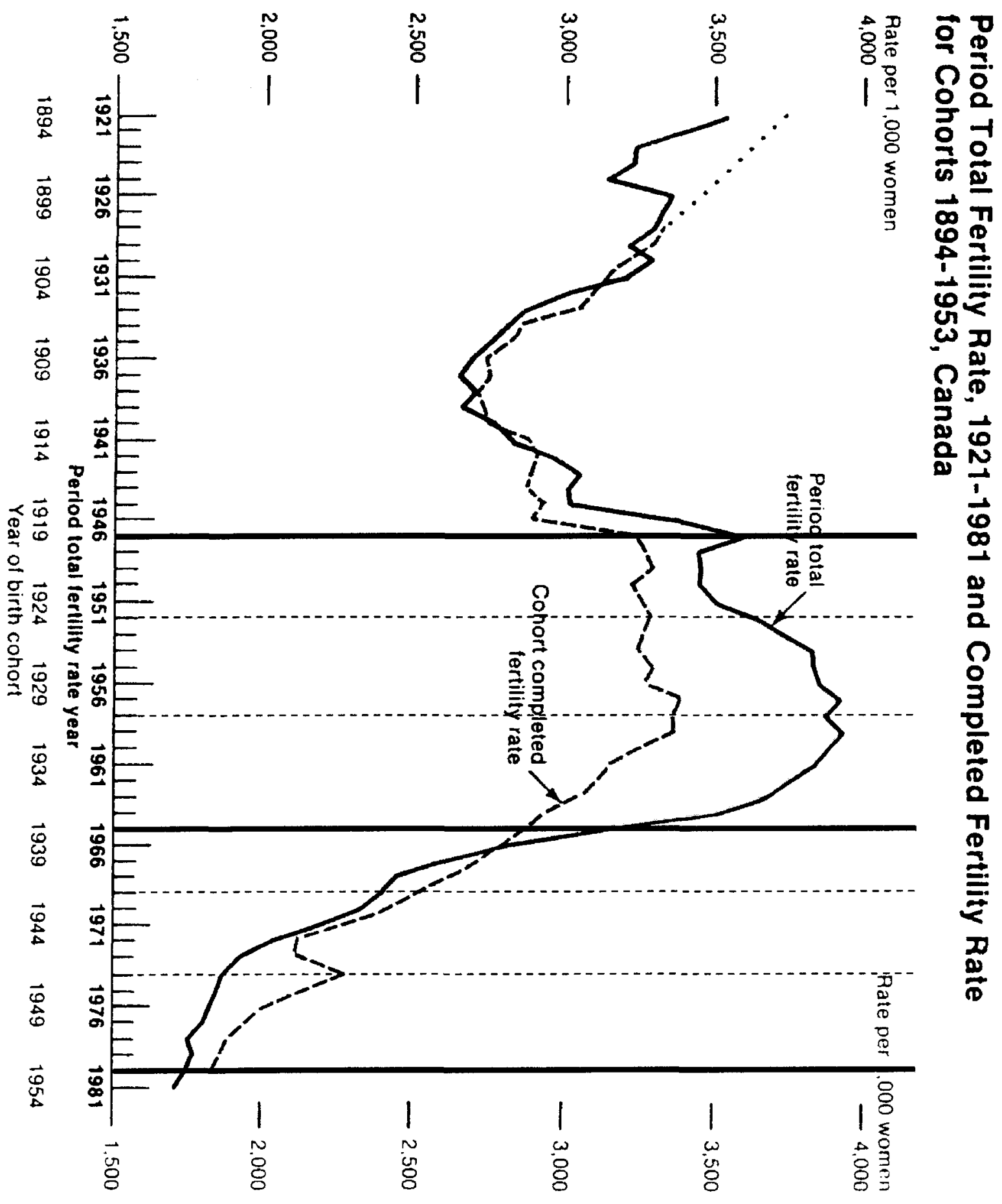




\section{Appendix F - Balancing Work, Family and Lifestyle National Study (adapted to include only relevant sections)}

\section{Section A: Your Job}

1. Please indicate the extent to which you agree or disagree with the following statements (where 1 is Strongly Disagree, 3 is Neutral and 5 is Strongly Agree):

\begin{tabular}{|l|c|c|c|c|c}
\hline $\begin{array}{l}\text { I am willing to put in a great deal of effort in order to help this organization be } \\
\text { successful }\end{array}$ & 1 & 2 & 3 & 4 & 5 \\
\hline I promote my organization to my friends as a great company to work for & 1 & 2 & 3 & 4 & 5 \\
\hline $\begin{array}{l}\text { I would accept almost any type of job assignment in order to keep working for } \\
\text { this organization }\end{array}$ & 1 & 2 & 3 & 4 & 5 \\
\hline I find that my values and my organization's values are very similar & 1 & 2 & 3 & 4 & 5 \\
\hline I am proud to tell others that I am part of this organization & 1 & 2 & 3 & 4 & 5 \\
\hline My organization inspires the very best in me in terms of performance & 1 & 2 & 3 & 4 & 5 \\
\hline $\begin{array}{l}\text { I am extremely glad that I chose this organization to work for over others I was } \\
\text { considering at the time I joined }\end{array}$ & 1 & 2 & 3 & 4 & 5 \\
\hline I really care about the fate of this organization & 1 & 2 & 3 & 4 & 5 \\
\hline For me, this is the best of all possible organizations for which to work & 1 & 2 & 3 & 4 & 5 \\
\hline
\end{tabular}

\section{Section I: Information about you}

46. Are you male or female?

$\square$ Male

$\square$ Female

47. What is your age?

48a. What is your present marital status?

口 Never Married

口 Married or Living with a Partner

$\square$ Separated or Divorced

$\square$ Widowed

49. How many children do you have? $\quad \begin{array}{lllllllll}0 & \square 1 & \square 2 & \square 3 & \square 4 & \square 5 & \square 6 & \square 7+\end{array}$

59. Please (identify) the answer which best fits more of the work:

You do:

Your partner does: 


\author{
$\square$ Managerial \\ $\square$ Professional \\ 口 Technical \\ - Administrative \\ - Clerical \\ 口 Retail \\ 口 Production \\ $\square$ Other \\ ㅁ Homemaker
}

$\square$ Managerial

- Professional

口 Technical

$\square$ Administrative

- Clerical

口 Retail

- Production

口 Other

口 Homemaker

61. How long have you worked for your current organization?

YEAR(S)

65. What is your employment status?

$\square$ Full Time

口 Part Time

66. Is your job a contract or temporary position?

$\square$ Contract

$\square$ Temporary 
Tabachnick \& Fidell, 1983, p. 62

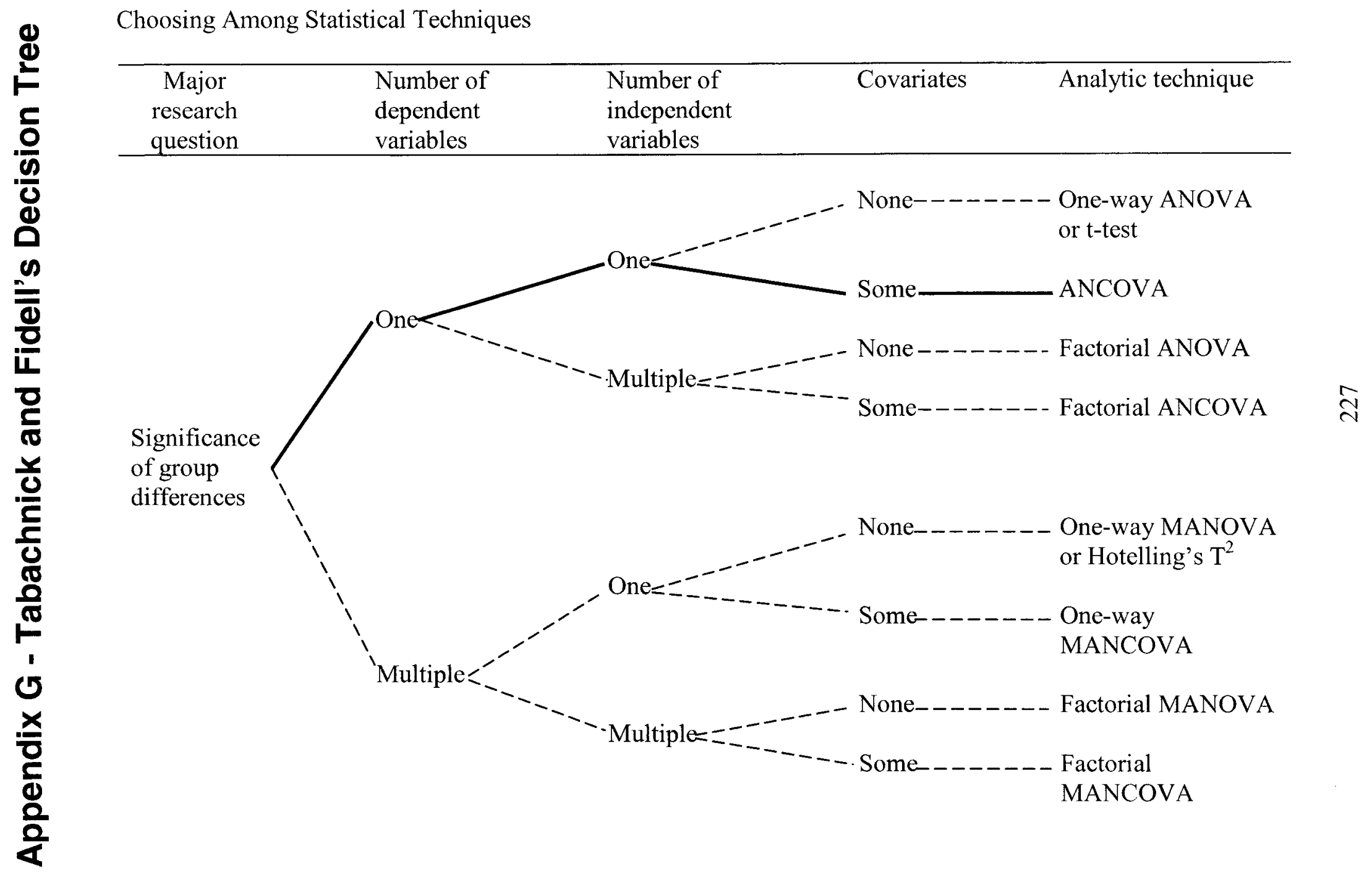




\section{Appendix H - Dummy Coding}

When performing an ANCOVA, covariates must be either continuous or dichotomous. If a covariate is not dichotomous, the values assigned to each of the groups will be considered levels of magnitude as they would be for continuous variables. Of the five covariates, only tenure (a continuous variable) and gender (a dichotomous variable) are already in this form. Therefore, tenure, life cycle stage, job type, and industry sector must be converted into dummy variables (Stevens, 1996). This is done by making $\mathrm{k}-1$ variables, where $\mathrm{k}$ is the number of groups for that variable. Therefore, industry sector and job type each must be broken down into two dummy variables and life cycle stage must be divided into three dummy variables.

Using industry sector as an example, there are three possible groups to which an individual may belong: the public sector, the private sector or the not-for-profit sector. The two dummy variables named "industry sector dummy 1" and "industry sector dummy 2" are used to code the three categories as seen in the following table.

\begin{tabular}{|l|c|c|}
\hline Group & $\begin{array}{c}\text { Value of "industry } \\
\text { sector dummy 1" }\end{array}$ & $\begin{array}{c}\text { Value of "industry } \\
\text { sector dummy 2" }\end{array}$ \\
\hline Public Sector & 1 & 0 \\
\hline Private Sector & 0 & 1 \\
\hline Not-for-profit Sector & 0 & 0 \\
\hline
\end{tabular}




\section{Appendix I - Paid Labour Force}

Class of Worker (12), Age Groups (10) and Sex (3) for Labour Force 15 Years and Over, for Canada, Provinces, Territories, Census Metropolitan Areas and Census Agglomerations, 2001 Census - 20\% Sample Data

\begin{tabular}{|l|l|l|l|}
\hline Canada - Paid Workers & Male & Female \\
\hline TITLE & Total - Sex & $7,504,235$ & $6,756,695$ \\
\hline Total - Age groups & $14,260,930$ & $1,252,830$ & $1,181,170$ \\
\hline 15-24 years & $2,434,000$ & 482,260 & 461,305 \\
\hline $15-19$ years & 943,560 & 770,570 & 719,865 \\
\hline $20-24$ years & $1,490,435$ & $1,640,320$ & $1,494,935$ \\
\hline $25-34$ years & $3,135,255$ & $2,047,825$ & $1,896,065$ \\
\hline 35-44 years & $3,943,885$ & $1,685,975$ & $1,558,465$ \\
\hline $45-54$ years & $3,244,440$ & 742,190 & 555,230 \\
\hline $55-64$ years & $1,297,420$ & 135,095 & 70,830 \\
\hline 65 years and over & 205,930 & 38.7 & 38.0 \\
\hline Average age & 38.4 & & \\
\hline
\end{tabular}




\title{
Appendix J - ANCOVAs for Supplemental Research Question 6
}

\author{
ANCOVA for Organization 1: Public Sector
}

\begin{tabular}{|l|l|l|l|l|}
\hline Source & $\begin{array}{l}\text { Type III Sum } \\
\text { of Squares }\end{array}$ & Mean Square & F & Sig. \\
\hline Corrected Model & 39.812 & 4.977 & 8.488 & .000 \\
Intercept & 610.683 & 610.683 & 1041.619 & .000 \\
Generation & 1.337 & 1.337 & 2.280 & .131 \\
Gender & 14.737 & 14.737 & 25.136 & .000 \\
Tenure & 7.900 & 7.900 & 13.476 & .000 \\
Job Type Dummy 1 & 15.892 & 15.892 & 27.106 & .000 \\
Job Type Dummy 2 & .005 & .005 & .008 & .928 \\
Life Cycle Stage & .596 & .596 & 1.017 & .314 \\
$\begin{array}{l}\text { Dummy 1 } \\
\text { Life Cycle Stage }\end{array}$ & .157 & .157 & .267 & .605 \\
$\begin{array}{l}\text { Dummy 2 } \\
\text { Life Cycle Stage }\end{array}$ & 2.646 & 2.646 & 4.513 & .034 \\
$\begin{array}{l}\text { Dummy 3 } \\
\text { Error }\end{array}$ & 742.234 & .586 & & \\
Total & 13615.532 & \multicolumn{3}{|l}{} \\
Corrected Total & 782.046 & & \\
\hline
\end{tabular}

R Squared $=0.051$ (Adjusted R Squared $=.045)$ 
ANCOVA for Organization 2: Public Sector

\begin{tabular}{|l|l|l|l|l|}
\hline Source & $\begin{array}{l}\text { Type III Sum } \\
\text { of Squares }\end{array}$ & Mean Square & F & Sig. \\
\hline Corrected Model & 20.816 & 2.602 & 4.353 & .000 \\
Intercept & 638.304 & 638.304 & 1067.900 & .000 \\
Generation & 1.024 & 1.024 & 1.713 & .191 \\
Gender & 6.815 & 6.815 & 11.402 & .001 \\
Tenure & 1.320 & 1.320 & 2.208 & .138 \\
Job Type Dummy 1 & .712 & .712 & 1.192 & .275 \\
Job Type Dummy 2 & 2.073 & 2.073 & 3.468 & .063 \\
Life Cycle Stage & 7.461 & 7.461 & 12.483 & .000 \\
Dummy 1 & & & & .417 \\
Life Cycle Stage & .394 & .394 & .658 & .646 \\
Dummy 2 & & .126 & .211 & \\
Life Cycle Stage & .126 & & & \\
Dummy 3 & & .598 & & \\
Error & 573.801 & & & \\
Total & 13037.960 & 594.627 & & \\
Corrected Total & 5 & & \\
\hline
\end{tabular}

R Squared $=0.035$ (Adjusted R Squared $=.027$ )

ANCOVA for Organization 3: Not-for-profit Sectors

\begin{tabular}{|l|l|l|l|l|}
\hline Source & $\begin{array}{l}\text { Type III Sum } \\
\text { of Squares }\end{array}$ & Mean Square & F & Sig. \\
\hline Corrected Model & 55.727 & 6.966 & 10.734 & .000 \\
Intercept & 359.242 & 359.242 & 553.594 & .000 \\
Generation & .703 & .703 & 1.084 & .298 \\
Gender & 3.488 & 3.488 & 5.375 & .021 \\
Tenure & 1.894 & 1.894 & 2.919 & .088 \\
Job Type Dummy 1 & 43.036 & 43.036 & 66.318 & .000 \\
Job Type Dummy 2 & .419 & .419 & .646 & .422 \\
Life Cycle Stage & 5.116 & 5.116 & 7.884 & .005 \\
Dummy 1 & & .112 & .172 & .678 \\
Life Cycle Stage & .112 & 3.834 & 5.908 & .015 \\
Dummy 2 & & & \\
Life Cycle Stage & 3.834 & .649 & & \\
Dummy 3 & & & \\
Error & 667.747 & & \\
Total & 12199.437 & 727.474 & & \\
Corrected Total & & & \\
\hline
\end{tabular}

R Squared $=0.077$ (Adjusted R Squared $=.070$ )

231 
ANCOVA for Organization 4: Private Sector

\begin{tabular}{|l|l|l|l|l|}
\hline Source & $\begin{array}{l}\text { Type III Sum } \\
\text { of Squares }\end{array}$ & Mean Square & F & Sig. \\
\hline Corrected Model & 52.413 & 6.552 & 10.958 & .000 \\
Intercept & 1093.315 & 1093.315 & 1828.694 & .000 \\
Generation & 3.303 & 3.303 & 5.525 & .019 \\
Gender & 2.370 & 2.370 & 3.965 & .047 \\
Tenure & .042 & .042 & .070 & .791 \\
Job Type Dummy 1 & 35.993 & 35.993 & 60.203 & .000 \\
Job Type Dummy 2 & 1.226 & 1.226 & 2.050 & .152 \\
Life Cycle Stage & 1.347 & 1.347 & 2.254 & .133 \\
Dummy 1 & & 1.411 & 2.361 & .125 \\
Life Cycle Stage & 1.411 & .091 & .151 & .697 \\
Dummy 2 & & & \\
Life Cycle Stage & .091 & .598 & & \\
Dummy 3 & & & & \\
Error & 1226.822 & & \\
Total & 28963.785 & 1279.235 & & \\
Corrected Total & & & \\
\hline
\end{tabular}

$\mathrm{R}$ Squared $=0.041$ (Adjusted R Squared $=.037$ ) 